\title{
LIBERAÇÃO DE HNO E NO POR NITROSILOS DE RUTÊNIO E SUA ATIVIDADE ANTILEISHMANIA
}

José Clayston Melo Pereira

Tese apresentada ao Instituto de Química de São Carlos, Universidade de São Paulo como um dos requisitos para a obtenção do Título de Doutor em Ciências. Área de concentração: Química Analítica

Orientador: Prof. Dr. Douglas Wagner Franco 
Aos meus pais, José Nilton Alves Pereira e Antônia Soares Melo Pereira e aos meus irmãos pelo apoio durante este longo período fora de casa. A minha namorada Tatiane pela atenção, paciência e carinho. E por tudo que representam em minha vida. 


\section{Agradecimentos}

\section{AGRADECIMENTOS}

Ao Professor Douglas por acreditar em meu trabalho e pelas lições tão valiosas aprendidas em todos estes anos de pós-graduação.

Ao Professor Daniel e ao Professor Benedito sempre dispostos a ajudar.

Aos Professores Fernando Q. Cunha e João Santana pelas discussões enriquecedoras e pela estrutura disponibilizada para os experimentos biológicos.

Aos meus colegas do Laboratório da Cachaça e da Inorgânica: Renatinha, Haruo, Vitória, Natália, Mariana, Jean, Gustavo, Mário, Milton, Patrícia, Daniela, Maykon, Antônio, Camila, Janete, Baiano, Seca, Heloísa, Simone, Evânia, Sula, Wendel, Itapira, Carlão, Eduardo, Luciana, Olívia, Waldemiro, Rafaela, André, Pedro, Silmara, Zé Luís, Viviane, Morte, Rafael, Flávio, Juliana e Thiago

Ao Gustavo e a Fefê pela grande ajuda na finalização da minha tese.

Aos colegas do GEMME: Muril, Rafael, Soninha, Fabiano e Prof. Sérgio.

Aos colegas de Ribeirão: Diego, Vanessa e Paulo pelas discussões na área biológica.

A Veroneide pela amizade e sempre disposta a ajudar.

Aos funcionários da biblioteca, técnicos do CAQUI, oficinas eletrônica, mecânica e vidraria que sempre estiveram prontos a nos atender.

Ao CNPq, CAPES e FAPESP pelo apoio financeiro. 
Os pequenos atos que se executam são melhores que todos aqueles grandes que se planejam.

George C. Marshall 


\section{Sumário}

Lista de Figuras $\quad$ i

Lista de Tabelas

Lista de Abreviaturas $\quad$ V

Resumo vii

Abstract $\quad$ ix

I - Introdução

1.1 - Leishmaniose 1

1.2 - Metalofármacos 4

1.3 - Doadores de NO e leishmaniose 5

1.4 - Tetraaminas de rutênio $\quad 7$

II - Objetivos 10

III - Experimental

3.1 - Reagentes 11

3.2 - Instrumentação e técnicas experimentais 12

3.2.1 - Espectroscopia vibracional na região do infravermelho 12

3.2.2 - Espectroscopia de ressonância magnética nuclear (RMN) 12

3.2.3 - Espectroscopia de ressonância paramagnética eletrônica (RPE) 12

3.2.4 - Experimentos de eletroquímica 13

3.2.5 - Espectros de absorção na região do Ultravioleta-visível 13

3.2.6 - Determinações de $\mathrm{pH} \quad 13$

3.2.7 - Eletrodo seletivo para detecção de óxido nítrico 13

3.2.8 - Espectroscopia de massa 14

3.2.9 - Medidas cinéticas 14

3.3 - Cálculos cinéticos 15

3.4 - Sínteses 15

3.5 - Testes biológicos 16

3.5.1 - Animais de experimentação 16

$\begin{array}{ll}3.5 .2 \text { - Cultura de parasitas } & 16\end{array}$

3.5.3 - Testes in vitro contra forma promastigota da Leishmania major 16

3.5.4 - Crescimento cinético 18

3.5.5 - Ensaio antiamastigota 20

3.5.6 - Teste de Toxicidade em macrófagos 20 
3.5.7 - Testes in vivo da atividade Leishmanicida dos compostos

nitrosilados

3.5.8 - Determinação do número de parasitas presentes nas orelhas de camundongos tratados com os nitrosilos complexos.

3.5.9 - Detecção de nitrito

3.5.10 - Métodos estatísticos

IV - Resultados e Discussão

4.1. Atividade antipromastigota dos nitrosilos de rutênio

4.2. Influência do potencial de redução sobre a ação antileishmania dos nitrosilos de rutênio

4.3. Cinética de crescimento parasitário na presença de nitrosilos de rutênio

4.4-Produção de óxido nítrico

4.5. Atividade antiparasitária do $\mathrm{HNO} / \mathrm{NO}$

4.6. Ação antiamastigota e citotoxicidade

4.7. Nitrosilação e nitrosação

4.8. Efeito leishmanicida in vivo de nitrosilos complexos

4.9. Efeito antileishmania de sulfato complexos

4.10.Conclusão parcial

4.11. Reação entre os nitrosilos complexos e a L-cisteína

4.12. Aspectos ligados a cinética da reação entre o complexo trans-[RuNO(NH$\left.)_{4} \mathrm{P}(\mathrm{OEt})_{3}\right]\left(\mathrm{PF}_{6}\right)_{3}$ e a L-cisteína

4.13. Aspectos ligados a cinética da reação entre a L-cisteína e complexos de rutênio do tipo trans- $\left[\mathrm{RuNO}\left(\mathrm{NH}_{3}\right)_{4} \mathrm{~L}\right]^{+3}$, onde $\mathrm{L}=$ piridina (py), isonicotinamida (isn), 4-picolina (4-pic).

4.14. Conclusão parcial 


\section{Lista de Figuras}

Figura 1 - Estrutura de compostos de antimônio utilizados para o tratamento de 3 leishmaniose

Figura 2 - Estrutura de compostos utilizados como alternativa para o tratamento 4 de leishmaniose.

Figura 3 - Produção de NO via oxidação de L-Arginina a L-Citrulina 6

Figura 4 - Valores de $\mathrm{k}_{-\mathrm{NO}}$ em função do $\mathrm{IC}_{50 \text { pro }}$ dos complexos trans- 25 $\left[\mathrm{Ru}(\mathrm{NO})\left(\mathrm{NH}_{3}\right)_{4} \mathrm{~L}\right] \mathrm{X}_{3},\left(\mathrm{X}=\mathrm{BF}_{4}^{-}\right.$ou $\mathrm{PF}_{6}^{-}$e $\mathrm{L}=\mathrm{imN}$, 4-pic, pz, py, $\mathrm{P}\left(\mathrm{OEt}_{3}\right), \mathrm{L}-$ hist, isn, nic) e [RuNO(Hedta)]

Figura 5 - Estrutura do complexo (a) trans- $\left[\mathrm{Ru}(\mathrm{NO})\left(\mathrm{NH}_{3}\right)_{4} \mathrm{ImN}\right]^{+3}$ e (b) do 26 complexo trans- $\left[\mathrm{Ru}(\mathrm{NO})\left(\mathrm{NH}_{3}\right)_{4} \mathrm{ImC}\right]^{+3}$

Figura 6 - Detecção eletroquímica do NO na presença do complexo (a) trans-

$\left[\mathrm{Ru}(\mathrm{NO})\left(\mathrm{NH}_{3}\right)_{4} \mathrm{imN}\right]\left(\mathrm{BF}_{4}\right)_{3}$ e do complexo (b) trans$\left[\mathrm{Ru}(\mathrm{NO})\left(\mathrm{NH}_{3}\right)_{4} \mathrm{imC}\right]\left(\mathrm{PF}_{6}\right)_{3}$ em meio Schneider.

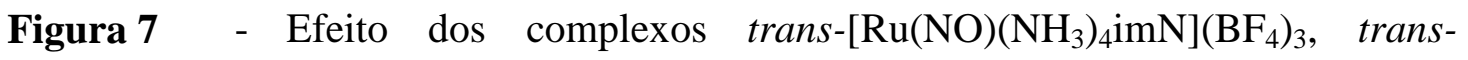

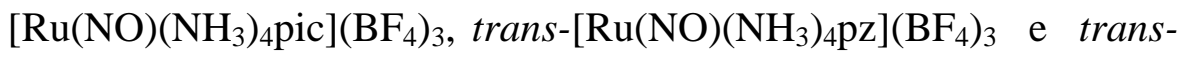
$\left[\mathrm{Ru}(\mathrm{NO})\left(\mathrm{NH}_{3}\right)_{4} \mathrm{py}\right]\left(\mathrm{BF}_{4}\right)_{3}$ sobre a proliferação de promastigotas da $L$. major

Figura 8 - Detecção de nitrito após 24 horas de incubação de parasitas L.major 32 com os complexos trans- $\left[\mathrm{RuNO}\left(\mathrm{NH}_{3}\right)_{4} \mathrm{imN}\right]\left(\mathrm{BF}_{4}\right)_{3}$, trans-[RuNO$\left.\left(\mathrm{NH}_{3}\right)_{4}(4-\mathrm{pic})\right]\left(\mathrm{BF}_{4}\right)_{3}$, trans- $\left[\mathrm{RuNO}\left(\mathrm{NH}_{3}\right)_{4} \mathrm{pz}\right]\left(\mathrm{BF}_{4}\right)_{3} \quad \mathrm{e}$ trans-[RuNO($\left.\left(\mathrm{NH}_{3}\right)_{4} \mathrm{py}\right]\left(\mathrm{BF}_{4}\right)_{3}$

Figura 9 - Efeito do HNO sobre a viabilidade das formas promastigotas tratados 36 com sal de Angeli.

Figura 10 - Ensaio de citotoxicidade in vitro dos compostos 37 trans- $\left[\mathrm{RuNO}\left(\mathrm{NH}_{3}\right)_{4} \mathrm{imN}\right]^{+3}$, trans- $\left[\mathrm{Ru}\left(\mathrm{NH}_{3}\right)_{4} \mathrm{imN}\left(\mathrm{H}_{2} \mathrm{O}\right)\right]^{+2}$ e sal de Angeli (SA). a) porcetagem de macrófagos mortos na presença de diferentes concentrações do complexo trans-[RuNO( $\left.\left(\mathrm{NH}_{3}\right)_{4} \mathrm{imN}\right]^{+3}$, trans- $\left[\mathrm{Ru}\left(\mathrm{NH}_{3}\right)_{4} \mathrm{imN}\left(\mathrm{H}_{2} \mathrm{O}\right)\right]^{+2}$ e sal de Angeli (SA). b) gráfico representativo da morte de macrófagos.

Figura 11 - Detecção cronoamperométrica de $\mathrm{NO}^{0}$ em meio Schneider na 41 presença de trans- $\left[\mathrm{Ru}(\mathrm{NO})\left(\mathrm{NH}_{3}\right)_{4} \mathrm{P}(\mathrm{OEt})_{3}\right]\left(\mathrm{PF}_{6}\right)_{3}$

Figura 12 - Efeito do composto trans-[RuNO(NH$\left.)_{4} \mathrm{imN}\right]\left(\mathrm{BF}_{4}\right)_{3}$ no curso de 45 
infecção de camundongos BALB/c

Figura 13 - a) Efeito dos compostos trans-[RuNO( $\left.\left(\mathrm{NH}_{3}\right)_{4} \mathrm{imN}\right]\left(\mathrm{BF}_{4}\right)_{3} \quad$ e 46 glucantime no curso de infecção de camundongos BALB/c. b) carga parasitária (após a quinta semana de infecção) de grupos de animais tratados com PBS, tratados com $0,5 \mu \mathrm{mol} \mathrm{Kg}^{-1}$ do composto trans$\left[\mathrm{RuNO}\left(\mathrm{NH}_{3}\right)_{4} \mathrm{imN}\right]\left(\mathrm{BF}_{4}\right)_{3}$ tratados com $33 \mu \mathrm{mol} \mathrm{Kg}{ }^{-1}$ de glucantime.

Figura 14 - a) Efeito do composto trans- $\left[\mathrm{Ru}\left(\mathrm{NH}_{3}\right)_{4} \mathrm{imN}\left(\mathrm{SO}_{4}\right)\right] \mathrm{Cl}$ no curso de infecção de camundongos BALB/c. b) carga parasitária de grupos de animais tratados com PBS e tratados com $0,5 \mu \mathrm{mol} \mathrm{Kg}^{-1}$ do composto trans- $\left[\mathrm{Ru}\left(\mathrm{NH}_{3}\right)_{4} \mathrm{imN}\left(\mathrm{SO}_{4}\right)\right] \mathrm{Cl}$.

Figura 15 - Cronoamperograma da reação entre o complexo 53 trans $\left[\mathrm{RuNO}\left(\mathrm{NH}_{3}\right)_{4} \mathrm{imN}\right]^{+3}$ e a L-cisteína.

Figura 16 - Espectro eletrônico da solução contendo a mistura do complexo 54 trans $\left[\mathrm{RuNO}\left(\mathrm{NH}_{3}\right)_{4} \mathrm{imN}\right]^{+3}$,metmioglobina e a L-cisteína.

Figura 17 - Cronoamperograma da reação entre o complexo 55 trans- $\left[\mathrm{RuNO}\left(\mathrm{NH}_{3}\right)_{4} \mathrm{P}(\mathrm{OEt})_{3}\right]\left(\mathrm{PF}_{6}\right)_{3}$ e a L-cisteína.

Figura 18 - Variação de concentração de NO em função do $\mathrm{pH}$ para a reação 56 entre o complexo trans- $\left[\mathrm{RuNO}\left(\mathrm{NH}_{3}\right)_{4} \mathrm{P}(\mathrm{OEt})_{3}\right]^{+3}$ e diferentes concentrações de L-cisteína.

Figura 19 - (a)espectro eletrônico da mistura das espécies 57 trans-[RuNO(NH$\left.)_{4} \mathrm{P}(\mathrm{OEt})_{3}\right]^{3+}$, L-cisteína e metmioglobina. (b) Espectro eletrônico da metmioglobina.

Figura 20 - Espectro de EPR da mistura da L-cisteína, do complexo 58 trans-[RuNO$\left.\left(\mathrm{NH}_{3}\right)_{4} \mathrm{P}(\mathrm{OEt})_{3}\right]\left(\mathrm{PF}_{6}\right)_{3}$ e da metmioglobina.

Figura 21 - (a)Espectro eletrônico da metmioglobina. (b) Espectro eletrônico do 59 nitrosilo ferroso $\left(\mathrm{Mb}-\mathrm{Fe}^{\mathrm{II}} \mathrm{NO}^{0}\right)$ com adição de L-cisteína.

Figura 22 - Espectro vibracional na região do infravermelho da mistura do 60 complexo trans-[RuNO(NH$\left.)_{4} \mathrm{P}(\mathrm{OEt})_{3}\right]\left(\mathrm{PF}_{6}\right)_{3}$ e a L-cisteína.

Figura 23 - Espectro de ressonância magnética nuclear de ${ }^{31} \mathrm{P}$ da reação entre o 61 complexo trans-[RuNO $\left.\left(\mathrm{NH}_{3}\right)_{4} \mathrm{P}(\mathrm{OEt})_{3}\right]^{+3}$ e a L-cisteína em $\mathrm{D}_{2} \mathrm{O}(\mathrm{pH}$ $=4,0)$.

Figura 24 - Espectro eletrônico da mistura das espécies 62 trans- $\left[\mathrm{Ru}\left(\mathrm{NH}_{3}\right)_{4} \mathrm{P}(\mathrm{OEt})_{3} \mathrm{NO}\right]^{3+}$, L-cisteína e pirazina

Figura 25 - Voltamogramas cíclicos referente a mistura entre o complexo rutênio 62 
$t$ - $\left[\mathrm{Ru}\left(\mathrm{NH}_{3}\right)_{4} \mathrm{P}(\mathrm{OEt})_{3} \mathrm{NO}\right]^{+3}$ e a L-cisteína.

Figura 26 - Espectro obtido utilizando stopped flow para a solução resultante da 64 mistura do complexo trans- $\left[\mathrm{RuNO}\left(\mathrm{NH}_{3}\right)_{4} \mathrm{P}(\mathrm{OEt})_{3}\right]^{+3}$ e a L-cisteína

Figura 27 - $\ln \left(\mathrm{A}_{\text {inf }}-\mathrm{A}_{\mathrm{t}}\right)$ em função do tempo (s) para a reação entre complexo 65 trans-[RuNO $\left.\left(\mathrm{NH}_{3}\right)_{4} \mathrm{P}(\mathrm{OEt})_{3}\right]^{+3}$ e a L-cisteína

Figura 28 - Dependência de $\mathrm{k}_{\mathrm{obs}}$ em função de concentração de L-cisteína 66

Figura 29 - Variações dos espectros para a reação entre o complexo 67 trans-[RuNO(NH$\left.)_{4} \mathrm{P}(\mathrm{OEt})_{3}\right]^{+3}$ e a L-cisteína

Figura 30 - Dependência de $\mathrm{k}_{\mathrm{obs}}$ em função de concentração de L-cisteína. 69

Figura 31 - Valores de $\mathrm{k}_{2}$ versus pH para a reação entre o complexo 70 trans- $\left[\mathrm{Ru}\left(\mathrm{NH}_{3}\right)_{4} \mathrm{P}(\mathrm{OEt})_{3} \mathrm{NO}\right]^{+3}$ e a L-cisteína

Figura 32 - Variações dos espectros da reação entre 0 complexo 71 trans- $\left[\mathrm{RuNO}\left(\mathrm{NH}_{3}\right)_{4} \mathrm{P}(\mathrm{OEt})_{3}\right]^{+3}$ e a cisteína em $\mathrm{pH}=4,5$

Figura 33 - Variações dos espectros do $\quad$ complexo 73 trans- $\left[\mathrm{Ru}\left(\mathrm{NH}_{3}\right)_{4} \mathrm{P}(\mathrm{OEt})_{3} \mathrm{~N}(\mathrm{O}) \mathrm{SR}\right]^{\mathrm{n}-2}$

Figura $34 \ln \left(\mathrm{A}_{\text {inf }}-\mathrm{A}_{\mathrm{t}}\right)$ em função de $\mathrm{t}(\mathrm{s})$ para a reação de decaimento do 73 complexo trans- $\left[\mathrm{Ru}\left(\mathrm{NH}_{3}\right)_{4} \mathrm{P}(\mathrm{OEt})_{3} \mathrm{~N}(\mathrm{O}) \mathrm{SR}\right]^{\mathrm{n}-2}$

Figura 35 Espectro eletrônico para a solução contendo o complexo 75 trans-[RuNO(NH$\left.)_{4}(4-p i c)\right]^{+3}$ e a L-cisteína, $\mathrm{pH}=7,4$

Figura 36 Variações dos espectros do complexo trans- $\left[\mathrm{Ru}\left(\mathrm{NH}_{3}\right)_{4} \mathrm{pyN}(\mathrm{O}) \mathrm{SR}\right]^{\mathrm{n}-1} \quad 77$ e do complexo trans-[Ru(NH 3$)_{4} 4-$ picN(O)SR $]^{\text {n-1 }}$

Figura 37 Dependência de $\mathrm{k}_{\mathrm{obs}}$ em função de concentração de L-cisteína para a 78 formação da espécie trans-[Ru( $\left.\left.\mathrm{NH}_{3}\right)_{4} \mathrm{pyN}(\mathrm{O}) \mathrm{SR}\right]^{\mathrm{n}-1}$ e trans$\left[\mathrm{Ru}\left(\mathrm{NH}_{3}\right)_{4} 4 \text { picN(O)SR }\right]^{\mathrm{n}-1}$

Figura $38 \quad$ Valores de $\ln _{\mathrm{k}_{2}\left(\mathrm{RS}^{-}\right)}$versus $\mathrm{E}_{\mathrm{NO}^{+} / \mathrm{NO}_{0}}$ de complexos nitrosilos 


\section{Lista de Tabelas}

Tabela 1 - Parâmetros de atividade antipromastigota de doadores de NO, sua respectiva toxicidade frente a células $\mathrm{V} 79$, índice terapêutico $\left(\mathrm{IC}_{50 \mathrm{~V} 79}\right.$ $\left./ \mathrm{IC}_{50 \mathrm{pro}}\right)$ e valores de $\mathrm{k}_{-\mathrm{NO}}$ e $\left.\mathrm{E}_{\left(\mathrm{NO}^{0} / \mathrm{NO}\right.}^{0}\right)$

Tabela 2 - Atividade in vitro de compostos contra amastigotas e citotoxicidade em macrófagos

Tabela 3 - Atividade antipromastigota (\%IC) do nitrosilo complexo trans-[RuNO(NH$\left.)_{4} \mathrm{P}(\mathrm{OEt})_{3}\right]\left(\mathrm{PF}_{6}\right)_{3}$ na presença e ausência de ácido ascórbico.

Tabela 4 - Atividade In vivo do composto trans- $\left[\mathrm{RuNO}\left(\mathrm{NH}_{3}\right)_{4} \mathrm{imN}\right]\left(\mathrm{BF}_{4}\right)_{3}$ contra o parasito L. major em camundongo BALB/c

Tabela 5 - Atividade antipromastigota e $\mathrm{E}_{1 / 2}$ de sulfato complexos 48

Tabela 6 - Valores de $\mathrm{k}_{\text {obs }}$ em função da concentração de L-cisteína 68

Tabela 7 - Valores de $\mathrm{E}_{\left(\mathrm{NO}^{+} / \mathrm{NO}^{0}\right)}, \mathrm{k}_{1(\mathrm{cis})}, \mathrm{k}_{-1(\mathrm{cis})}$ e $\mathrm{k}_{1\left(\mathrm{RS}^{-}\right)}$para a reação da L-cisteína 76 com nitrosilos de rutênio trans-[RuNO($\left.\left(\mathrm{NH}_{3}\right)_{4} \mathrm{~L}\right]^{+3}$ onde $\mathrm{L}=\mathrm{P}(\mathrm{OEt})_{3}$, pz, isn, py e 4-pic

Tabela 8 - Valores de constante de velocidade $\left(\mathrm{K}_{2}\right)$ para trans- $\left[\mathrm{RuNO}\left(\mathrm{NH}_{3}\right)_{4} \mathrm{~L}\right]^{+3} \quad 79$

Tabela 9 Valores de constante de velocidade para a decomposição do complexo 81 trans- $\left[\mathrm{Ru}\left(\mathrm{NH}_{3}\right)_{4} \mathrm{LN}(\mathrm{O}) \mathrm{SR}\right]^{\mathrm{n}-2}$ ou do trans- $\left[\mathrm{Ru}\left(\mathrm{NH}_{3}\right)_{4} \mathrm{LN}(\mathrm{O})(\mathrm{SR})_{2}\right]^{\mathrm{n}-2}$ 


\section{Lista de Abreviaturas}
AA
- ácido ascórbico
$\mathrm{BF}_{4}{ }^{-}$
- íon tetrafluorborato
$\left.\mathrm{E}_{\left(\mathrm{NO}^{+}\right.}{ }^{\mathrm{NNO}}{ }^{0}\right)$
- potencial de redução [Ru"NO $\left.\mathrm{NO}^{+}\right]\left[\mathrm{Ru}^{\prime \prime} \mathrm{NO}^{0}\right]$
ECS
- eletrodo de calomelano saturado
edta
- Etilenodiamino tetraacético
$\mathrm{ENH}$
- eletrodo normal de hidrogênio
$\mathrm{HNO}$
- nitroxil
IC 50 pro
- concentração correspondente a 50\% de inibição de formas promastigotas em 24 horas de incubação
$\mathrm{IC}_{50 \mathrm{~V} 79}$ concentração correspondente a 50\% de inibição de células V79 em 24 horas de incubação
$\mathrm{imC}$
- imidazol coordenado pelo oxigênio
$\mathrm{imN}$
- imidazol coordenado pelo nitrogênio
ip
- lodeto de propídio
isn
- isonicotinamida
IT
- índice terapêutico
k-NO
- constante de velocidade específica de dissociação do NO
$k_{\text {obs }}$
- constante observada
L
- ligante trans ao óxido nítrico
L-cis
- L-cisteína
$\mathrm{LD}_{50}$
- dose letal a $50 \%$ dos indivíduos
L-hist
- L-histidina
L. major
- Leishmania major
MTT
$\mathrm{NaNO}_{2}$
- brometo de 3-(4,5-dimetiltiazol-2-il)-2,5-difenil tetrazolio
nic
- nitrito de sódio
NO
- nicotinamida
- óxido nítrico
NOS
- óxido nítrico sintase
NP
- nitroprussiato de sódio
PBS
- phosphate-buffered saline (tampão fosfato)
$\mathrm{PF}_{6}$
- íon hexafluorfosfato 


\begin{tabular}{|c|c|c|}
\hline 4-pic & - & 4-picolina \\
\hline $\mathrm{P}(\mathrm{OEt})_{3}$ & & trietilfosfito \\
\hline Py & - & piridina \\
\hline $\mathrm{Pz}$ & - & pirazina \\
\hline $\mathrm{Ru}$ & - & rutênio \\
\hline SA & - & sal de Angeli \\
\hline sc & - & subcutâneo \\
\hline $\mathrm{SO}_{3}{ }^{2-}$ & - & sulfito \\
\hline $\mathrm{SO}_{4}{ }^{2-}$ & - & sulfato \\
\hline V79 & - & Fibroblasto d \\
\hline
\end{tabular}




\section{RESUMO}

Foram testados complexos de rutênio trans- $\left[\mathrm{RuNO}\left(\mathrm{NH}_{3}\right)_{4} \mathrm{~L}\right](\mathrm{X})_{3}\left(\mathrm{X}=\mathrm{BF}_{4}^{-}\right.$ou $\mathrm{PF}_{6}^{-}$e $\mathrm{L}$ $=$ imN, 4-pic, isn, py, pz, L - hist, nic, imC, $\left.\mathrm{P}(\mathrm{OEt})_{3}, \mathrm{SO}_{3}{ }^{-2}\right)$ e $\left.[\mathrm{Ru}(\mathrm{NO}) \mathrm{Hedta})\right]$ como agentes antiproliferativos contra o parasito Leishamania major. Os complexos onde $\mathrm{L}=\mathrm{imN}, \mathrm{pz}$, 4-pic, py, isn, e $\mathrm{P}(\mathrm{OEt})_{3}$ exibem $\mathrm{IC}_{50 \text { pro }}$ na faixa de $36(\mathrm{~L}=\mathrm{imN})$ a $280 \mu \mathrm{M}$ $(\mathrm{L}=\mathrm{isn})$. A curva de crescimento das formas promastigotas, incubadas com os compostos mais promissores, trans-[RuNO $\left.\left(\mathrm{NH}_{3}\right)_{4} \mathrm{~L}\right]\left(\mathrm{BF}_{4}\right)_{3} \quad(\mathrm{~L}=\mathrm{imN}, \mathrm{pz}$, py, 4-pic), foi avaliada por meio de contagem de células viáveis e por ensaio colorimétrico (MTT). Uma relação entre os valores de $\mathrm{k}_{\text {-No }}$ e efeito antipromastigota segue a seguinte ordem: imN>4-pic>pz>py. Foi observado um aumento na inibição do crescimento das formas promastigotas incubadas com 0 complexo trans-[RuNO $\left.\left(\mathrm{NH}_{3}\right)_{4} \mathrm{P}(\mathrm{OEt})_{3}\right]\left(\mathrm{PF}_{6}\right)_{3}$ na presença de ácido ascórbico, confirmando o mecanismo de nitrosilação dos complexos utilizados. O complexo trans-[RuNO(NH$\left.)_{4} 4 \mathrm{imN}\right]\left(\mathrm{BF}_{4}\right)_{3}$ e o sal de Angeli $\left(\mathrm{Na}_{2} \mathrm{~N}_{2} \mathrm{O}_{3}\right)$ exibiram efeitos similares frente as formas amastigotas intracelulares. $O$ composto trans-[RuNO(NH$\left.\left.)_{4}\right)_{4 m N}\right]\left(B_{4}\right)_{3}$ apresentou efeito antileishmania em experimentos in vivo . A reação entre trans- $\left[\mathrm{RuNO}\left(\mathrm{NH}_{3}\right)_{4} \mathrm{~L}\right](\mathrm{X})_{3}\left(\mathrm{X}=\mathrm{BF}_{4}{ }^{-}\right.$or $\mathrm{PF}_{6}^{-}$and $\mathrm{L}=\mathrm{imN}$, 4-pic, py, isn, $\mathrm{P}\left(\mathrm{OEt}_{3}\right)$ ) e excesso de L-cisteína foi investigada e os seus produtos analisados. $\mathrm{HNO}$ e $\mathrm{NO}^{0}$ foram encontrados como produtos da redução do ligante nitrosônio. Esta reação ocorre em varias etapas com a formação dos complexos trans- $\left[\mathrm{Ru}\left(\mathrm{NH}_{3}\right)_{4} \mathrm{LN}(\mathrm{O}) \mathrm{SR}\right]^{\mathrm{n}-1}$ e trans-[Ru(NH$\left.)_{4} \mathrm{LN}(\mathrm{O})(\mathrm{SR})_{2}\right]^{\mathrm{n}-2}$ cujo as constantes de formação $k_{1}\left(1,7 \times 10^{7}-2,2 \times 10^{4} \mathrm{~mol}^{-1} \mathrm{Ls}^{-1}\right)$ e $\mathrm{k}_{2}\left(3,3 \times 10^{4}-4,9 \times 10^{1} \mathrm{~mol}^{-1} \mathrm{Ls}^{-1}\right)$ foram calculados para $L=P(O E t) 3$, 4-pic, py e isn). Estas espécies podem sofrer reações subseqüentes com dissociação de $H N O$ e $N O$. Exceto para $L=P\left(\mathrm{OEt}_{3}\right)$, a reação 
não ocorre quando $\mathrm{C}_{\mathrm{H}^{+}} \geq 1 \times 10^{-6} \mathrm{~mol} \mathrm{~L} \mathrm{~L}^{-1}$. Em solução onde $\mathrm{C}_{\mathrm{H}^{+}}=4 \times 10^{8} \mathrm{~mol} \mathrm{~L}^{-1}$, a reação ocorre principalmente segundo:

trans- $\left[\mathrm{RuNO}\left(\mathrm{NH}_{3}\right)_{4} \mathrm{~L}\right]^{+3}+2 \mathrm{RS}^{-}+\mathrm{H}_{2} \mathrm{O}$

$$
\text { trans- }\left[\mathrm{Ru}\left(\mathrm{NH}_{3}\right)_{4} \mathrm{~L}\left(\mathrm{H}_{2} \mathrm{O}\right)\right]^{2+}+\mathrm{RSSR}+\mathrm{NO}^{-}
$$

Para $\mathrm{L}=\mathrm{P}\left(\mathrm{OEt}_{3}\right)$, e em meio ácido, $\mathrm{NO}^{0}$ é preferencialmente o produto da redução do ligante $\mathrm{NO}^{+}$:

trans-[RuNO$\left.\left(\mathrm{NH}_{3}\right)_{4} \mathrm{P}(\mathrm{OEt})_{3}\right]^{+3}+\mathrm{RSH}+\mathrm{H}_{2} \mathrm{O}$

$$
\text { trans- }\left[\mathrm{Ru}\left(\mathrm{NH}_{3}\right)_{4} \mathrm{P}(\mathrm{OEt})_{3}\left(\mathrm{H}_{2} \mathrm{O}\right)\right]^{2+}+1 / 2 \mathrm{RSSR}+\mathrm{NO}^{0}+\mathrm{H}^{+}
$$

Os resultados experimentais em solução sugerem que ambas as espécies NO e HNO podem ser responsáveis pelo efeito antiparasitário dos nitrosilos de rutênio aqui estudados. A relação entre a concentração das espécies NO/HNO será determinada pelas condições de pH do meio e concentração do redutor. 


\section{Abstract}

Ruthenium complexes type trans-[RuNO$\left.\left(\mathrm{NH}_{3}\right)_{4} \mathrm{~L}\right](\mathrm{X})_{3}\left(\mathrm{X}=\mathrm{BF}_{4}^{-}\right.$or $\mathrm{PF}_{6}^{-}$and $\mathrm{L}=\mathrm{imN}$, 4-pic, isn, py, pz, L- hist, nic, imC, $\left.\mathrm{P}(\mathrm{OEt})_{3}, \mathrm{SO}_{3}{ }^{2-}\right)$, and [RuNO(Hedta)] were tested as antiproliferative agents against the Leishmania major parasite. The complexes where $L=i m N, p z$, 4-pic, py, isn, and $P(O E t)_{3}$ exhibited $I C_{50 p r o}$ ranging from 36 for trans- $\left[\mathrm{RuNO}\left(\mathrm{NH}_{3}\right)_{4} \mathrm{imN}\right]\left(\mathrm{BF}_{4}\right)_{3}$ to $280 \mu \mathrm{M}$ for trans-[RuNO$\left(\mathrm{NH}_{3}\right)_{4}$ isn $]\left(\mathrm{BF}_{4}\right)_{3}$. The growth rate of the promastigote forms incubated with the most promising compounds, trans-[RuNO$\left.\left(\mathrm{NH}_{3}\right)_{4} \mathrm{~L}\right]\left(\mathrm{BF}_{4}\right)_{3} \quad(\mathrm{~L}=\mathrm{imN}, \mathrm{pz}$, py, 4-pic) had been evaluated trough motile cell counting and colorimetric assay (MTT). The trend between $\mathrm{k}_{-\mathrm{NO}}$ values and the antipromastigote effect follows the order: imN>4-pic $>p z>p y$. An increase on the inhibition of the promastigote forms growth by the trans-[RuNO$\left.\left(\mathrm{NH}_{3}\right)_{4} \mathrm{P}(\mathrm{OEt})_{3}\right]\left(\mathrm{PF}_{6}\right)_{3}$ and trans-[RuNO$\left.\left(\mathrm{NH}_{3}\right)_{4} \mathrm{imN}\right]\left(\mathrm{BF}_{4}\right)_{3}$ species was observed when the ruthenium complexes and ascorbic acid were simultaneously incubated, confirming the nitrosylation behavior of these complexes. Inhibitory effects of the trans-[RuNO$\left.\left(\mathrm{NH}_{3}\right)_{4} \mathrm{imN}\right]\left(\mathrm{BF}_{4}\right)_{3}$ and of the Angeli's salt $\left(\mathrm{Na}_{2} \mathrm{~N}_{2} \mathrm{O}_{3}\right)$ were similar on the intramacrophage amastigote form grown. Encouraged by the antileishmanial effect of the complex trans-[RuNO$\left.\left(\mathrm{NH}_{3}\right)_{4} \mathrm{imN}\right]\left(\mathrm{BF}_{4}\right)_{3}$ observed in vitro, in vivo experiments were carried out in infected BALB/c mice. The reaction between trans- $\left[\mathrm{RuNO}\left(\mathrm{NH}_{3}\right)_{4} \mathrm{~L}\right](\mathrm{X})_{3}\left(\mathrm{X}=\mathrm{BF}_{4}^{-}\right.$or $\mathrm{PF}_{6}^{-}$and $\mathrm{L}=\mathrm{imN}$, 4-pic, isn, $\left.\mathrm{P}(\mathrm{OEt})_{3}\right)$ and excess of L-cysteine was investigated and the products analysed. $\mathrm{HNO}$ and $\mathrm{NO}$ are the products of nitrosonium ligand reduction. This reaction yields the complexes trans- $\left[\mathrm{Ru}\left(\mathrm{NH}_{3}\right)_{4} \mathrm{LN}(\mathrm{O}) \mathrm{SR}\right]^{\mathrm{n}-1}$ and trans-[Ru(NH$\left.)_{4} \mathrm{LN}(\mathrm{O})(\mathrm{SR})_{2}\right]^{\mathrm{n}-2}$ which present $\mathrm{k}_{1}$ $\left(1,7 \times 10^{7}-2,2 \times 10^{4} \mathrm{~mol}^{-1} \mathrm{Ls}^{-1}\right)$ and $\mathrm{k}_{2}\left(3,3 \times 10^{4}-4,9 \times 10^{1} \mathrm{~mol}^{-1} \mathrm{Ls}^{-1}\right)$ for $\mathrm{L}=\mathrm{P}(\mathrm{OEt}) 3,4-$ pic, py e isn). This species react with $\mathrm{RS}^{-}$producing $\mathrm{HNO}$ and/or NO. Exception for 
$\mathrm{L}=\mathrm{P}(\mathrm{OEt})_{3}$, this reaction does not occurs when $\mathrm{C}_{\mathrm{H}^{+}} \geq 1 \times 10^{-6} \mathrm{~mol} \mathrm{~L}^{-1}$. For solution in which $\mathrm{C}_{\mathrm{H}^{+}}=4 \times 10^{-8} \mathrm{~mol} \mathrm{~L}^{-1}$, the reaction occur mainly trough:

trans- $\left[\mathrm{RuNO}\left(\mathrm{NH}_{3}\right)_{4} \mathrm{~L}\right]^{+3}+2 \mathrm{RS}^{-}+\mathrm{H}_{2} \mathrm{O}$

$$
\text { trans- }\left[\mathrm{Ru}\left(\mathrm{NH}_{3}\right)_{4} \mathrm{~L}\left(\mathrm{H}_{2} \mathrm{O}\right)\right]^{2+}+\mathrm{RSSR}+\mathrm{NO}^{-}
$$

For $\mathrm{L}=\mathrm{P}(\mathrm{OEt})_{3}$, and in acid media, $\mathrm{NO}^{0}$ is preferentially the reduction product of $\mathrm{NO}^{+}$ ligand.

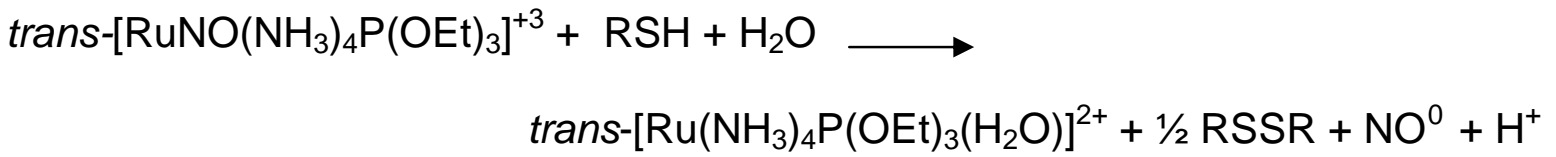

The experimental results from solution studies suggest that both $\mathrm{NO}$ and HNO could be responsible for the antiparasitaric effect of these ruthenium nitrosyl. The concentration ratio of $\mathrm{NO} / \mathrm{HNO}$ could be dictated by the local conditions of $\mathrm{pH}$. 


\section{Introdução}

\subsection{Leishmaniose}

Leishmaniose é uma doença negligenciada causada por protozoários tripanosomatídeos do gênero Leishmania [1], o qual pode ser encontrado sob a forma promastigota (flagelada) no tubo digestivo do inseto vetor ou amastigota (aflagelada) nos tecidos dos vertebrados. Entre os reservatórios do parasito da leishmaniose podemos citar a raposa no ciclo silvestre e rural e o cão no ciclo rural e urbano[2].

A transmissão do parasito ocorre após o inseto (fêmea) do gênero Lutzomia picar um mamífero parasitado. As formas amastigotas ingeridas pelo inseto iniciam a multiplicação por divisão binária e invadem suas glândulas salivares sob a forma promastigota. Em seguida, o inseto transmite o parasito para um animal sadio durante a hematofagia. Nos vertebrados, o parasito é fagocitado por macrófagos, transformando-se em formas amastigotas que procedem a divisão binária. Estas formas rompem os macrófagos contaminando outras células de defesa proliferando a doença no hospedeiro[2].

A leishmaniose é uma doença que afeta mais de 12 milhões de pessoas em todo o mundo, com incidência de 2 milhões de novos casos anualmente[1]. Esta doença é encontrada em vários países na Ásia, na Europa, no Oriente Médio, na África e nas Américas. No Brasil, $90 \%$ dos casos de leishmaniose ocorrem principalmente na região Nordeste. Inicialmente, a leishmaniose era uma doença encontrada em ambientes rurais e periurbanos[3]. Recentemente, este quadro vem mudando sendo reportados casos de transmissão do parasito no meio urbano. 
A leishmaniose causa uma série de manifestações clínicas, tais como lesões cutâneas na região infectada, úlceras nas mucosas e lesões difusas características de leishmaniose cutânea, mucocutânea e disseminada, respectivamente[2]. Estes três tipos de leishmaniose podem ser provocados por diferentes espécies tais como L. braziliensis e L. mexicana nas Américas, L. tropica e L. major no continente europeu. A leishmaniose visceral (LV) é o tipo mais grave da doença, a qual pode provocar morte em $95 \%$ dos casos em seres humanos não tratados. A LV pode ser causada por diferentes espécies de leishmania: L. infatum, L. donovani e L. chagasi (encontrada no Brasil). As manifestações clínicas incluem hemorragia aguda, insuficiência cardíaca, broncopneumonia, cefaléia, dores musculares, etc [3].

O tratamento mais comum contra a leishmaniose é uso de compostos de antimônio pentavalentes (Figura 1), estibogluconato de sódio $\left(\mathrm{C}_{12} \mathrm{H}_{38} \mathrm{Na}_{3} \mathrm{O}_{26} \mathrm{Sb}_{2}\right)$ e/ou antimoniato de $\mathrm{N}$-metil-glucamina (glucantime, $\mathrm{C}_{14} \mathrm{H}_{29} \mathrm{O}_{10} \mathrm{~N}_{2} \mathrm{Sb}$ )[2], os quais inibem a atividade glicolítica e a via oxidativa de ácidos graxos do parasito [4]. Tem sido reportado, no entanto, que os antimônios pentavalentes são pro - drogas ativadas por meio de redução por tiois do parasita tais como glutationa ou triponationa, formando antimônio trivalente[4]. Devido à resistência adquirida pelo parasito a estas drogas a Organização Mundial de Saúde vem recomendando doses cada vez mais elevadas destes medicamentos para o tratamento da doença. Outro problema decorrente do uso destas drogas diz respeito ao efeito colateral oriundo de sua ação no sistema cardiovascular[4a]. 


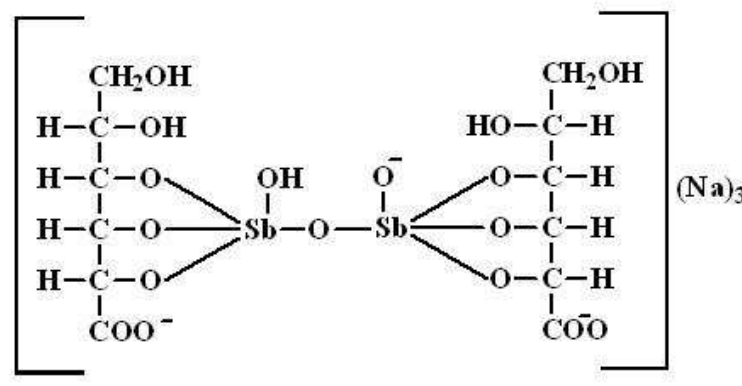

Estibogluconato de Sódio

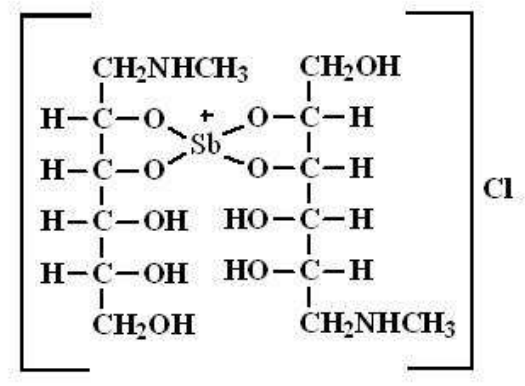

Glucantime

Figura 1 - Estrutura de compostos de antimônio utilizados para o tratamento de leishmaniose.

Outra droga importante para o tratamento da leishmaniose é a anfotericina B (Figura 2) a qual liga-se a ésteres presentes na membrana plasmática da Leishmania[5]. Esta droga também apresenta diversos efeitos colaterais, principalmente complicações renais[4]. Existem outros medicamentos para o tratamento da leishmaniose tais como a pentamidina (Figura 2) utilizadas na Europa e na África e a miltefosine (Figura 2), droga oral utilizada na Índia com resultados promissores. No entanto, ainda se faz necessária a busca por drogas que apresentem maior eficiência contra o parasito e menos efeitos colaterais[3, 5]. 
<smiles>CCCCOP(=O)([O-])OCCN(C)CCCC</smiles><smiles>CC(/C=C/C=C/C=C/C=C/C=C/C=C/C=C/C(CC1OC(O)(CC(O)CC(O)C(O)CCC(O)CC(O)CC(=O)OC(C)C(C)C(O)C(C)O)CC(O)C1C(=O)O)OC1OC(C)C(O)C(N)C1C)C(=O)O</smiles>

Figura 2 - Estrutura de compostos utilizados como alternativa para o tratamento de leishmaniose.

\subsection{Metalofármacos}

Complexos metálicos têm sido utilizados em aplicações contra diversas doenças nos últimos anos devido a resultados da cisplatina no combate ao câncer e novos compostos contendo platina para este fim [6,7]. O uso de outros metais, como rutênio e titânio, contra câncer também vem despertando atenção de pesquisadores[7]. A busca de medicamentos menos tóxicos tem levado pesquisadores a associarem metais com fármacos orgânicos conhecidos, aumentando assim seu desempenho e diminuindo sua toxicidade. O efeito sinérgico oriundo desta associação também favorece maior estabilidade da droga no organismo[8].

Devido ao crescente emprego de complexos metálicos como agentes antitumorais, compostos de platina e rutênio têm sido utilizados em pesquisas como agentes antiparasitários[9, 10]. Além disto, a estratégia de utilizar complexos contendo fármacos antiparasitários na esfera de coordenação de metais também 
vem sendo empregada contra doenças parasitárias[11-13]. Complexos de rutênio contendo fármacos na esfera de coordenação tais como $\left[\mathrm{RuCl}_{2}(\text { clotrimazol })_{2}\right][11]$ e trans- $\left[\mathrm{Ru}(\right.$ benznidazol $\left.)\left(\mathrm{NH}_{3}\right)_{4} \mathrm{SO}_{2}\right]\left(\mathrm{CF}_{3} \mathrm{SO}_{3}\right)_{2}[14], \quad$ apresentaram resultados promissores contra malária e doença de Chagas, respectivamente. Recentemente, tionicotinamida (thio) coordenada ao complexo pentacianoferrato $\left(\mathrm{Na}_{3}\left[\mathrm{Fe}(\mathrm{CN})_{5}\right.\right.$ (thio)]) demonstrou inibição de enzimas de cepas de bactérias resistentes da tuberculose[15].

Contra a leishmaniose, complexos também vem sendo empregado contra o parasito de forma eficiente[9]. Foi reportado na literatura o uso de complexos de platina contra leishmaniose, sendo observada interação do metal com DNA do parasito L. infantum[7]. Outro metal que vem despertando interesse para 0 tratamento de leishmaniose é o zinco que possui aplicação oral na forma de sulfato de zinco. Pacientes iraquianos que apresentavam leishmaniose cutânea foram submetidos a este tratamento verificando-se a cura em até $96,9 \%$ dos pacientes[16]. O possível mecanismo de ação deste sal pode ser o efeito imunomodulatório sobre as funções de macrófagos[16, 17].

\subsection{Doadores de NO e leishmaniose}

O óxido nítrico é um radical pouco estável ( $\left.\mathrm{t}_{1 / 2} \approx 5 \mathrm{~s}\right)$ e com elevada constante de difusão (3300 $\left.\mu \mathrm{m}^{2} \mathrm{~s}^{-1}\right)$, capaz de difundir-se através de membranas celulares em meio fisiológico. Também apresenta grande reatividade com ferro presente em várias proteínas[18]. Esta molécula vem sendo intensamente estudada principalmente devido as suas diversas funções em processos fisiológicos, tais como 
participação no sistema imunológico, relaxação da musculatura do endotélio e regulação do sistema vascular [18].

No organismo, o óxido nítrico é produzido pela oxidação da L-arginina que é convertida a L-citrulina (Figura 3), reação catalisada pela NO-sintase, a qual apresenta três isoformas pertencentes a duas categorias: a NO-sintase constitutiva (c-NOS) envolvida na sinalização celular e a NO-sintase induzível (i-NOS) produzida por macrófagos e outras células ativadas por citocinas [19].<smiles>NC(N)CCC[NH+](N)C(=O)[O-]</smiles>

L - Arginina<smiles>N/C(=N/O)NCCC[C@H](N)C(=O)[O-]</smiles>

N-hidr oxi-L-Arginina<smiles>NC(=O)NCCC[C@H](N)C(=O)[O-]</smiles>

\section{L-Citrulina}

Figura 3 - Produção de NO via oxidação de L-Arginina a L-Citrulina.

A produção de óxido nítrico pela enzima i-NOS em macrófagos é um dos principais mecanismos de defesa de células hospedeiras contra parasitas como a Leishmania ssp [20]. O óxido nítrico pode reagir com radicais, como o superóxido $\left(\mathrm{O}_{2}^{\circ}\right)$, produzindo o íon peroxinitrito $\left(\mathrm{ONOO}^{-}\right)$(Equação 1) que apresenta efeito citostático e citotóxico contra o parasito [18, 19]. Por outro lado, a produção excessiva de NO pode causar danos as células hospedeiras agindo principalmente no ciclo respiratório celular [18].

$$
\mathrm{O}_{2}^{\bullet}+\mathrm{NO} \longrightarrow \mathrm{ONOO}^{-}
$$


Uma alternativa para o controle de diversas doenças parasitárias é o uso de compostos capazes de liberar óxido nítrico exógeno de forma controlada. A aplicação de compostos doadores de óxido nítrico, como a nitroglicerina[21] em pacientes com leishmaniose cutânea vem mostrando resultados promissores[22]. Foi reportado que doadores de NO utilizados contra formas promastigotas e amastigotas da leishmania inibe a respiração mitocondrial do parasito[22, 23]. Também foi reportado que nitrosotiois inibem enzimas da L. major e da L.infantum por meio de reações de transnitrosação, na qual o grupo nitrosônio é transferido diretamente do grupo RSNO ao tiol da proteína (Equação 2)[22].

$$
\mathrm{RSNO}+\text { pCys-SH } \longrightarrow \text { RSH + pCys-SNO }
$$

Assim, é de interesse o uso de compostos liberadores de óxido nítrico para aplicação farmacológica, tais como nitrosotiois[22], diazeniumdiolatos[24] e complexos metálicos nitrosilados[25, 26].

\subsection{Tetraaminas de rutênio}

É conhecido que a enzima NO sintase não é ativa na ausência de oxigênio, ou seja, em ambiente redutor (hipoxia) resultante de infecções[27]. O parasita Leishmania major exibe mecanismo de defesa[28] o qual deve interferir com a produção de NO e assim aumentar sua resistência aos macrófagos[29]. Sob condições de hipoxia, complexos de rutênio nitrosilados são capazes de liberar óxido nítrico (NO) após redução de um elétron ou por irradiação de luz UV-vis (Equações $3,4$ e 7$)[15,18,24,25,26,27]$. Desta forma, estes complexos podem agir como 
substitutos inorgânicos da NOS, proporcionando um suporte adicional ao sistema imunológico [26, 30-36]. Estes compostos também podem potencialmente ser passíveis liberadores de HNO quando ativados por redução de dois elétrons (Equação 3,5 e 6).

$$
\begin{aligned}
& \text { trans }-\left[\mathrm{Ru}(\mathrm{NO})\left(\mathrm{NH}_{3}\right) 4(\mathrm{~L})\right]^{3+}+\mathrm{e}^{-} \stackrel{\text { rápido }}{\longrightarrow} \text { trans }-\left[\mathrm{Ru}(\mathrm{NO})\left(\mathrm{NH}_{3}\right) 4(\mathrm{~L})\right]^{2+}
\end{aligned}
$$

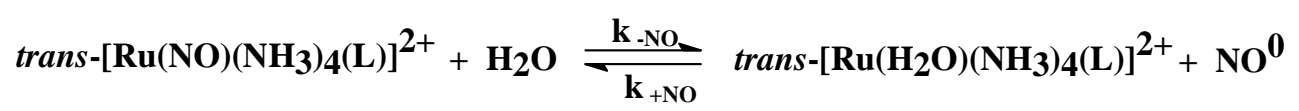

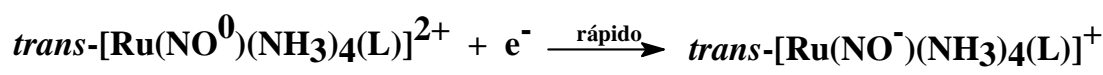

$$
\begin{aligned}
& \text { trans- }\left[\mathrm{Ru}\left(\mathrm{NO}^{-}\right)\left(\mathrm{NH}_{3}\right) 4(\mathrm{~L})\right]^{+}+\mathrm{H}_{2} \mathrm{O} \longrightarrow \text { trans }-\left[\mathrm{Ru}\left(\mathrm{H}_{2} \mathrm{O}\right)\left(\mathrm{NH}_{3}\right) 4(\mathrm{~L})\right]^{2+}+\mathrm{HNO} \\
& \text { trans- }\left[\mathrm{Ru}(\mathrm{NO})\left(\mathrm{NH}_{3}\right)_{4}(\mathrm{~L})\right]^{3+} \stackrel{\mathrm{hv}}{\longrightarrow} \text { trans- }\left[\mathrm{Ru}\left(\mathrm{H}_{2} \mathrm{O}\right)\left(\mathrm{NH}_{3}\right)_{4}(\mathrm{~L})\right]^{3+}+\mathrm{NO}^{0}
\end{aligned}
$$

A faixa de potencial redox do nitrosônio coordenado às tetraaminas de rutênio varia entre $-0,50$ a $-0,11$ V vs ECS. Portanto, o ligante nitrosônio nestes complexos é passível de redução por moléculas biológicas como a glutationa ou a cisteína. O potencial redox destes nitrosilos é função de interação dos orbitais $t_{2 g}$ do metal $\left(d^{6}\right.$, baixo spin) e dos orbitais $p \pi^{*}$ do $\mathrm{NO}^{+}$. A extensão da retrodoação pode ser observada pela estabilização do estado de oxidação $\mathrm{Ru}(\mathrm{II})$ em relação ao $\mathrm{Ru}(\mathrm{III})$, refletindo nos valores de potenciais formais de redução do $\mathrm{NO}^{+}$[34] . Assim, quanto mais positivo o valor $\mathrm{E}^{0} \mathrm{NO}^{+} / \mathrm{NO}^{0}$, mais intensa o retrodoação $\mathrm{Ru}(4 \mathrm{~d} \pi) \rightarrow \mathrm{NO}^{+}\left(\mathrm{p} \pi^{\star}\right) . A$ freqüência de estiramento $\left(v \mathrm{NO}^{+}\right)$também é afetada pela retrodoação $\mathrm{Ru}(4 \mathrm{~d} \pi) \rightarrow \mathrm{NO}^{+}\left(\mathrm{p} \pi^{*}\right)$, sendo o valor de estiramento menor a medida que a retrodoação aumenta.

Mudanças na reatividade do centro metálico em função da retrodoação $\mathrm{Ru}(4 \mathrm{~d} \pi) \rightarrow \mathrm{NO}^{+}\left(\mathrm{p} \pi^{*}\right)$ também são observadas. O ligante em posição trans ao $\mathrm{NO}^{+}$ torna-se inerte com respeito a reação de substituição. Assim, a molécula de $\mathrm{H}_{2} \mathrm{O}$ no 
complexo trans-[RuNO $\left.\left(\mathrm{NH}_{3}\right)_{4}\left(\mathrm{H}_{2} \mathrm{O}\right)\right]^{3+}$ na presença de $1,0 \mathrm{M}$ pirazina, não é substituída em até 24 horas de reação. Entretanto, quando o $\mathrm{NO}^{+}$é reduzido a $\mathrm{NO}^{0}$, ocorre a população dos orbitais $p \pi^{*}$ da ligação $\mathrm{Ru}-\mathrm{NO}$, ocorrendo a dissociação de $\mathrm{NO}^{0}$ devido ao efeito trans de $\mathrm{L}$ [33]. Assim, as constantes de velocidade específica para dissociação de $\mathrm{NO}^{0}$ nos complexos trans-[RuNO$\left.\left.\left(\mathrm{NH}_{3}\right)_{4} \mathrm{~L}\right)\right]^{+2}$ obedece a série de efeito trans de L já reportada [33].

Nosso Laboratório vêm desenvolvendo o estudo da síntese, caracterização, reatividade e o uso de tetraaminas de rutênio nitrosiladas na sua exploração como agentes terapêuticos contra parasitas intracelulares[25]. Estes compostos são metalofármacos promissores visto que são solúveis em água e estáveis em solução aquosa na presença de oxigênio. Além disto, estes compostos exibem baixa toxicidade in vitro (células V79) e in vivo [25, 37, 38].

Resultados in vitro e in vivo utilizando compostos trans-[RuNO$\left.\left(\mathrm{NH}_{3}\right)_{4} \mathrm{~L}\right] \mathrm{X}_{3},(\mathrm{X}$ $=\mathrm{BF}_{4}^{-}$ou $\mathrm{PF}_{6}^{-}$e $\mathrm{L}=\mathrm{imN}, 4-p i c, p z, p y, \mathrm{P}(\mathrm{OEt})_{3}, \mathrm{~L}-$ hist, isn, imC, nic, $\left.\mathrm{SO}_{3}{ }^{2-}\right) \mathrm{e}$ [RuNO(Hedta)] contra Trypanosoma cruzi [25], demonstraram que estes são ativos contra o parasita sem promover danos a célula hospedeira. 


\section{II - Objetivos}

Considerando a experiência acumulada sobre reatividade térmica e fotoquímica dos nitrosilo complexos trans-[RuNO $\left.\left(\mathrm{NH}_{3}\right)_{4}(\mathrm{~L})\right](\mathrm{X})_{3}$ e estimulados pelos resultados obtidos em experimentos in vitro e in vivo contra o parasito T.cruzi, prolongou-se o estudo ao tripanosomatídeos Leishmania major. Assim, pretendeuse:

- Avaliar a atividade antileishmania in vitro de compostos do tipo trans-[RuNO$\left.\left(\mathrm{NH}_{3}\right)_{4} \mathrm{~L}\right](\mathrm{X})_{3}, \quad\left(\mathrm{X}=\mathrm{BF}_{4}^{-}\right.$ou $\mathrm{PF}_{6}^{-}$e $\mathrm{L}=\mathrm{imN}, 4$-pic, pz, py, $\mathrm{P}(\mathrm{OEt})_{3}, \quad \mathrm{~L}-\quad$ hist, $\quad$ isn, $\quad \mathrm{imC}, \quad$ nic, $\left.\quad \mathrm{SO}_{3}{ }^{2-}\right), \quad[\mathrm{RuNO}($ Hedta) $)]$ e trans-[Ru( $\left.\left.\mathrm{NH}_{3}\right)_{4} \mathrm{~L}\left(\mathrm{SO}_{4}\right)\right] \mathrm{Cl},(\mathrm{L}=\mathrm{imN}, \mathrm{pz}, \mathrm{py}, \mathrm{L}$ - hist, isn, nic);

- Avaliar a atividade antileishmania in vivo do composto mais promissor, determinado na fase de testes in vitro;

- Procurar correlacionar os efeitos antiparasitários com a capacidade destes compostos de liberarem NO e/ou HNO;

- Discutir alguns aspectos da reação dos nitrosilos de rutênio com a Lcisteína. 


\section{III - Experimental}

\section{1 - Reagentes}

$\mathrm{RuCl}_{3} \cdot \mathrm{xH}_{2} \mathrm{O}$, trietilfosfito, pirazina, 4-picolina, nicotinamida, isonicotinamida, imidazol, L-histidina, monohidrato de hidrazina, hexafluorofosfato de amônio, nitrito de sódio, ácido trifluroacético, ácido acético, ácido tetrafluorobórico, L-cisteína, óxido de deutério foram utilizados como fornecidos devido ao alto grau de pureza descrito pelos fabricantes (Sigma-Aldrich, Merck e J.T. Baker). Solventes foram purificados anteriormente à utilização, conforme procedimento descrito na literatura[39].

O argônio utilizado nas sínteses e nos experimentos foi purificado para eliminar traços de oxigênio por meio de seu fluxo através de frascos lavadores contendo solução de ácido perclórico $0,5 \mathrm{~mol} \mathrm{~L}^{-1}$ e $5 \%$ de cromo (II) em contato com amálgama de zinco. A solução de $\operatorname{Cr}($ II) foi obtido por meio da redução do $\mathrm{Cr}$ (III), oriundo de uma solução $0,3 \mathrm{~mol} \mathrm{~L}^{-1}$ de $\mathrm{CrCl}_{3}$ contendo $1,0 \mathrm{~mol} \mathrm{~L}^{-1}$ de $\mathrm{HCl}$, por amálgama de zinco. A redução foi completa após um período de seis horas sob atmosfera de argônio.

Amálgama de zinco também foi utilizada para a preparação dos nitrosilo complexos de rutênio. Amálgama foi preparada após um tratamento prévio do zinco com uma solução $6,0 \mathrm{~mol} \mathrm{~L}^{-1}$ de $\mathrm{HCl}$ e em seguida adição de gotas de mercúrio. $\mathrm{O}$ zinco amalgamado foi lavado várias vezes com água destilada, seco com papel de filtro e utilizado imediatamente. 


\section{2 - Instrumentação e Técnicas Experimentais}

\subsection{1 - Espectroscopia vibracional na região do infravermelho}

Os espectros na região do infravermelho foram obtidos em um espectrofotômetro BOMEM FTIR MB-102 na região de $4000-400 \mathrm{~cm}^{-1}$. As amostras foram preparadas sob forma de pastilha de $\mathrm{KBr}$ em concentração de $1 \%$. Os experimentos em solução foram realizados utilizando uma cela de janelas de fluoreto de cálcio.

\subsection{2 - Espectroscopia de ressonância magnética nuclear (RMN)}

Os espectros de ressonância magnética nuclear de ${ }^{31} \mathrm{P}$ foram efetuados em um espectrômetro BRUKER AC-200. Os espectros de RMN foram obtidos em solução de $\mathrm{D}_{2} \mathrm{O}$ e ajustado com HTFA para pH 4,0. Utilizou-se ácido fosfórico como referência para os espectros de ${ }^{31} \mathrm{P}$.

As soluções contendo os reagentes foram deaeradas e transferidas por meio de cânula de teflon sob fluxo de argônio para o tubo de RMN previamente desaerado.

\subsubsection{Espectroscopia de Ressonância Paramagnética eletrônica}

Os experimentos de RPE foram efetuados em um espectrômetro BRUKER ESP 300E à temperatura do nitrogênio líquido (77K). As amostras foram efetuadas em solução aquosa com $\mathrm{CF}_{3} \mathrm{COONa}$.

As amostras em solução foram previamente deaeradas e transferidas para um tubo de RPE, também previamente deaerado, e imediatamente seladas e congelados em nitrogênio líquido. 


\subsection{4 - Experimentos de eletroquímica}

Os experimentos de voltametria cíclica foram efetuados em potenciostato EG\&G PAR modelo 264A. Utilizou-se uma célula eletroquímica constituída por três eletrodos: eletrodo de trabalho: disco de carbono vítreo; eletrodo de referência: eletrodo de calomelano saturado (ECS) e eletrodo auxiliar: placa de platina. Todos os experimentos foram realizados a $25 \pm 0,2^{\circ} \mathrm{C}$ e na ausência de oxigênio.

\subsection{5 - Espectros de absorção na região do ultravioleta-visível}

As medidas de espectroscopia de ultravioleta-visível foram realizadas em um espectrofotômetro Hitachi modelo U-3501. Utilizou-se cela de quartzo de caminho ótico de $1,0 \mathrm{~cm}$. As medidas de absorção foram efetuadas pela leitura direta dos espectros, sendo utilizado como branco o próprio solvente.

\subsection{6 - Determinações de pH}

As determinações de $\mathrm{pH}$ foram efetuadas através de um eletrodo combinado marca Metrohm, modelo A691000 Herisau, acoplado a um pHmetro CORNING, modelo 130.

\subsubsection{Eletrodo Seletivo para detecção de óxido nítrico}

A detecção e quantificação de óxido nítrico foi realizado por meio do uso do eletrodo Amino-700 acoplado a um sensor marca Innovative instruments modelo inNO-T. As medidas foram realizadas em solução de $\mathrm{CF}_{3} \mathrm{COONa} 0,2 \mathrm{M}(\mathrm{pH}=2,0$ 7,4) [51]. Para a quantificação do óxido nítrico foi construída uma curva de calibração com uma solução estoque de óxido nítrico. Para obter esta solução, gás NO foi gerado a partir de um sistema constituído de um funil de separação contendo 
ácido sulfúrico concentrado acoplado a um kitassato contendo uma solução saturada de nitrito de sódio. A reação entre o ácido e o nitrito produz o gás NO que é conduzido por dois frascos lavadores contendo solução aquosa e solução $4,0 \mathrm{~mol} \mathrm{~L}^{-1}$ de $\mathrm{NaOH}$ até uma balão reacional contendo solução aquosa. Diferentes alíquotas (50, 100 e $150 \mu \mathrm{L})$ desta solução contendo $2,0 \mathrm{~mol} \mathrm{~L}^{-1}$ de NO foram transferidas para um balão reacional contendo $20 \mathrm{~mL}$ de solução tampão $(\mathrm{pH} 2,0-7,0)$. Um gráfico de corrente em função da concentração foi construído e utilizado para o cálculo de concentração de NO gerado da reação em estudo.

\subsubsection{Espectroscopia de Massa}

A identificação e quantificação da cistina, gerada da reação entre o complexo trans-[RuNO $\left.\left(\mathrm{NH}_{3}\right)_{4} \mathrm{P}(\mathrm{OEt})_{3}\right]\left(\mathrm{PF}_{6}\right)_{3}$ e a L-cisteína, foram realizadas por meio da utilização do sistema de HPLC Shimadzu LC20AT acoplado a espectrômetro de massas de multiplo estágio do tipo “ion trap” Bruker Esquire 4000.

\subsubsection{Medidas Cinéticas}

As reações entre os íons complexos trans-[RuNO $\left.\left(\mathrm{NH}_{3}\right)_{4} \mathrm{~L}\right] \mathrm{X}_{3},\left(\mathrm{X}=\mathrm{BF}_{4}^{-}\right.$ou $\mathrm{PF}_{6}{ }^{-}$ e $\mathrm{L}=$ 4-pic, py, $\mathrm{P}(\mathrm{OEt})_{3}$, isn, nic,) e a L-cisteína foram acompanhadas por meio de variação espectral na região do UV-Vis. As reações foram estudadas em condições de pseudo primeira ordem com no mínimo 10 vezes de excesso de L-cisteína em relação ao complexo de rutênio. Os experimentos foram realizados com soluções com força iônica controlada em $0,2 \mathrm{~mol} \mathrm{~L}^{-1}\left(\mathrm{CF}_{3} \mathrm{COONa}\right)$ e valores de $\mathrm{pH}$ na faixa de

2,0 a 7,4. Os tampões utilizados foram $\mathrm{H}_{3} \mathrm{PO}_{4} / \mathrm{KH}_{2} \mathrm{PO}_{4}(\mathrm{pH} \quad 6,2$ e 7,4) e $\mathrm{CH}_{3} \mathrm{COOH} / \mathrm{CH}_{3} \mathrm{COONa}(\mathrm{pH} 3,5 ; 4,0$ e 4,5$)$. A temperatura $\left(25 \pm 0,2^{\circ} \mathrm{C}\right)$ foi controlada por meio de um banho termostático da Tecnal, modelo TE 184. 
Para a reação cujo $t_{1 / 2}<1 \mathrm{seg}$, foi utilizado um espectrofotômetro stopped-flow, Aminco. A reação foi monitorada por meio da variação de absorbância na região do visível em comprimentos de onda previamente definidos para cada complexo estudado.

\subsection{Cálculos cinéticos}

As medidas cinéticas foram realizadas sob condições de pseudo primeira ordem com excesso de pelo menos 10 vezes de um dos reagentes.

As constantes de pseudo primeira ordem observadas ( $k_{\text {obs }}$ ) foram determinadas a partir dos gráficos de $\ln \left(\mathrm{A}_{\infty}-\mathrm{A}_{t}\right)$ versus tempo (s) (Equação 8).

$$
\ln \left(A_{\infty}-A_{t}\right)=k_{\text {obs }} \times t
$$

$A_{\infty}=$ absorbância no tempo final da reação

$A_{t}=$ absorbância em cada instante da reação

$\mathrm{t}=$ tempo em segundos

\section{4 - Sínteses}

Os complexos $\quad\left[\mathrm{Ru}\left(\mathrm{NH}_{3}\right)_{5} \mathrm{Cl}\right] \mathrm{Cl}{ }_{2}$, trans-[Ru($\left.\left(\mathrm{NH}_{3}\right)_{4} \mathrm{Cl}\left(\mathrm{SO}_{2}\right)\right] \mathrm{Cl}[39]$, trans- $\left[\mathrm{Ru}\left(\mathrm{NH}_{3}\right)_{4} \mathrm{P}(\mathrm{OEt})_{3}\left(\mathrm{H}_{2} \mathrm{O}\right)\right]\left(\mathrm{PF}_{6}\right)_{2}, \quad$ trans-[Ru(NO)$\left.\left(\mathrm{NH}_{3}\right)_{4} \mathrm{P}(\mathrm{OEt})_{3}\right]\left(\mathrm{PF}_{6}\right)_{3}[40] \quad$ e trans-[Ru(NO)(NH$\left.)_{4}(\mathrm{~L})\right]\left(\mathrm{BF}_{4}\right)_{3} \quad(\mathrm{~L}=$ piridina, 4-picolina, pirazina, isonicotinamida, nicotinamida, imidazol, L-histidina) foram preparados segundo metodologias descritas na literatura[41]. As estruturas químicas dos ligantes encontram-se no Apêndice (Figura 1A). 


\section{5 - Testes biológicos}

Esta etapa foi desenvolvida em parceria com o Prof. Dr. Fernando Q. Cunha do Departamento de Farmacologia e com o Prof. Dr. João Santana da Silva do Departamento de Imunologia da Faculdade de Medicina de Ribeirão Preto (FMRPUSP), onde foram realizados experimentos in vitro e in vivo para testar a atividade leishmanicida dos compostos nitrosilados.

\subsection{1 - Animais de experimentação}

Foram utilizados camundongos BALB/c, fêmeas, com idade aproximada de sete semanas, criados e mantidos no biotério do Departamento de Farmacologia da Faculdade de Medicina de Ribeirão Preto (FMRP-USP). A utilização de camundongos BALB/c nos testes in vivo se faz necessário por estes apresentarem genótipo de susceptibilidade à infecção experimental por Leishmania major. Os experimentos foram conduzidos de acordo com o Comitê de Ética em Pesquisa Animal (CETEA) da FMRP-USP.

\subsection{2 - Cultura de parasitas}

Formas promastigotas de L. major (LV-39, clone 5-Rho/SU/59/P) foram mantidas em meio de cultura Schneider (Sigma), contendo soro bovino fetal a $20 \%$ (Cultilab) e $2 \%$ de urina humana masculina em garrafas de cultura (Corning Inc.).

\subsection{3 - Testes in vitro contra forma promastigota da Leishmania} major

Os parasitas foram cultivados em meio Schneider, suplementados com $20 \%$ de soro bovino fetal e $2 \%$ de urina humana masculina a $28^{\circ} \mathrm{C}$ com agitação (cerca 
de 120 rpm). A avaliação da atividade antipromastigota dos compostos trans$\left[\operatorname{RuNO}\left(\mathrm{NH}_{3}\right)_{4} \mathrm{~L}\right](\mathrm{X})_{3},\left(\mathrm{X}=\mathrm{BF}_{4}^{-}\right.$ou $\mathrm{PF}_{6}^{-} \mathrm{e} \mathrm{L}=\mathrm{imN}, 4$-pic, pz, py, $\mathrm{P}(\mathrm{OEt})_{3}, \mathrm{~L}-$ hist, isn, imC, nic, $\left.\mathrm{SO}_{3}{ }^{2-}\right),[\mathrm{RuNO}(\mathrm{Hedta})]$ e trans- $\left[\mathrm{Ru}\left(\mathrm{NH}_{3}\right)_{4} \mathrm{~L}\left(\mathrm{SO}_{4}\right)\right] \mathrm{Cl},(\mathrm{L}=\mathrm{imN}, \mathrm{pz}, \mathrm{py}, \mathrm{L}-$ hist, isn, nic) foi determinada pela contagem do número de parasitas. $\mathrm{mL}^{-1}$ quando as culturas controle atingiram a concentração de $1 \times 10^{6}$ parasitas. $\mathrm{mL}^{-1}$. Os compostos foram adicionados em soluções aquosas nas concentrações $0,011-8,1 \mathrm{mmol} \mathrm{L}{ }^{-1}$. A proliferação foi acompanhada pela contagem do número de parasitas por $\mathrm{mL}$ em câmara de Neubauer com ajuda de microscópio óptico (aumento de 40 vezes) após um período de no mínimo 24 horas de incubação. Para o controle negativo, grupos de parasitas não foram incubados com as drogas. Para o controle positivo, foi utilizado o complexo $\mathrm{Na}_{2}\left[\mathrm{Fe}(\mathrm{CN})_{5} \mathrm{NO}\right]$ o qual também é um doador de óxido nítrico. A atividade antiparasitária dos compostos trans- $\left[\mathrm{Ru}(\mathrm{NO})\left(\mathrm{NH}_{3}\right)_{4} \mathrm{P}(\mathrm{OEt})_{3}\right]\left(\mathrm{PF}_{6}\right)_{3}$ e trans- $\left[\mathrm{Ru}(\mathrm{NO})\left(\mathrm{NH}_{3}\right)_{4} i m \mathrm{C}\right]\left(\mathrm{PF}_{6}\right)_{3}$ também foi avaliada na presença de ácido ascórbico (redutor biológico).

Para avaliar a atividade do nitroxil (HNO), foi utilizado sal de Angeli $\left(\mathrm{Na}_{2} \mathrm{~N}_{2} \mathrm{O}_{3}\right)$ como fonte desta molécula[42]. $\mathrm{O}$ sal $\mathrm{Na}_{2} \mathrm{~N}_{2} \mathrm{O}_{3}$ se decompõe formando $\mathrm{HNO}$ e $\mathrm{NO}_{2}{ }^{-}$ com tempo de meia vida de $2,1 \mathrm{~min}$ a $37^{\circ} \mathrm{C}$ (Equação 9)[43]. A atividade avaliada para o sal de Angeli foi extrapolada para o $\mathrm{HNO}$ visto que o nitrito em $\mathrm{pH} 7,4$ não apresenta atividade antileishmania como descrito na Literatura [23].

$$
\mathrm{N}_{2} \mathrm{O}_{3}^{2-}+\mathrm{H}^{+} \longrightarrow \mathrm{HNO}+\mathrm{NO}_{2}^{-}
$$

$\mathrm{O} \mathrm{HNO}$ se dimeriza formando a molécula $\mathrm{N}_{2} \mathrm{O}$ com constante de velocidade igual a $8 \times 10^{6} \mathrm{~mol}^{-1}$.L.s $\mathrm{s}^{-1}$ (Equação 10)[44]. Para a atividade do $\mathrm{N}_{2} \mathrm{O}$, o sal de Angeli foi adicionado em meio Schneider por no mínimo 15 minutos antes da incubação parasitária.

$$
\mathrm{HNO}+\mathrm{HNO} \longrightarrow \mathrm{HON}=\mathrm{NOH} \longrightarrow \mathrm{N}_{2} \mathrm{O}+\mathrm{H}_{2} \mathrm{O}
$$


Para avaliar a atividade do gás NO, foi preparada uma solução estoque por meio de saturação de uma solução PBS com gás óxido nítrico. Esta solução foi diluída em meio Schneider contendo os parasitas e mantida por um período de 24 horas.

A inibição de crescimento foi calculada segundo a Equação 11:

$$
(G \mathrm{I})=\left\{1-\left[\left(P_{D t}-P_{D t o}\right) /\left(P_{C t}-P_{C t o}\right)\right]\right\} \times 100
$$

Onde:

$\mathrm{P}_{\mathrm{Dt}}$ : número de formas viáveis dos parasitas incubadas com as drogas no tempo $\mathrm{t}$; $\mathrm{P}_{\mathrm{Dto}}$ : número de formas viáveis dos parasitas incubadas com as drogas no zero; $\mathrm{P}_{\mathrm{Ct}}$ : número de formas viáveis dos parasitas incubadas na ausência de drogas (controle negativo) no tempo t;

$\mathrm{P}_{\mathrm{Ct}}$ : número de formas viáveis dos parasitas incubadas na ausência de drogas (controle negativo) no tempo zero.

Os testes foram executados em triplicata e os resultados foram expressos como $\mathrm{IC}_{50 \mathrm{pro}} / 24 \mathrm{hrs}$. Os valores de $\mathrm{IC}_{50}$ foram extraídos de gráficos de porcentagem de inibição em função do $\log \mathrm{C}_{\mathrm{Ru}}\left(\mathrm{C}_{\mathrm{Ru}}=\right.$ concentração do complexo).

\subsection{4 - Crescimento cinético}

$1 \times 10^{6}$ parasitas. $\mathrm{mL}^{-1}$ foram incubados com 100,300 e $900 \mu \mathrm{mol} \mathrm{L} \mathrm{L}^{-1}$ dos compostos trans- $\left[\mathrm{RuNO}\left(\mathrm{NH}_{3}\right)_{4} \mathrm{imN}\right]\left(\mathrm{BF}_{4}\right)_{3}, \quad$ trans- $\left[\mathrm{RuNO}\left(\mathrm{NH}_{3}\right)_{4}(4-\mathrm{pic})\right]\left(\mathrm{BF}_{4}\right)_{3}$, trans-[RuNO $\left.\left(\mathrm{NH}_{3}\right)_{4} \mathrm{pz}\right]\left(\mathrm{BF}_{4}\right)_{3}$, e trans- $\left[\mathrm{RuNO}\left(\mathrm{NH}_{3}\right)_{4} \mathrm{py}\right]\left(\mathrm{BF}_{4}\right)_{3}$ em meio Schneider a $25^{\circ} \mathrm{C}$. O crescimento da população parasitária foi acompanhado por meio de contagem de células viáveis utilizando câmara de Neubauer e por meio de método colorimétrico (MTT) em intervalos de 24 horas após 48, 72. 96 e 120 horas de incubação. 
O MTT é um método colorimétrico baseado na capacidade das células vivas de reduzirem o sal brometo de 3-(4,5-dimetiltiazol-2-il)-2,5-difenil tetrazolio no produto formazana[44]. Após o plaqueamento dos parasitas em meio Schneider e incubados com 100, 300 e $900 \mu \mathrm{mol} \mathrm{L^{-1 }}$ dos nitrosilos citados acima, foram mantidas a $25^{\circ} \mathrm{C}$ por períodos determinados $(48,72,96$ ou $120 \mathrm{~h})$. Quatro horas antes de terminar o tempo estabelecido foram adicionados $20 \mu \mathrm{L}$ de MTT (concentração final de $10 \mu \mathrm{g} \mathrm{mL}^{-1}$ ). As placas foram mantidas em estufa pelas quatro horas restantes. Após o tempo estipulado foram retirados $180 \mu \mathrm{L}$ do sobrenadante de cada poço e depois adicionados $150 \mu \mathrm{L}$ de dimetilsulfóxido e homogeneizado para a completa dissolução dos cristais de sal formados pelo metabolismo mitocondrial. A placa de 96 poços foi lida espectrofotometricamente utilizando o comprimento de onda de 570nm[45]. Os resultados foram analisados através da absorbância de cada poço. 0 percentual de viabilidade foi obtido através da Equação 12:

$$
\% V=\left(A_{p t} / A_{p n t}\right) \times 100
$$

Onde:

$\%$ V: percentual de viabilidade

$A_{p t}$ : Absorbância dos parasitas tratados.

$A_{\text {pnt: }}$ Absorbância dos parasitos não tratados.

Neste trabalho, tratamos os dados como porcentagem de inibição de crescimento segundo a equação 13.

$$
\% I C=100-\% V
$$

Os experimentos foram realizados em triplicata. 


\subsection{5 - Ensaio antiamastigota}

Tioglicolato de sódio (Sigma-Aldrich) foi injetado em camundongos fêmeas do tipo BALB/c e foram sacrificados após 96 horas. Os leucócitos foram retirados da cavidade peritoneal com PBS estéril e contados com câmara de Neubauer[46].

Macrófagos foram marcados com trypan blue e depois contados. Posteriormente, $1 \times 10^{5}$ células foram incubadas por 24 horas a $37{ }^{\circ} \mathrm{C}, 5 \% \mathrm{CO}_{2}$, em $300 \mu \mathrm{L}$ meio RPMI 1640 completo - RPMI 1640 (Sigma-Aldrich) com 10\% de soro bovino fetal (Cultilab), $2 \mathrm{mmol} \mathrm{L}^{-1}$ de L-glutamina, $100 \mathrm{U} / \mathrm{mL}$ penicilina e $100 \mathrm{mg} \mathrm{mL}^{-1}$ estreptomicina (Invitrogen-Gibco) por poço (Nalge Nunc, Miami, FL, USA). As células não aderidas foram removidas com PBS estéril enquanto as células aderidas foram desafiadas com promastigotas na fase estacionária em meio RPMI 1640 apenas (Invitrogen-Gibco) e na presença dos compostos trans-[RuNO$\left.\left(\mathrm{NH}_{3}\right)_{4} \mathrm{imN}\right]^{3+}, \mathrm{Na}_{2} \mathrm{~N}_{2} \mathrm{O}_{3}$ e trans- $\left[\mathrm{Ru}\left(\mathrm{NH}_{3}\right)_{4} \mathrm{imN}\left(\mathrm{H}_{2} \mathrm{O}\right)\right]^{2+}$, nas concentrações de 100,33 e $11 \mu \mathrm{mol} \mathrm{L}{ }^{-1}$. Vinte e quatro horas após o desafio, as lâminas foram coradas com giemsa. O número de parasitas intracelulares foi determinado por contagem de pelo menos 100 macrófagos em duplicata. Os resultados foram expressos como porcentagem de parasitas vivos comparados ao controle[47].

\subsection{6 - Teste de toxicidade em macrófagos}

Macrófagos $\left(5 \times 10^{5}\right.$ células) foram adicionados em placa de 96 poços e incubados em meio de RPMI-1640 contendo diferentes concentrações dos complexos trans-[RuNO $\left.\left(\mathrm{NH}_{3}\right)_{4} \mathrm{imN}\right]^{3+}, \quad \mathrm{Na}_{2} \mathrm{~N}_{2} \mathrm{O}_{3}$ e trans- $\left[\mathrm{Ru}\left(\mathrm{NH}_{3}\right)_{4} \mathrm{imN}\left(\mathrm{H}_{2} \mathrm{O}\right)\right]^{2+}$ (3-8100 $\left.\mathrm{mmolL}^{-1}\right)$ por 24 horas, a $37^{\circ} \mathrm{C}, 5 \% \mathrm{CO}_{2}$.

Após o tempo de incubação, a suspensão celular obtida foi diluída em PBS, homogeneizada em tubos para citometria de fluxo com $10 \mu \mathrm{L}$ de iodeto de propídio 
por 10 minutos a temperatura ambiente e protegido da luz. As células foram analisadas em um citômetro de fluxo FACSCantoll (BD Biosciences, San Jose, CA). As células marcadas com IP, que penetra apenas em células não viáveis, foram detectadas no canal FL2 (emissão de fluorescência na faixa de 560-580 nm)[34]. O iodeto de propídio é um composto que se liga apenas ao DNA de células inviáveis emitindo fluorescência. Desta forma, é possível distinguir células viáveis e inviáveis definindo a toxicidade de uma droga. Os dados foram salvos automaticamente pelo software FACSDiva (BD Biosciences). O software Flow Jo (Three Star, Ashland, OR, USA) foi utilizado para análise dos dados.

\subsection{7 - Testes in vivo da atividade Leishmanicida dos compostos nitrosilados}

Seis grupos de camundongos BALB/c fêmeas foram infectados com $1 \times 10^{5}$ formas promastigotas de L. major intradermicamente na orelha. Os camundongos foram tratados diariamente intradermicamente na região lombar com solução PBS contendo o complexo trans-[Ru(NO) $\left.\left(\mathrm{NH}_{3}\right) \operatorname{ImN}\right]\left(\mathrm{BF}_{4}\right)_{3}\left(0,5,1,0\right.$ e $10 \mu \mathrm{mol} \mathrm{Kg}^{-1}$, grupos 1,2 e 3) entre a terceira e a sexta semana de infecção [47]. Como controle negativo (grupo 4), os camundongos foram tratados apenas com solução PBS. Como controle positivo, um grupo de camundongos foi tratado com $10 \mathrm{mg} \mathrm{Kg}^{-1} \mathrm{de}$ glucantime (grupo 5) e outro grupo tratado com $0,5 \mu \mathrm{mol} \mathrm{Kg}^{-1}$ do composto trans$\left[\mathrm{Ru}\left(\mathrm{NH}_{3}\right) \operatorname{ImN}\left(\mathrm{SO}_{4}\right)\right] \mathrm{Cl}$ (grupo 6).

Para a verificação da função leishmanicida dos compostos nitrosilados, o tamanho da lesão cutânea foi avaliado semanalmente utilizando-se um paquímetro. O tamanho da lesão foi determinado através da diferença entre o tamanho da orelha infectada e a contralateral (não infectada), em milímetros (mm). 


\subsection{8 - Determinação do número de parasitas presentes nas} orelhas de camundongos tratados com os nitrosilos complexos.

Para avaliação da função leishmanicida do composto nitrosilado, foi quantificado o número de parasitos presentes nas orelhas dos camundongos tratados por meio da utilização da técnica de diluição limitante [73]. Assim, 6 orelhas por grupo de animal foram trituradas por MedMachine em um volume de $2 \mathrm{~mL}$ do meio de cultura Schneider suplementado. Em seguida, foram feitas diluições seriadas em placas de 96 poços contendo ágar-sangue. As contagens dos poços positivos foram realizadas no dia 10 após plaqueamento. O número de parasitas por orelha foi estimado utilizando-se o programa ELIDA [74].

\subsection{9 - Detecção de nitrito}

A concentração de nitrito no meio de cultura $(0,1 \mathrm{~mL})$ foi determinada por meio da adição de $0,1 \mathrm{~mL}$ reagente de Griess. A absorbância em $540 \mathrm{~nm}$ foi lida 10 minutos depois e a concentração de $\mathrm{NO}_{2}^{-}$foi determinada pela diferença de calibração de $\mathrm{NaNO}_{2}\left(1-100 \mathrm{mmol} \mathrm{L}^{-1}\right)[75]$.

\subsubsection{0 - Métodos estatísticos}

Todos os resultados foram considerados significativos quando $\mathrm{P}<0,05$. Os resultados foram expressos como média \pm desvio padrão (DP) ou média \pm erro padrão da média (EPM). A análise estatística foi realizada utilizando-se o teste Mann-Whitney para comparação entre duas amostras independentes. A análise de variância (ANOVA) e o método de Tukey-Kramer foram utilizados para comparar os resultados obtidos do grupo experimental de camundongos infectados e do grupo controle. Para todas as análises, foi utilizado o programa Prisma 4.0 (Prism GraphPad Software, Inc.) 


\section{RESULTADOS E DISCUSSÃO}

\subsection{Atividade antipromastigota dos nitrosilos de rutênio}

Os primeiros experimentos in vitro foram de caráter exploratório com o intuito de avaliar a atividade antileishmania dos complexos trans-[RuNO$\left.\left(\mathrm{NH}_{3}\right)_{4} \mathrm{~L}\right] \mathrm{X}_{3},(\mathrm{X}=$ $\mathrm{BF}_{4}^{-}$ou $\mathrm{PF}_{6}^{-}$e $\mathrm{L}=\mathrm{imN}$, 4-pic, pz, py, $\mathrm{P}(\mathrm{OEt})_{3}, \mathrm{~L}-$ hist, isn, imC, nic, $\left.\mathrm{SO}_{3}^{-2}\right) \mathrm{e}$ [RuNO(Hedta)] (Apêndice, Tabela 1A). Inicialmente, foram utilizadas formas promastigotas do parasita Leishmania major incubadas com os complexos por um período de 24 horas. Por meio do gráfico de porcentagem de inibição de crescimento em função do log da concentração do complexo, foram calculados os valores de $\mathrm{IC}_{50 \text { pro }}$ para todos os nitrosilos complexos citados acima (Apêndice, Figura 2A). Os complexos estudados apresentaram $I_{50 p r o}$ na faixa de $36(L=i m N)$ a > $5000 \mu \mathrm{mol} \mathrm{L}^{-1}(\mathrm{~L}=\mathrm{imC})$ (Tabela 1). De acordo com os dados da Tabela 1, os complexos onde $\mathrm{L}=\mathrm{imN}$, 4-pic , pz, py, $\mathrm{P}(\mathrm{OEt})_{3}$, L-hist, apresentaram um pronunciado efeito antipromastigota em comparação ao nitroprussiato de sódio $\left(\mathrm{Na}_{2}\left[\mathrm{FeNO}(\mathrm{CN})_{5}\right]\right.$, NP) utilizado como referência. Os complexos trans-[RuNO $\left(\mathrm{NH}_{3}\right)_{4}$ nic $]\left(\mathrm{BF}_{4}\right)_{3}, \quad$ trans- $\left[\mathrm{RuNO}\left(\mathrm{NH}_{3}\right)_{4}\right.$ isn $]\left(\mathrm{BF}_{4}\right)_{3} \quad$ e $\quad[\mathrm{RuNO}(\mathrm{Hedta})]$ apresentaram eficiência menor que os demais. Conforme observado na Figura 4, o primeiro grupo de complexos apresenta valores mais elevados de constantes específicas de dissociação do ligante NO (k-NO) e também exibem maior efeito antipromastigota sugerindo, portanto, uma possível tendência de relação entre estes dois parâmetros. 
Tabela 1 - Parâmetros de atividade antipromastigota de doadores de NO, sua respectiva toxicidade frente a células $\mathrm{V} 79$, índice terapêutico $\left(\mathrm{IC}_{50 \mathrm{v79}} / \mathrm{IC}_{50 \mathrm{pro}}\right)$ e valores de $\mathrm{k}_{-\mathrm{NO}} \mathrm{e}$ $\mathrm{E}_{(\mathrm{NO} / \mathrm{NO}) \text {. }}^{0}$

\begin{tabular}{|c|c|c|c|c|c|}
\hline Compostos & $\begin{array}{c}\mathrm{IC}_{50 \mathrm{pro}} \\
\left(\mu \mathrm{molL}^{-1}\right)^{\mathrm{a}}\end{array}$ & $\begin{array}{c}\mathrm{IC}_{50 \mathrm{~V} 79} \\
\left(\mu \mathrm{molL}^{-1}\right)^{\mathrm{b}}\end{array}$ & $\begin{array}{l}I_{50 v 79} \\
/ I_{50 p r o}\end{array}$ & $\begin{array}{l}\mathrm{K}_{-\mathrm{NO}} \\
\left(\mathrm{s}^{-1}\right)^{\mathrm{C}}\end{array}$ & $\begin{array}{c}\mathrm{E}_{\left(\mathrm{NO}^{+} / \mathrm{NO}^{0}\right)} \\
(\mathrm{V} v s \mathrm{ENH})^{d}\end{array}$ \\
\hline Gás NO & 12 & ND & ND & - & - \\
\hline Trans-[Ru(NO) $\left.\left(\mathrm{NH}_{3}\right)_{4} \mathrm{imN}\right]\left(\mathrm{BF}_{4}\right)_{3}$ & 36 & 646 & 18 & 0,160 & $-0,118$ \\
\hline trans-[Ru(NO) $\left.\left(\mathrm{NH}_{3}\right)_{4} 4-\mathrm{pic}\right]\left(\mathrm{BF}_{4}\right)_{3}$ & 38 & ND & ND & 0,090 & $-0,008$ \\
\hline Trans-[Ru(NO) $\left.\left(\mathrm{NH}_{3}\right)_{4} \mathrm{pz}\right]\left(\mathrm{BF}_{4}\right)_{3}$ & 41 & 120 & 3 & 0,070 & 0,112 \\
\hline Trans-[Ru(NO)($\left.\left(\mathrm{NH}_{3}\right)_{4} \mathrm{py}\right]\left(\mathrm{BF}_{4}\right)_{3}$ & 42 & 930 & 22 & 0,060 & 0,012 \\
\hline trans-[Ru(NO) $\left.\left(\mathrm{NH}_{3}\right)_{4} \mathrm{P}(\mathrm{OEt})_{3}\right]\left(\mathrm{PF}_{6}\right)_{3}$ & 82 & 2260 & 28 & 0,98 & 0,132 \\
\hline trans-[Ru(NO) $\left.\left(\mathrm{NH}_{3}\right)_{4} \mathrm{~L}-\mathrm{hist}\right]\left(\mathrm{BF}_{4}\right)_{3}$ & 95 & 414 & 4 & 0,14 & $-0,108$ \\
\hline $\mathrm{Na}_{2} \mathrm{~N}_{2} \mathrm{O}_{3}$ & 158 & ND & ND & - & - \\
\hline $\mathrm{Na}_{2}\left[\mathrm{FeNO}(\mathrm{CN})_{5}\right]$ & 214 & 51 & 0,2 & ND & $-0,195$ \\
\hline Trans-[Ru(NO) $\left.\left(\mathrm{NH}_{3}\right)_{4} \mathrm{isn}\right]\left(\mathrm{BF}_{4}\right)_{3}$ & 280 & 743 & 3 & 0,043 & 0,052 \\
\hline trans-[Ru(NO)($\left.\left(\mathrm{NH}_{3}\right)_{4} \mathrm{SO}_{3}\right] \mathrm{Cl}$ & $>300$ & 1000 & 3 & ND & $-0,138$ \\
\hline Trans-[Ru(NO) $\left.\left(\mathrm{NH}_{3}\right)_{4} \mathrm{nic}\right]\left(\mathrm{BF}_{4}\right)_{3}$ & $>900$ & ND & ND & 0,025 & 0,072 \\
\hline [Ru(NO)Hedta)] & $>900$ & ND & ND & 0,002 & $-0,068$ \\
\hline Trans-[Ru(NO) $\left.\left(\mathrm{NH}_{3}\right)_{4} \mathrm{imC}\right]\left(\mathrm{PF}_{6}\right)_{3}$ & $>5000$ & ND & ND & 5,1 & $-0,320$ \\
\hline
\end{tabular}




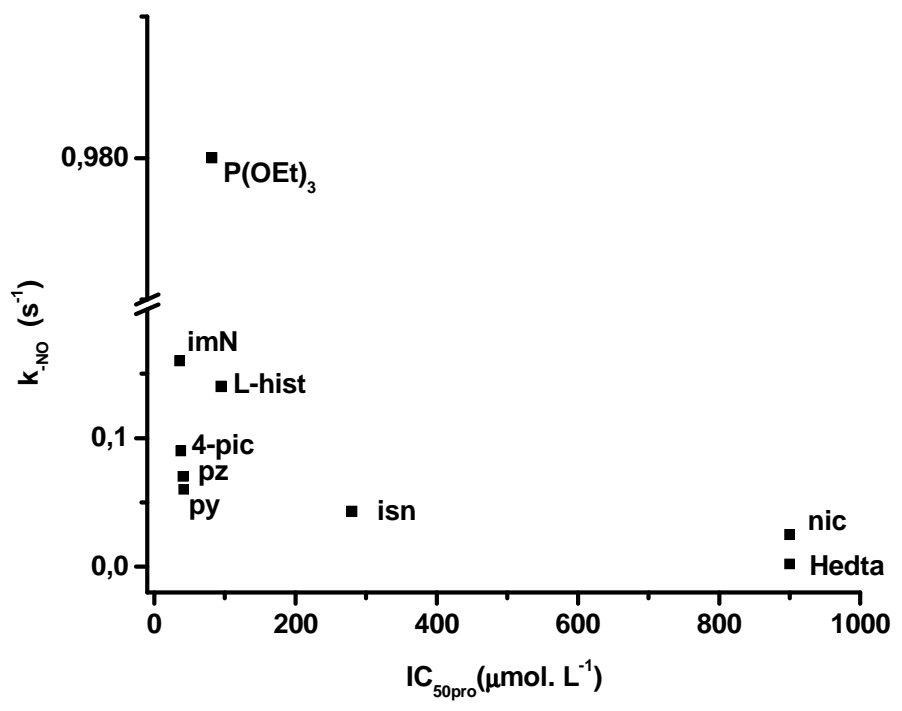

Figura 4 - Valores de $\mathrm{K}_{-\mathrm{NO}}$ em função do $I_{50 \text { pro }}$ dos complexos trans-[Ru(NO) $\left.\left(\mathrm{NH}_{3}\right)_{4} \mathrm{~L}\right] \mathrm{X}_{3},\left(\mathrm{X}=\mathrm{BF}_{4}{ }^{-}\right.$ou $\mathrm{PF}_{6}^{-}$e $\mathrm{L}=\mathrm{imN}$, 4-pic, pz, py, $\mathrm{P}\left(\mathrm{OEt}_{3}\right), \mathrm{L}$ - hist, isn, nic) e [RuNO(Hedta)]

\subsection{Influência do potencial de redução sobre a ação antileishmania dos} nitrosilos de rutênio

Conforme discutido anteriormente, estes compostos são ativados por redução do ligante nitrosônio $\left(\mathrm{NO}^{+}\right)$. Assim, esta etapa que precede a liberação do $\mathrm{NO}$ é crucial e, portanto, condição necessária para a ação antiparasitária dos nitrosilos como foi observado nos experimentos in vitro com 0 complexo trans-[RuNO$\left(\mathrm{NH}_{3}\right)_{4}$ imC] $\left(\mathrm{BF}_{4}\right)_{3}$.

O ligante imidazol pode coordenar ao centro metálico por meio do nitrogênio (trans-[RuNO $\left.\left.\left(\mathrm{NH}_{3}\right)_{4} \mathrm{imN}\right]\left(\mathrm{BF}_{4}\right)_{3}\right)$ ou do carbono (trans-[RuNO$\left.\left.\left(\mathrm{NH}_{3}\right)_{4} \mathrm{imC}\right]\left(\mathrm{BF}_{4}\right)_{3}\right)$ conferindo diferentes parâmetros físico-químicos ao complexo[48] (Figura 5). Quando o ligante imidazol está ligado ao centro metálico pelo átomo de carbono, o potencial de redução do nitrosônio é bem mais negativo comparado ao complexo 
trans-[Ru(NO) $\left.\left(\mathrm{NH}_{3}\right)_{4} \mathrm{ImN}\right]\left(\mathrm{BF}_{4}\right)_{3}$ [48]. Este fato pode ser explicado devido ao forte caráter $\sigma$ doador do ligante imidazol no complexo trans-[RuNO $\left.\left(\mathrm{NH}_{3}\right)_{4} \mathrm{imC}\right]\left(\mathrm{BF}_{4}\right)_{3}[48]$. Isto também explica o alto valor de $\mathrm{k}_{-\mathrm{NO}}\left(5,1 \mathrm{~s}^{-1}\right)$ observado para este complexo comparado aos demais nitrosilos de rutênio. A dissociação do óxido nítrico é fortemente favorecida devido ao elevado caráter trans labilizante do ligante imidazol no complexo trans-[RuNO $\left.\left(\mathrm{NH}_{3}\right)_{4} \mathrm{imC}\right]\left(\mathrm{BF}_{4}\right)_{3}[48]$.
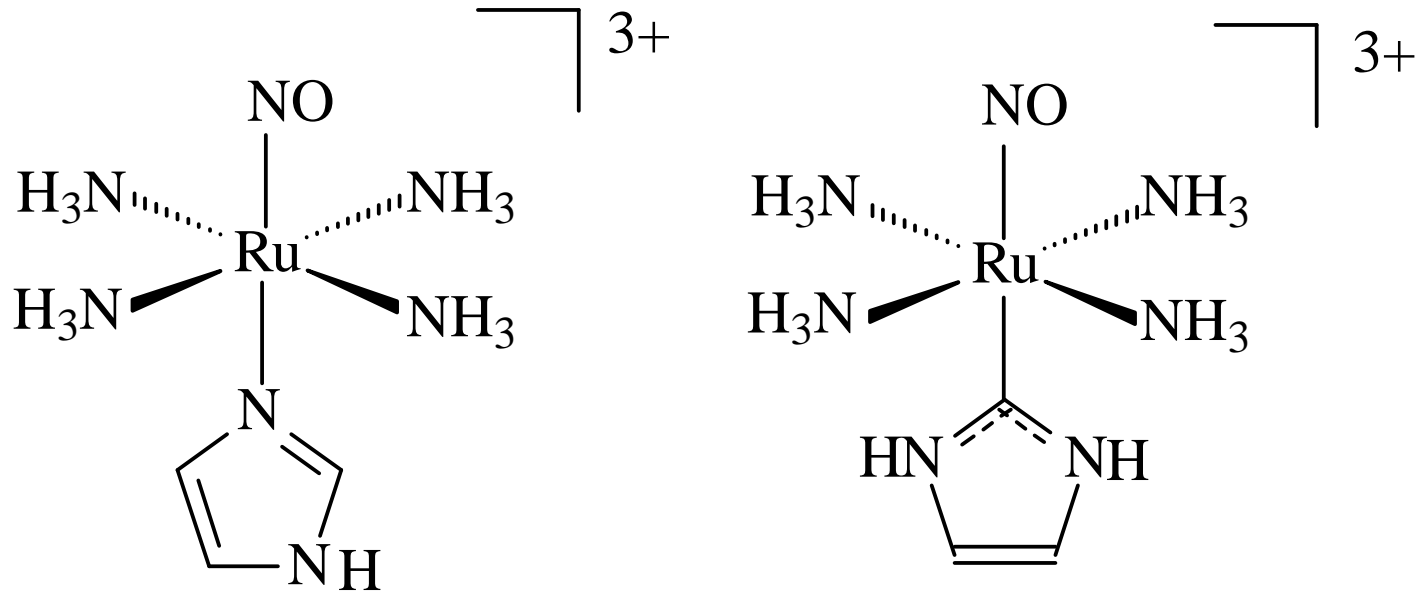

$\mathbf{a}$

b

Figura 5 - Estrutura do (a) complexo trans- $\left[\mathrm{Ru}(\mathrm{NO})\left(\mathrm{NH}_{3}\right)_{4} \mathrm{ImN}\right]^{+3} \mathrm{com} \mathrm{E}_{(\mathrm{NO}+/ \mathrm{NO})}=$ $-0,118 \mathrm{~V}$ vs ENH e k-NO $=0,16 \mathrm{~s}^{-1}$ e (b) do complexo trans-[Ru(NO) $\left.\left(\mathrm{NH}_{3}\right)_{4} \mathrm{ImC}\right]^{+3} \mathrm{com}$ $\mathrm{E}_{(\mathrm{NO}+\mathrm{NOO})}=-0,320 \mathrm{~V}$ vs $\mathrm{ENH}$ e $\mathrm{k}_{-\mathrm{NO}}=5,1 \mathrm{~s}^{-1}$

Observando apenas o valor de k-No seria esperado que o complexo trans-[RuNO$\left.\left(\mathrm{NH}_{3}\right)_{4} \mathrm{imC}\right]\left(\mathrm{BF}_{4}\right)_{3}$ apresentasse a melhor atividade antipromastigota, visto que este comportamento é observado para os outros complexos da série de nitrosilos de rutênio. Entretanto, como descrito acima, este complexo exibe um potencial de redução mais negativo comparado ao seu similar trans-[RuNO(NH$\left.\left.)_{4}\right)_{1 m N}\right]\left(\mathrm{BF}_{4}\right)_{3}$. Visto que a liberação do $\mathrm{NO}$ da esfera de coordenação deve ser precedida por sua redução, o efeito antiparasitário do 
complexo trans-[RuNO $\left.\left(\mathrm{NH}_{3}\right)_{4} \mathrm{imC}\right]\left(\mathrm{BF}_{4}\right)_{3}$ seria menos efetivo devido sua baixa acessibilidade a redutores biológicos.

Experimentos cronoamperométricos realizados com eletrodo seletivo para detecção de óxido nítrico demonstraram que em meio Schneider o complexo trans-[RuNO$\left.\left(\mathrm{NH}_{3}\right)_{4} \mathrm{imC}\right]\left(\mathrm{BF}_{4}\right)_{3}$ não libera $\mathrm{NO}$ contrariamente ao observado para o complexo trans-[RuNO(NH$\left.\left.)_{4}\right)_{4 m N}\right]\left(B_{4}\right)_{3}$ (Figura 6). É importante salientar que o meio Schneider contém uma grande quantidade de redutores biológicos, suficiente para promover a redução do ligante nitrosônio. Assim, podemos sugerir que existe uma relação entre a capacidade do complexo liberar óxido nítrico e o efeito antiparasitário destes nitrosilos.

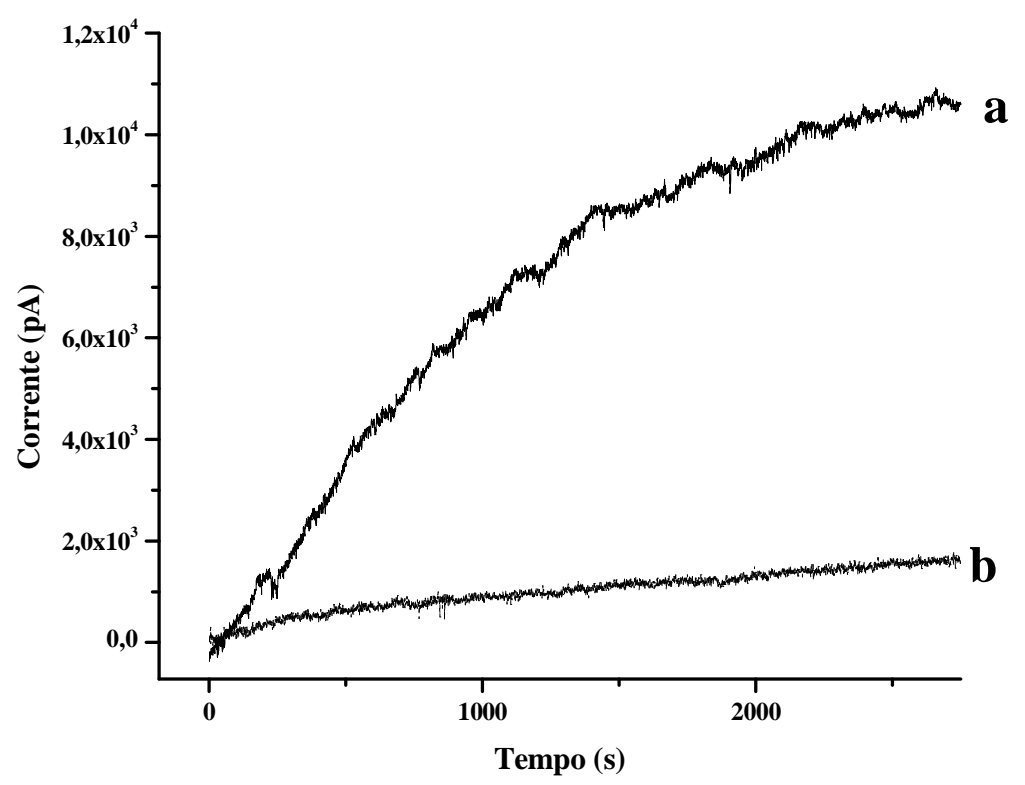

Figura 6 - Detecção eletroquímica do NO na presença do complexo (a) trans-

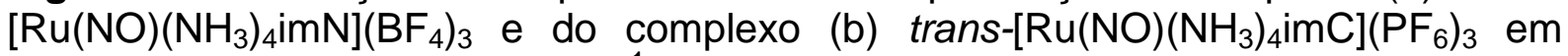
meio Schneider. $\mathrm{C}_{\mathrm{Ru}}=100 \mu \mathrm{mol} \mathrm{L} \mathrm{L}^{-1} \cdot \mathrm{T}=25^{\circ} \mathrm{C} \pm 0,5$. 


\subsection{Cinética de crescimento parasitário na presença de nitrosilos de} rutênio

Os dados presentes na Tabela 1 apontam os compostos trans-[RuNO$\left.\left(\mathrm{NH}_{3}\right)_{4} \mathrm{imN}\right]\left(\mathrm{BF}_{4}\right)_{3}, \quad$ trans-[RuNO$\left.\left(\mathrm{NH}_{3}\right)_{4}(4-\mathrm{pic})\right]\left(\mathrm{BF}_{4}\right)_{3}, \quad$ trans$\left[\mathrm{RuNO}\left(\mathrm{NH}_{3}\right)_{4} \mathrm{pz}\right]\left(\mathrm{BF}_{4}\right)_{3}$ e trans- $\left[\mathrm{RuNO}\left(\mathrm{NH}_{3}\right)_{4} \mathrm{py}\right]\left(\mathrm{BF}_{4}\right)_{3}$ como os mais promissores com valores de $\mathrm{IC}_{50 \text { pro }}$ similares dentro do erro experimental $\left(39 \pm 3 \mu \mathrm{mol} \mathrm{L}^{-1}\right)$. Para melhor avaliar o efeito antiproliferativo destes nitrosilos, os testes in vitro foram prolongados por um período de cinco dias e analisados por meio de contagem de parasitas viáveis utilizando um microscópio ótico e por método colorimétrico (MTT).

A Figura 7 resume os resultados de percentual de inibição de crescimento dos complexos trans-[RuNO $\left.\left(\mathrm{NH}_{3}\right)_{4} \mathrm{imN}\right]\left(\mathrm{BF}_{4}\right)_{3}, \quad$ trans-[RuNO$\left(\mathrm{NH}_{3}\right)_{4}(4-$ pic $\left.)\right]\left(\mathrm{BF}_{4}\right)_{3}$, trans- $\left[\mathrm{RuNO}\left(\mathrm{NH}_{3}\right)_{4} \mathrm{pz}\right]\left(\mathrm{BF}_{4}\right)_{3}$, e trans-[RuNO$\left.\left(\mathrm{NH}_{3}\right)_{4} \mathrm{py}\right]\left(\mathrm{BF}_{4}\right)_{3}$ em três concentrações diferentes, monitorados até o quinto dia da curva de crescimento das formas promastigotas do parasita.

Observa-se que o complexo trans-[RuNO$\left.\left(\mathrm{NH}_{3}\right)_{4} \mathrm{imN}\right]\left(\mathrm{BF}_{4}\right)_{3}$ apresenta o maior efeito antiproliferativo com $100 \%$ de inibição para todas as concentrações em um período de 120 horas após a incubação. Para os outros complexos, este fato não foi observado quando utilizado o método de contagem de células viáveis. Portanto, segundo os dados presentes na Figura 7, a toxicidade sobre o parasito segue a seguinte ordem: trans-[RuNO $\left.\left(\mathrm{NH}_{3}\right)_{4} \mathrm{imN}\right]\left(\mathrm{BF}_{4}\right)_{3}>$ trans-[RuNO$\left(\mathrm{NH}_{3}\right)_{4}(4-$ pic $\left.)\right]\left(\mathrm{BF}_{4}\right)_{3}>$ trans- $\left[\mathrm{RuNO}\left(\mathrm{NH}_{3}\right)_{4} \mathrm{pz}\right]\left(\mathrm{BF}_{4}\right)_{3}>$ e trans-[RuNO$\left.\left(\mathrm{NH}_{3}\right)_{4} \mathrm{py}\right]\left(\mathrm{BF}_{4}\right)_{3}$, a qual coincide com a ordem decrescente dos correspondentes valores de $\mathrm{k}_{\text {-NO }}$ da Tabela 1. É importante ressaltar que a relevância de k-No também foi observada em estudos sobre a atividade vasodilatadora destes complexos[22, 30]. 

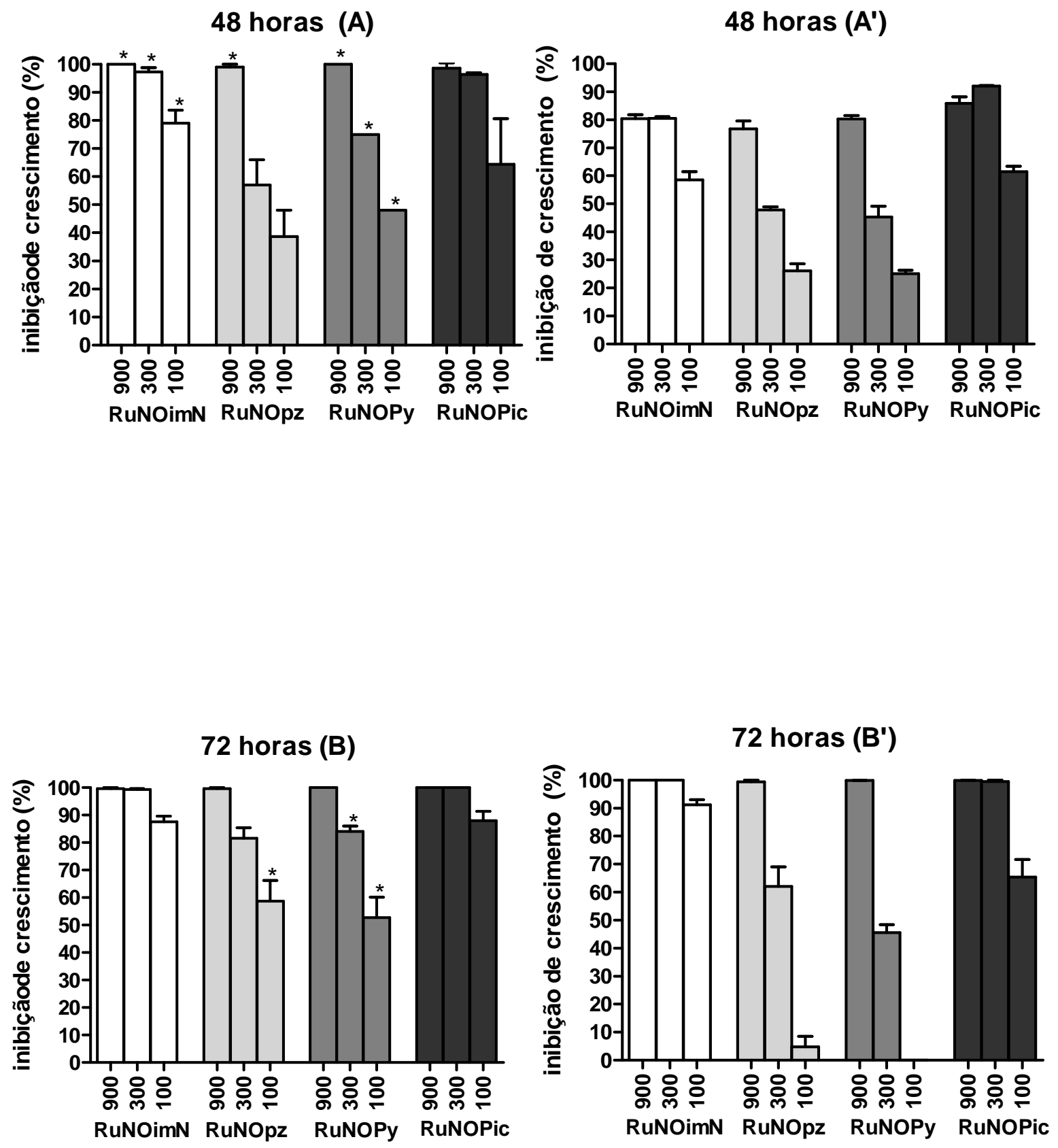

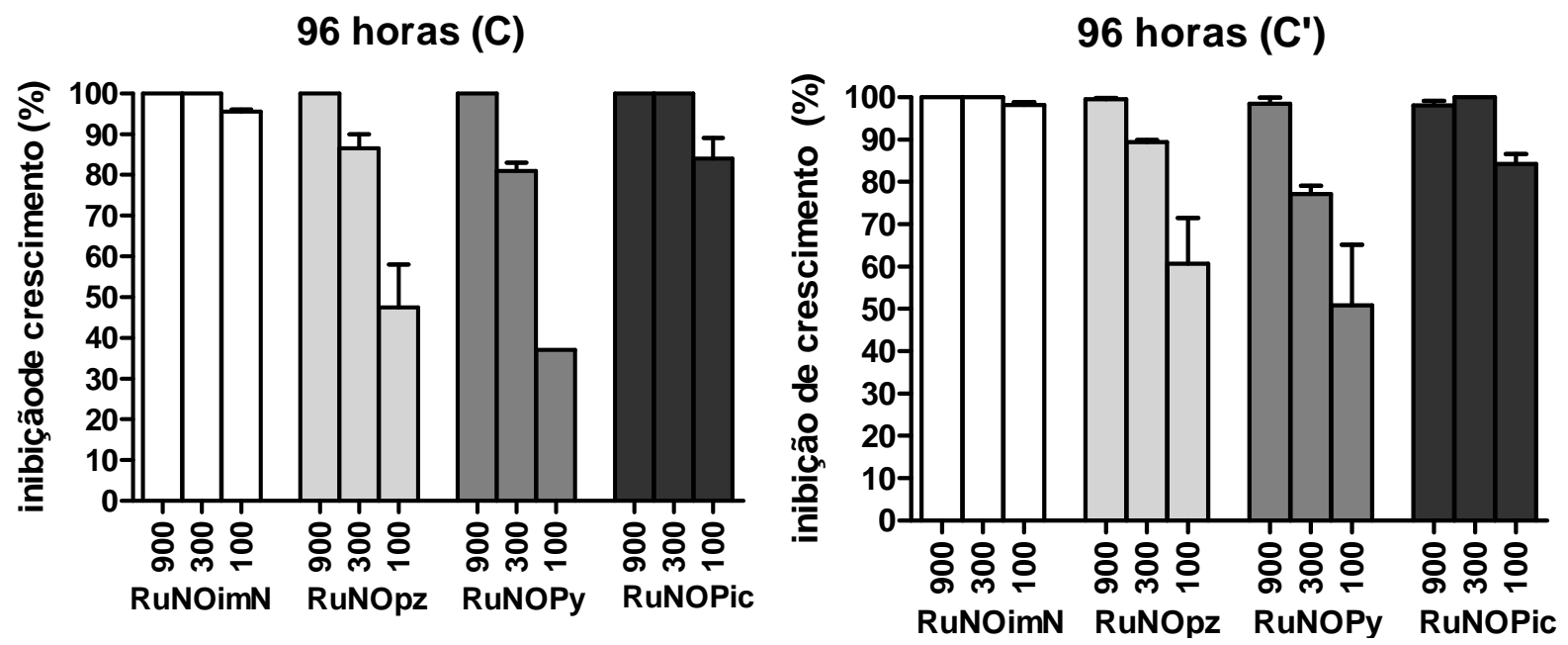

120 horas (D)
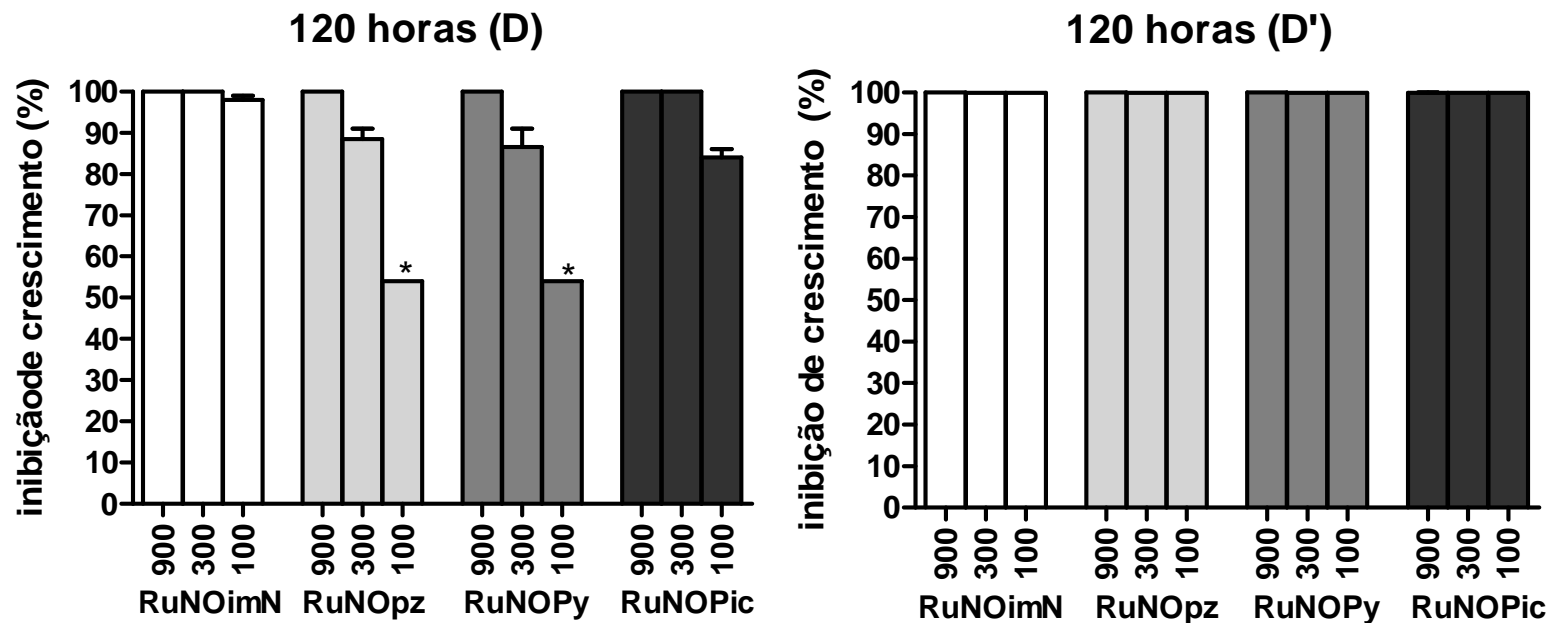

Figura 7 - Efeito dos complexos $\square$ trans-[Ru(NO) $\left.\left(\mathrm{NH}_{3}\right)_{4} \mathrm{imN}\right]\left(\mathrm{BF}_{4}\right)_{3}$, trans-

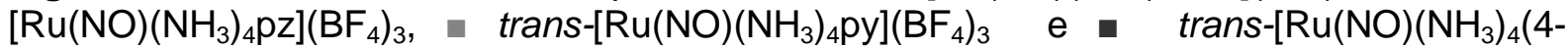
pic)] $\left(\mathrm{BF}_{4}\right)_{3}$ sobre a proliferação de promastigotas da $L$. major. A, B, C, e D: \% inibição de crescimento dos complexos após 48, 72, 96 e $120 \mathrm{~h}$ de incubação, respectivamente (determinado por meio de contagem de células viáveis). A', B', C', and 'D': \% inibição de crescimento dos complexos após 48, 72, 96 e $120 \mathrm{~h}$ de incubação, respectivamente (determinado por ensaio colorimétrico, MTT). O número de parasitas foi comparado ao controle (somente parasitas em meio Schneider). Concentração: 100, 300 e $900 \mu \mathrm{mol} \mathrm{L}^{-1}$. * Valor significativamente diferente do valor determinado por meio do ensaio colorimétrico $(P<0.05)$. 


\section{4-Produção de óxido nítrico}

Concomitante a análise de atividade antiproliferativa dos compostos nitrosilados trans- $\left[\mathrm{RuNO}\left(\mathrm{NH}_{3}\right)_{4} \mathrm{imN}\right]\left(\mathrm{BF}_{4}\right)_{3}, \quad$ trans- $\left[\mathrm{RuNO}\left(\mathrm{NH}_{3}\right)_{4}(4-\right.$ pic $\left.)\right]\left(\mathrm{BF}_{4}\right)_{3}$, trans- $\left[\mathrm{RuNO}\left(\mathrm{NH}_{3}\right)_{4} \mathrm{pz}\right]\left(\mathrm{BF}_{4}\right)_{3} \quad$ e trans-[RuNO$\left.\left(\mathrm{NH}_{3}\right)_{4} \mathrm{py}\right]\left(\mathrm{BF}_{4}\right)_{3}$, foram realizados experimentos para determinação de geração de óxido nítrico no meio de cultura (Figura 8). A produção de óxido nítrico foi determinada por meio de dosagem de nitrito no meio de cultura de parasitas incubados em diferentes tempos (24 - 120 horas) e concentrações $\left(100,300\right.$ e $\left.900 \mu \mathrm{mol} \mathrm{L}^{-1}\right)$ dos complexos.

No primeiro dia após a incubação, verificou-se que a concentração de nitrito produzida é proporcional a concentração dos nitrosilos complexos

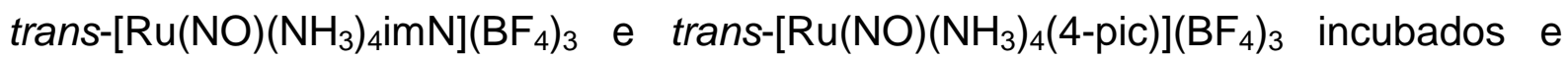
significativamente maior que o controle (meio de cultura contendo apenas parasitas) (Figura 8 a,b e c). Os nitrosilo complexos que apresentaram maior produção de nitrito no meio de cultura também apresentam maior atividade antiproliferativa seguindo a ordem:

$$
\begin{aligned}
& \text { trans- }\left[\mathrm{Ru}(\mathrm{NO})\left(\mathrm{NH}_{3}\right)_{4} \mathrm{imN}\right]\left(\mathrm{BF}_{4}\right)_{3} \quad>\quad \text { trans- }\left[\mathrm{Ru}(\mathrm{NO})\left(\mathrm{NH}_{3}\right)_{4}(4-\mathrm{pic})\right]\left(\mathrm{BF}_{4}\right)_{3} \quad> \\
& \text { trans-[Ru(NO) } \left.\left(\mathrm{NH}_{3}\right)_{4}(\mathrm{pz})\right]\left(\mathrm{BF}_{4}\right)_{3}>\text { trans- }\left[\mathrm{Ru}(\mathrm{NO})\left(\mathrm{NH}_{3}\right)_{4}(\mathrm{py})\right]\left(\mathrm{BF}_{4}\right)_{3} \text {. }
\end{aligned}
$$



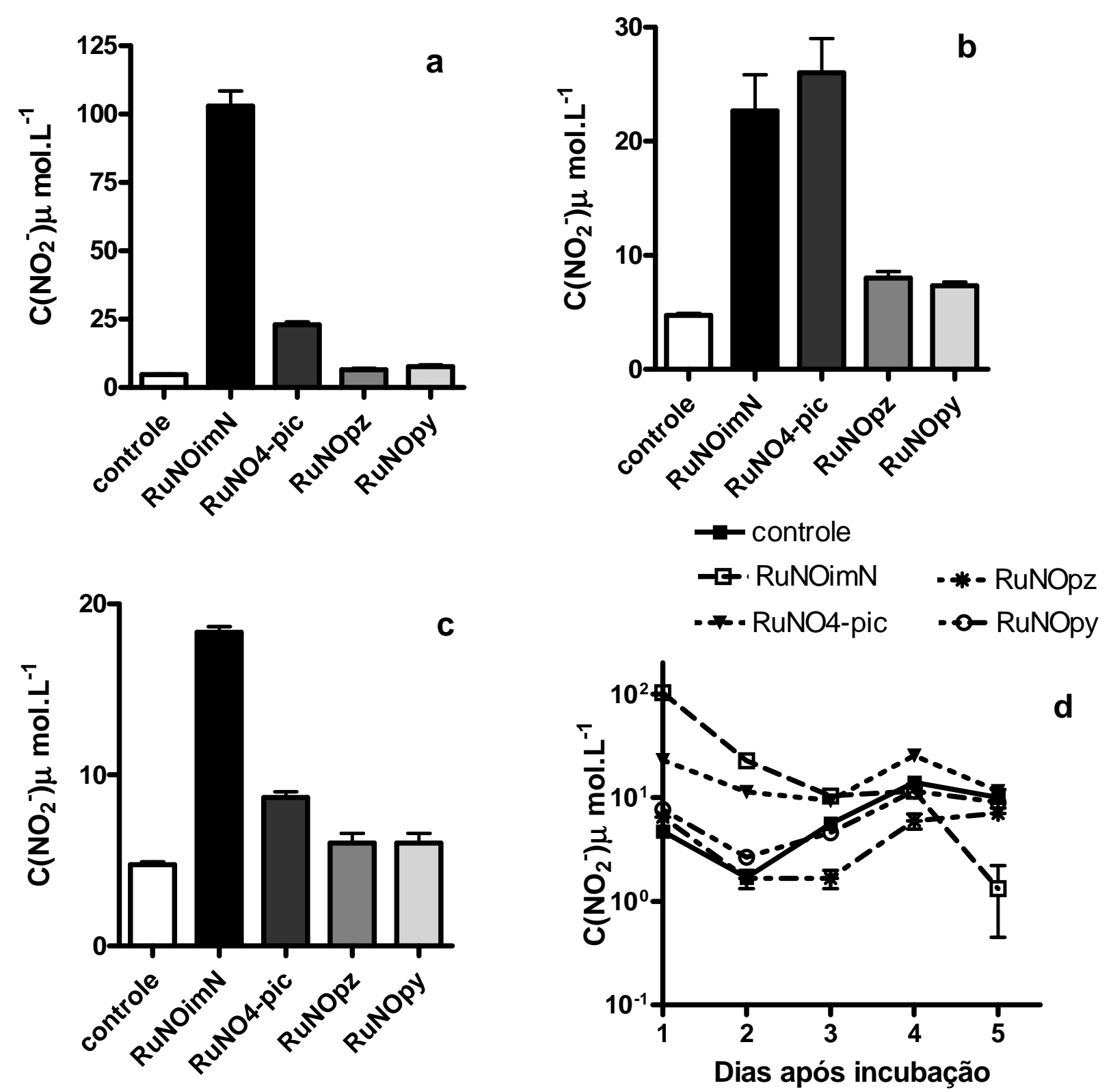

Figura 8 - Detecção de nitrito após 24 horas de incubação de parasitas L.major com os complexos trans-[RuNO $\left.\left(\mathrm{NH}_{3}\right)_{4} \mathrm{imN}\right]\left(\mathrm{BF}_{4}\right)_{3}$, trans-[RuNO$\left.\left(\mathrm{NH}_{3}\right)_{4}(4-\mathrm{pic})\right]\left(\mathrm{BF}_{4}\right)_{3}$, trans-[RuNO$\left.\left(\mathrm{NH}_{3}\right)_{4} \mathrm{pz}\right]\left(\mathrm{BF}_{4}\right)_{3}$ e trans-[RuNO$\left.\left(\mathrm{NH}_{3}\right)_{4} \mathrm{py}\right]\left(\mathrm{BF}_{4}\right)_{3}$, nas concentrações de (a) 900 , (b) $300 \mathrm{e}$ (c) $100 \mu \mathrm{mol} \mathrm{L}{ }^{-1}$, ( controle, sem adição de composto). (d) Produção de nitrito em um período de 5 dias após incubação de parasitas L.major com os complexos trans-[RuNO $\left.\left(\mathrm{NH}_{3}\right)_{4} \mathrm{imN}\right]\left(\mathrm{BF}_{4}\right)_{3}$, trans- $\left[\mathrm{RuNO}\left(\mathrm{NH}_{3}\right)_{4}(4-\mathrm{pic})\right]\left(\mathrm{BF}_{4}\right)_{3}$, trans-[RuNO $\left.\left(\mathrm{NH}_{3}\right)_{4} \mathrm{pz}\right]\left(\mathrm{BF}_{4}\right)_{3}$ e trans-[RuNO$\left.\left(\mathrm{NH}_{3}\right)_{4} \mathrm{py}\right]\left(\mathrm{BF}_{4}\right)_{3}$ na concentração de 900 $\mu \mathrm{mol} \mathrm{L}-1$ 
Foi observado também que a concentração de nitrito no meio de cultura decresce com o tempo chegando a níveis menores que o controle, principalmente nos poços contento o complexo trans-[RuNO$\left.\left(\mathrm{NH}_{3}\right)_{4} \mathrm{imN}\right]\left(\mathrm{BF}_{4}\right)_{3}$ (Figura 8d). Observase que a concentração de $\mathrm{NO}_{2}^{-}$para os poços contendo apenas parasitas aumenta no decorrer dos dias. Foi reportado na literatura[49, 50] que formas promastigotas de Leishmania produzem óxido nítrico relacionado a expressão da isoforma constitutiva da NO sintase (cNOS) do parasita. Além disto, o NO produzido pela Leishmania pode modular a atividade da iNOS dos macrófagos[50].

Portanto, parte da concentração de nitrito é gerado pelos parasitas visto que os poços do controle contém nitrito sendo que sua concentração cresce até o quarto dia da curva de crescimento parasitário. Por outro lado, os dados sugerem que a produção de NO é formada principalmente devido a dissociação de óxido nítrico do centro metálico destes compostos. O complexo do tipo trans-[Ru(NH $\left.\left.\mathrm{NH}_{3}\right)_{4} \mathrm{~L}\left(\mathrm{H}_{2} \mathrm{O}\right)\right]^{+2}$ é um produto da liberação do óxido nítrico (Esquema 1). O nitrito contido no meio de cultura pode coordenar ao centro metálico deste complexo formando o nitrosilo trans- $\left[\mathrm{Ru}^{\prime \prime}\left(\mathrm{NO}^{+}\right)\left(\mathrm{NH}_{3}\right)_{4} \mathrm{~L}\right]^{+3}$ gerando, assim, um ciclo catalítico $[51,52]$ como mostrado no Esquema 1. Este ciclo catalítico pode explicar a diminuição da concentração de nitrito durante os dias após incubação. Além disto, a diminuição de parasitas vivos no meio de cultura também pode explicar em parte o decréscimo na concentração de $\mathrm{NO}_{2}^{-}$. 


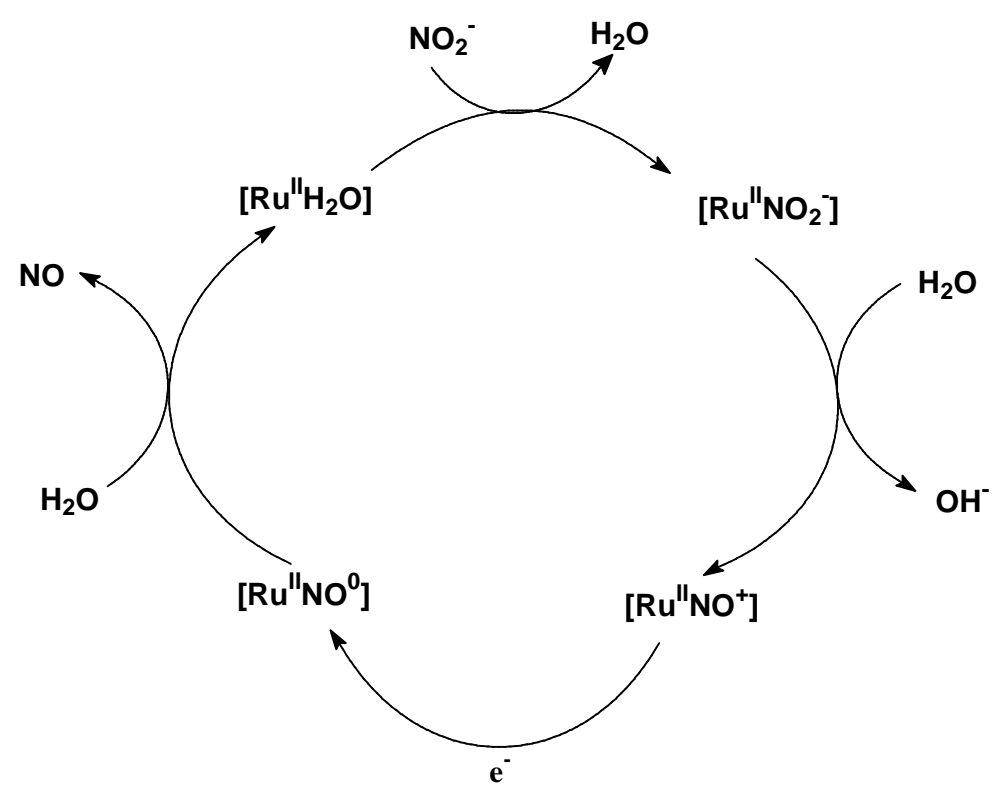

Esquema 1 - Ciclo catalítico da conversão de $\mathrm{NO}_{2}^{-}$para $\mathrm{NO}^{+}$nos complexos trans-[Ru" $\left.\left(\mathrm{NO}^{+}\right)\left(\mathrm{NH}_{3}\right)_{4} \mathrm{~L}\right]^{+3}$

\subsection{Atividade antiparasitária do HNO/NO}

Outro fator importante relacionado a redução do ligante nitrosônio é a possibilidade de produção de nitroxil (HNO) conforme mencionado anteriormente na introdução. Neste trabalho, veremos mais adiante que o ligante $\mathrm{NO}^{+}$pode ser reduzido por um ou dois elétrons dependendo do redutor presente e de sua concentração no meio. A reação entre o complexo trans-[RuNO$\left.\left(\mathrm{NH}_{3}\right)_{4} \mathrm{P}(\mathrm{OEt})_{3}\right]\left(\mathrm{PF}_{6}\right)_{3}$ com a L-cisteína gera $\mathrm{NO}$ e $\mathrm{HNO}$ sendo que a razão $\mathrm{C}_{\mathrm{NO}} / \mathrm{C}_{\mathrm{HNO}}$ é dependente do $\mathrm{pH}$ e da concentração do redutor. Assim, visto que redutores RSH estão presente em meio biológico, sob a forma de glutationa ou L-cisteína $\left(C>1 \mathrm{mmol}^{-1}\right)[44]$, o efeito antileishmania do nitroxil também foi avaliado (Tabela 1). Para tanto, o sal de Angeli $\left(\mathrm{Na}_{2} \mathrm{~N}_{2} \mathrm{O}_{3}\right)$ foi usado como fonte de nitroxil visto que o mesmo se decompõe espontaneamente em água ( $\mathrm{t}_{1 / 2}=2,3 \mathrm{~min}, \mathrm{pH}=7,0$, Equação 14) gerando $\mathrm{HNO} \mathrm{e}$ 
$\mathrm{NO}_{2}^{-}$[44]. O efeito antileishmania do $\mathrm{N}_{2} \mathrm{O}\left(\mathrm{k}=8 \times 10^{6} \mathrm{~mol}^{-1} \mathrm{~L} \mathrm{~s}^{-1}\right.$, Equação 15[44]), produto da decomposição do HNO, também foi investigado.

$$
\begin{gathered}
\mathrm{N}_{2} \mathrm{O}_{3}{ }^{2-}+\mathrm{H}^{+} \longrightarrow \mathrm{HNO}+\mathrm{NO}_{2}{ }^{-} \\
\mathrm{HNO}+\mathrm{HNO} \longrightarrow \mathrm{HON}=\mathrm{NOH} \longrightarrow \mathrm{N}_{2} \mathrm{O}+\mathrm{H}_{2} \mathrm{O}
\end{gathered}
$$

De acordo com os dados experimentais, o sal de Angeli (SA) promoveu inibição sobre o crescimento das formas promastigotas do L.major, mas nenhum efeito foi observado quando testado o Sal de Angeli degradado, ou seja, uma solução contendo $\mathrm{N}_{2} \mathrm{O}$ (Figura 9). Estes resultados sugerem que 0 efeito antipromastigota do sal de Angeli está relacionado ao HNO visto que o outro produto da decomposição deste sal (nitrito, $\mathrm{NO}_{2}^{-}$) (Equação 14) não apresenta efeito antiparasitário em pH 7,4 como descrito na literatura [23]. Além disto, o produto da dimerização do HNO $\left(\mathrm{N}_{2} \mathrm{O}\right)$ também não apresentou efeito antileishmania como demonstrado o baixo efeito do Sal de Angeli degradado. Os valores de $\mathrm{IC}_{50 \text { pro }}$ do sal de Angeli $\left(\mathrm{IC}_{50}=158 \mu \mathrm{mol} \mathrm{L} \mathrm{L}^{-1}\right)$ foram comparados a toxicidade do gás $\mathrm{NO}\left(\mathrm{IC}_{50}=12\right.$ $\mu \mathrm{mol} \mathrm{L}^{-1}$ ) indicando, portanto, maior toxicidade do óxido nítrico sobre o parasita (Tabela 1). 


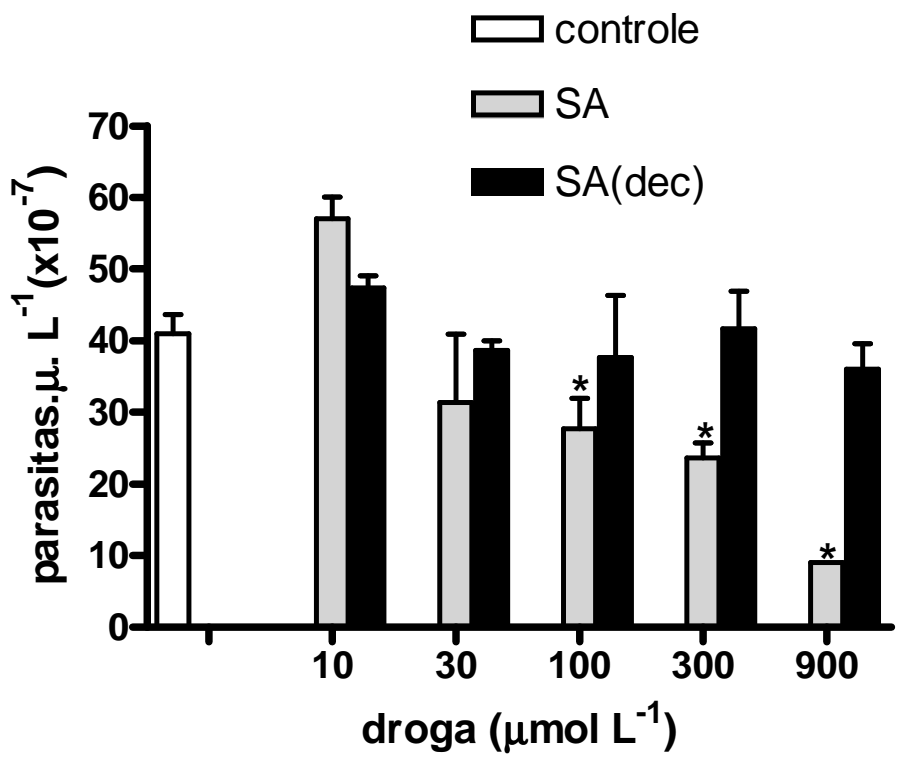

Figure 9 - Efeito do HNO sobre a viabilidade das formas promastigotas tratados com sal de Angeli. Viabilidade celular dos promastigotas $L$. major foi avaliada após $24 \mathrm{~h}$ de incubação em meio Schneider ( $\square$ controle) $\backsim$ Sal de Angeli - Sal de Angeli decomposto. * Valor significativamente menor que o controle $(\mathrm{P}<0,05)$.

\subsection{Ação antiamastigota e citoxicidade}

Neste ponto, investigamos a atividade dos nitrosilos sobre a forma amastigota do parasita. Assim, avaliamos a atividade do complexo mais promissor trans-[RuNO(NH$\left.\left.)_{4}\right)_{4} \mathrm{mN}\right]\left(\mathrm{BF}_{4}\right)_{3}$, do $\mathrm{HNO}$ (usando o sal de Angeli como fonte de nitroxil) e do complexo trans- $\left[\mathrm{Ru}\left(\mathrm{NH}_{3}\right) 4 \mathrm{imN}\left(\mathrm{H}_{2} \mathrm{O}\right)\right]^{2+}$ sobre a forma amastigota intracelular do L.major e a respectiva toxicidade destes compostos sobre macrófagos.

Os testes de toxicidade destes compostos em macrófagos foram realizados por meio do método de incorporação do iodeto de propídio [34]. A Figura 10a apresenta a porcentagem de células mortas para diferentes concentrações dos compostos trans- $\left[\mathrm{RuNO}\left(\mathrm{NH}_{3}\right)_{4} \mathrm{imN}\right]^{+3}$, trans- $\left[\mathrm{Ru}\left(\mathrm{NH}_{3}\right)_{4} \mathrm{imN}\left(\mathrm{H}_{2} \mathrm{O}\right)\right]^{+2}$ e sal de Angeli (SA). A figura 10b apresenta o gráfico representativo de morte de macrófagos na presença dos complexos de rutênio e do sal de Angeli e na presença de triton $5 \%$ 
como controle positivo ( $99 \%$ de morte). Os dados de citotoxicidade destes 3 compostos indicam que apresentam efeito similar sobre macrófagos de camundongos BALB/c com valores de $\mathrm{IC}_{50 \mathrm{M}}=240 \pm 19 \mu \mathrm{mol} \mathrm{L}^{-1}$ (Tabela 2).
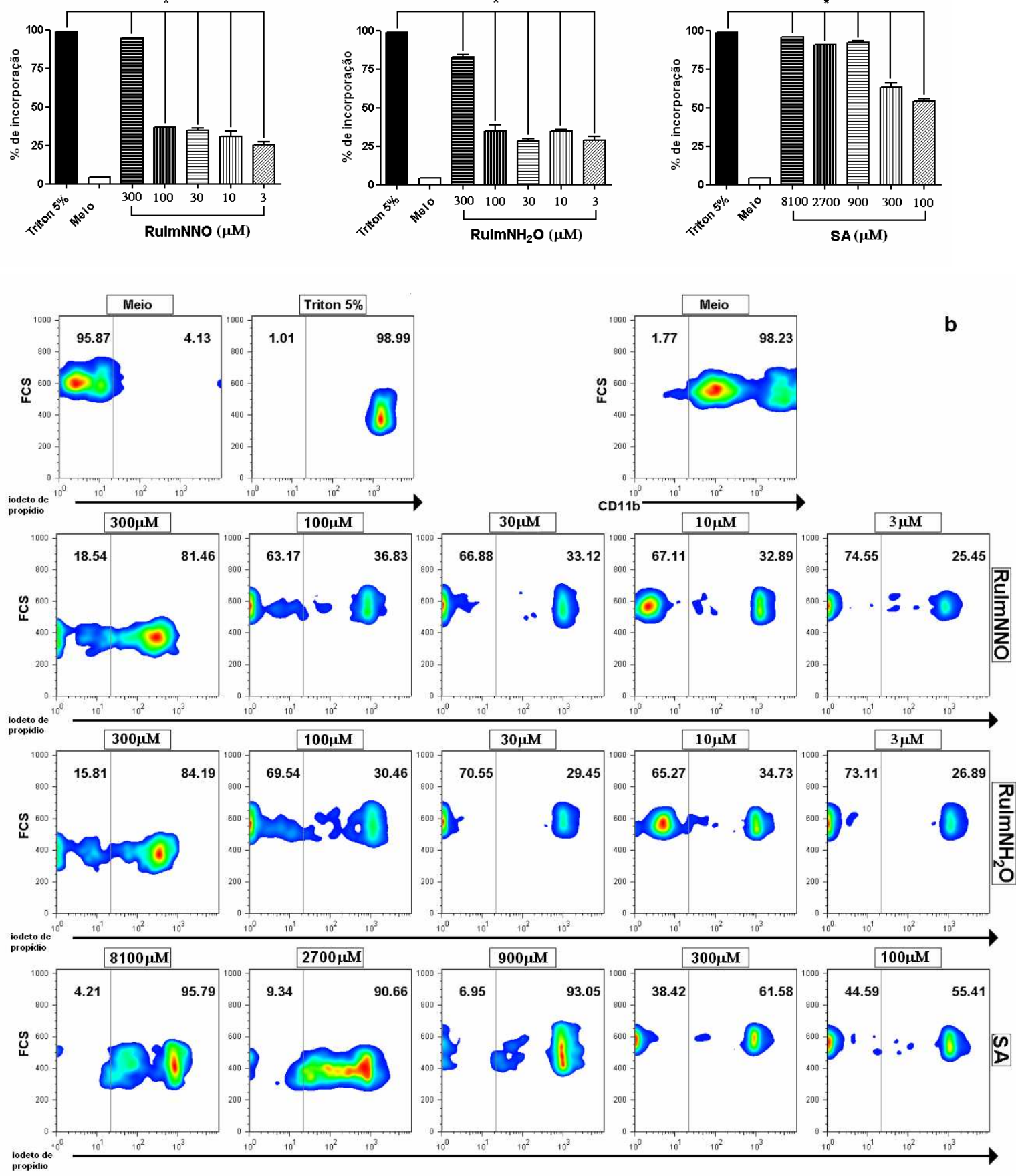

Figura 10 - Ensaio de citotoxicidade in vitro dos compostos trans-[RuNO $\left.\left(\mathrm{NH}_{3}\right)_{4} \mathrm{imN}\right]^{+3}$, trans- $\left[\mathrm{Ru}\left(\mathrm{NH}_{3}\right)_{4} \mathrm{imN}\left(\mathrm{H}_{2} \mathrm{O}\right)\right]^{+2}$ e sal de Angeli (SA). a) porcetagem de macrófagos mortos na presença de diferentes concentrações do complexo trans- $\left[\mathrm{RuNO}\left(\mathrm{NH}_{3}\right)_{4} \mathrm{imN}\right]^{+3}$, trans- $\left[\mathrm{Ru}\left(\mathrm{NH}_{3}\right)_{4} \mathrm{imN}\left(\mathrm{H}_{2} \mathrm{O}\right)\right]^{+2}$ e sal de Angeli (SA). b) gráfico representativo da morte de macrófagos. * Valor significativamente menor que o controle $(P<0,05)$. 
A Tabela 2 também apresenta os dados de inibição de crescimento de formas amastigotas para os três compostos estudados. De acordo com a avaliação in vitro, o complexo trans-[Ru( $\left.\left(\mathrm{NH}_{3}\right)_{4} \mathrm{imN}\left(\mathrm{H}_{2} \mathrm{O}\right)\right]^{+2}$ não apresenta nenhum efeito antileishmania

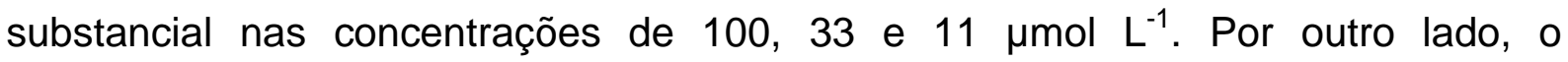
correspondente complexo nitrosilado e o sal de Angeli exibiram inibição de crescimento parasitário na mesma intensidade, dentro do erro experimental (Tabela 2). Assim, os resultados apresentados na Tabela 2 sugerem que o efeito antiamastigota do complexo trans-[RuNO$\left.\left(\mathrm{NH}_{3}\right)_{4} \mathrm{imN}\right]\left(\mathrm{BF}_{4}\right)_{3}$ estaria relacionado a ação do NO ou do HNO liberado da esfera de coordenação visto que o complexo trans- $\left.\left[\mathrm{Ru}\left(\mathrm{NH}_{3}\right)_{4} i m \mathrm{~N}_{(} \mathrm{H}_{2} \mathrm{O}\right)\right]^{+2}$ não apresentou efeito significativo contra as formas amastigotas do parasito.

Tabela 2 - Atividade in vitro de compostos contra amastigotas e citotoxicidade em macrófagos

\begin{tabular}{|c|c|c|c|c|}
\hline \multirow[t]{2}{*}{ Compostos } & \multicolumn{3}{|c|}{ \% Inibição } & \multirow{2}{*}{$\begin{array}{l}\text { Citotoxidade } \\
\left(\mathbf{I C}_{50}\right) \mu \mathrm{mol} \mathrm{L}^{-1} \\
\text { macrófagos } \\
\end{array}$} \\
\hline & $100 \mu \mathrm{mol} \mathrm{L}^{-1}$ & $33 \mu \mathrm{mol} \mathrm{L}^{-1}$ & $11 \mu \mathrm{mol} \mathrm{L}^{-1}$ & \\
\hline trans-[RuNO$\left.\left(\mathrm{NH}_{3}\right)_{4} \mathrm{imN}\right]^{+3}$ & $47 \pm 2$ & $39 \pm 3$ & $36 \pm 3$ & 225 \\
\hline trans- $\left[\mathrm{Ru}\left(\mathrm{NH}_{3}\right)_{4} \mathrm{imN}\left(\mathrm{H}_{2} \mathrm{O}\right)\right]^{+2}$ & $8 \pm 9$ & $10 \pm 5$ & $2 \pm 1$ & 233 \\
\hline $\mathrm{Na}_{2} \mathrm{~N}_{2} \mathrm{O}_{3}$ & $49 \pm 6$ & $49 \pm 2$ & $44 \pm 3$ & 262 \\
\hline
\end{tabular}

${ }^{a}$ Porcentagem de inibição em amastigotas após $24 \mathrm{~h}$ de incubação nas concentrações de 100 , 33 e $11 \mu \cdot \mathrm{mol} \mathrm{L}^{-1}$. $(\mathrm{P}<0,05)$.

Adicionalmente, estes resultados sugerem que 0 complexo trans-[Ru(NO) $\left(\mathrm{NH}_{3}\right)_{4}$ imN] $\left(\mathrm{BF}_{4}\right)_{3}$ apresenta capacidade de lisar o parasito no interior do macrófago, porém, ainda não está claro o mecanismo de ação deste composto. É bem aceito que em água, o óxido nítrico apresenta constante de difusão com valor de $3300 \mu \mathrm{m}^{2} \mathrm{~s}^{-1}$ com um tempo de meia vida de 5-10 s[18]. Isto implica que o NO é potencialmente capaz de atravessar a membrana celular (diâmetro $=5 \mu \mathrm{m}$ ) durante seu tempo de vida[18]. Desta forma, o complexo metálico pode exibir efeito contra 
as formas intracelulares independente de sua capacidade de penetração nos macrófagos [18].

Neste ponto, é interessante comparar a atividade antiproliferativa do HNO e do NO. O nitroxil deve existir em meio biológico na forma protonada (HNO) tendo em vista seu valor de pKa > 11[44]. Como a auto-oxidação do HNO é considerada relativamente lenta e sua dimerização dependente de sua concentração local[53], podemos assumir que os raios de ação do NO e do HNO são relativamente próximos. Logo, a diferença do efeito antiparasitário destas duas moléculas pode estar relacionada principalmente as suas propriedades redox e ao seu alvo de ação no parasito. Na Tabela 1, nota-se que a espécie NO é mais eficiente como agente antipromastigota comparado ao nitroxil. Porém, em um sistema mais complexo como o meio intracelular é difícil determinar a exata contribuição destas duas espécies de óxido nítrico. Como vimos anteriormente, a concentração de NO e HNO liberada do centro metálico vai depender de vários fatores tais como redutores envolvidos na reação, $\mathrm{pH}$ do meio e interação do complexo e as diversas biomoléculas do macrófago e do parasito.

\subsection{Nitrosilação e nitrosação}

Como mencionado anteriormente no item 4.5, as tetraaminas de rutênio podem reagir com redutores biológicos tendo como produto NO e HNO. Em sistemas biológicos as espécies $\mathrm{NO}, \mathrm{HNO}\left(\mathrm{NO}^{-}\right)$e $\mathrm{NO}^{+}$podem reagir com oxigênio molecular $\left(\mathrm{O}_{2}\right)$, superóxido $\left(\mathrm{O}_{2}^{\circ}\right)$ e complexos metálicos [54]. Estas reações podem gerar espécies tóxicas como o peroxinitrito (Equação 1) responsáveis por efeitos 
antiparasitários ou capazes de inibir proteínas de parasitas contendo centros metálicos[54].

Doadores de óxido nítrico tais como S-nitrosoglutationa (GSNO), nitrito $\left(\mathrm{NO}_{2}{ }^{-}\right)$, S-nitroso-N-acetil-D,L-penicilamina (SNAP), nitroprussiato de sódio (NP) foram utilizados contra parasitas como Trypanosoma cruzi e Plasmodium falciparum e em alguns casos pacientes com leishmaniose foram tratados com estes compostos com resultados animadores[22].

O alvo de ação destes doadores de NO vai depender do mecanismo de transferência do óxido nítrico. Em nitrosotiois como o GSNO, o óxido nítrico é transferido diretamente ao grupo tiol de proteínas de parasitas onde o NO se liga ao enxofre como íon nitrosônio em uma reação de transnitrosação (Equação 2) [22]. Este tipo de inibição enzimática é revertida pela adição de redutores biológicos como o ditiotreitol e o L-ácido ascórbico (AA) (Equação 16)[22, 54, 55].

$$
2 \mathrm{pCysSNO}+\mathrm{AA} \longrightarrow 2 \mathrm{pCysSH}+\mathrm{DAA}+2 \mathrm{NO}
$$

Em compostos como o S-nitroso-N-acetilcisteína (SNAC), a rápida clivagem homolítica do grupo RS-NO produz altas concentrações de $\mathrm{NO}^{0}$ livre (nitrosilação) o qual inibe enzimas por meio de coordenação a centros de íons metálicos[54]. Assim, o tratamento de promastigotas e amastigotas de Leishmania com doadores de NO ou com gás NO leva a inibição da respiração mitocrondrial diminuindo a atividade da aconitase devido a perda de ferro[22].

Os complexos nitrosilados estudados neste trabalho liberam NO que pode agir como reagente nitrosilante. Contrariamente ao observado para o GSNO, a ação antileishmania dos complexos nitrosilados não é inibida pela adição de redutores tais 
como o ácido ascórbico. Observou-se que a ação antiparasitária do complexo trans-[RuNO $\left.\left(\mathrm{NH}_{3}\right)_{4} \mathrm{P}(\mathrm{OEt})_{3}\right]\left(\mathrm{PF}_{6}\right)_{3}$, por exemplo, é mais intensa na presença de ácido ascórbico (Tabela 3). A adição deste redutor no meio de cultura contendo o complexo trans-[RuNO(NH$\left.)_{4} \mathrm{P}(\mathrm{OEt})_{3}\right]\left(\mathrm{PF}_{6}\right)_{3}$ conduziu a uma maior concentração de NO dissociado do centro metálico como observado em experimentos cronoamperométricos (Figura 11). O aumento da concentração de NO livre no meio aumenta o efeito antileishmania do complexo sugerindo que um mecanismo de transferência de NO por nitrosilação estaria operante.

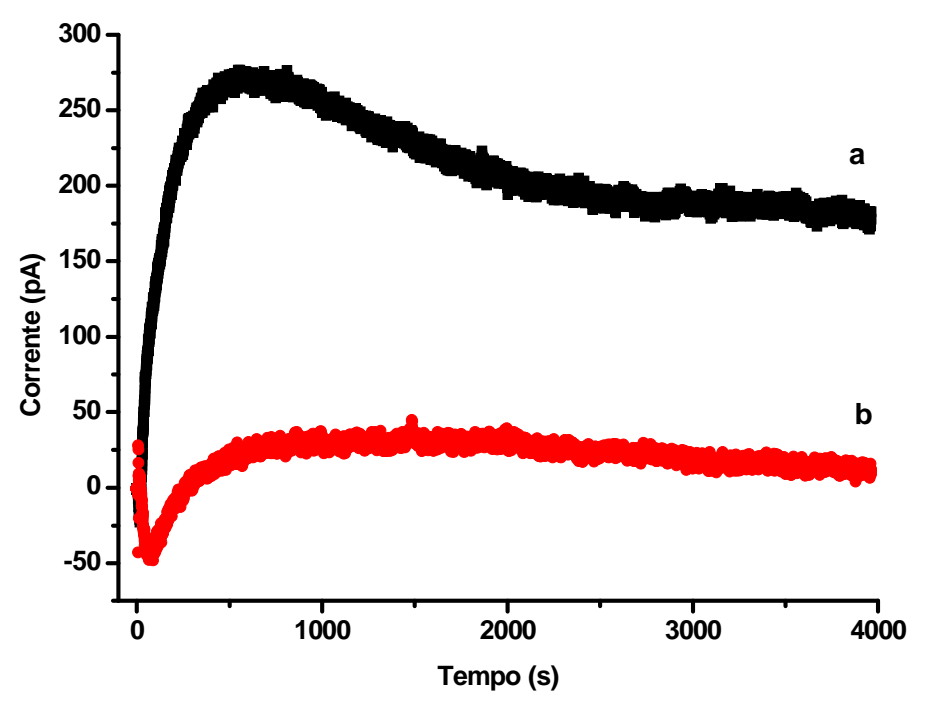

Figura 11 - Detecção cronoamperométrica de $\mathrm{NO}^{0}$ em meio Schneider na presença de trans-[Ru(NO) $\left.\left(\mathrm{NH}_{3}\right)_{4} \mathrm{P}(\mathrm{OEt})_{3}\right]\left(\mathrm{PF}_{6}\right)_{3}$ com ácido ascórbico (a) e sem ácido ascórbico (b). Concentrações: $\mathrm{C}_{\mathrm{AA}}=100 \mu \mathrm{mol} \mathrm{L}^{-1}$ e $\mathrm{C}_{\mathrm{Ru}}=100 \mu \mathrm{mol} \mathrm{L} \mathrm{L}^{-1}$. 
Tabela 3 - atividade antipromastigota (\%IC) do nitrosilo complexo trans-[RuNO $\left.\left(\mathrm{NH}_{3}\right)_{4} \mathrm{P}(\mathrm{OEt})_{3}\right]\left(\mathrm{PF}_{6}\right)_{3}$ na presença e ausência de ácido ascórbico.

\begin{tabular}{ccc}
\hline Compostos & \%IC $^{\mathbf{a}}$ & $\mathbf{E}_{\left(\mathrm{NO}^{+} / \mathrm{NO}\right.}{ }^{0}$ ) $\mathbf{s E N H}$ \\
\hline trans-[RuNO$\left.\left(\mathrm{NH}_{3}\right)_{4} \mathrm{P}(\mathrm{OEt})_{3}\right]\left(\mathrm{PF}_{6}\right)_{3}$ & $62 \pm 9{ }^{*}$ & 0,132 \\
trans-[RuNO$\left.\left(\mathrm{NH}_{3}\right)_{4} \mathrm{P}(\mathrm{OEt})_{3}\right]\left(\mathrm{PF}_{6}\right)_{3}+\mathrm{AA}$ & $90 \pm 5$ & \\
\hline $\mathrm{a}_{\%} \mathrm{IC}=$ porcentagem de inibição de crescimento. ENH & $=$ Eletrodo Normal Hidrogênio. \\
$\mathrm{C}_{\mathrm{Ru}}=\mathrm{C}_{\mathrm{AA}}=100 \mu \mathrm{mol} \mathrm{L}^{-1}\left({ }^{*} \mathrm{P}<0,05\right)$. &
\end{tabular}

Outro dado importante é a ação antiproliferativa dos nitrosilos complexos determinada por contagem de parasita por meio de microscópio óptico e o uso da técnica colorimétrica (teste com MTT). Até o período de 48 horas após a incubação, foi observado que a porcentagem de parasitas viáveis em todos os poços contento as drogas é significativamente menor que a de mitocôndrias intactas. No quarto dia após a incubação, a inibição de crescimento determinada por contagem de parasita por meio de microscópio óptico e do uso da técnica colorimétrica não apresenta diferenças significativas (Figura 7). Estes dados sugerem que inibição da respiração mitocondrial pode ser um dos fatores de degradação parasitária pelos complexos nitrosilados.

Outro ponto de interesse está relacionado à ação do HNO contra o parasita o qual não foi reportado anteriormente na literatura. No entanto, já foi documentada a ação desta molécula contra células cancerosas e sua ação atribuída à formação do radical $\mathrm{OH}^{\bullet}$ quando o nitroxil está presente em meio ácido[56]. Também foi relatado que o HNO inibe a respiração mitocondrial via modificação de resíduos de cisteína em proteínas [57] e que o HNO comporta-se como um inibidor de enzimas do tipo cisteína protease de forma muito mais eficiente que as espécies NO e ONOO` [44]. Portanto, o efeito do HNO sobre enzima cisteína proteases de parasitas pode ser uma via de ação desta molécula. 


\subsection{Efeito leishmanicida in vivo de nitrosilos complexos}

O Índice Terapêutico ( $\left(\mathrm{I}_{50 \mathrm{~V} 79} / \mathrm{IC}_{50 \mathrm{pro}}\right)$ dos complexos nitrosilados foi empregado como critério para a seleção do composto a ser utilizado no teste in vivo contra a leishmaniose. Quanto maior o valor de $\mathrm{IC}_{50 \mathrm{~V} 79} / \mathrm{IC}_{50 \text { pro, }}$ maior a segurança na utilização do composto sem danos ao animal. Os compostos trans- $\left[\mathrm{RuNO}\left(\mathrm{NH}_{3}\right)_{4} \mathrm{imN}\right]\left(\mathrm{BF}_{4}\right)_{3}, \quad$ trans- $\left[\mathrm{RuNO}\left(\mathrm{NH}_{3}\right)_{4} \mathrm{py}\right]\left(\mathrm{BF}_{4}\right)_{3} \quad$ e trans-[RuNO $\left.\left(\mathrm{NH}_{3}\right)_{4} \mathrm{P}(\mathrm{OEt})_{3}\right]\left(\mathrm{PF}_{6}\right)_{3}$ apresentaram os maiores valores de $I_{50 V 79} / I_{50 p r o}(>15)$ dentre os nitrosilos da série estudada (Tabela 1). Apesar da elevada atividade antiparasitária in vitro do composto trans-[RuNO $\left.\left(\mathrm{NH}_{3}\right)_{4} \mathrm{P}(\mathrm{OEt})_{3}\right]\left(\mathrm{PF}_{6}\right)_{3}$, a baixa estabilidade deste nitrosilo foi fator decisivo para sua exclusão em experimentos in vivo. Este complexo sofre ataque nucleofílico nos ligantes $\mathrm{P}(\mathrm{OEt})_{3}\left(\mathrm{k}=5,9 \pm 1,0 \times 10^{4} \mathrm{~mol}^{-1} \mathrm{~L} \mathrm{~s}^{-1}\right)$ e $\mathrm{NO}^{+}$ $\left(\mathrm{k}=4,0 \pm 1,0 \times 10^{4} \mathrm{~mol}^{-1} \mathrm{Ls}^{-1}\right)$ por íons hidroxila gerando os produtos trans$\left[\mathrm{Ru}\left(\mathrm{NH}_{3}\right)_{4} \mathrm{P}(\mathrm{OEt})_{3}\left(\mathrm{H}_{2} \mathrm{O}\right)\right]^{2+}$ e trans- $\left[\mathrm{RuNO}\left(\mathrm{NH}_{3}\right)_{4}\left(\mathrm{H}_{2} \mathrm{O}\right)\right]^{3+}$ (Esquema 2). Além disto, verificou-se que este composto também sofre degradação mesmo no estado sólido na escala de tempo de dias [58].

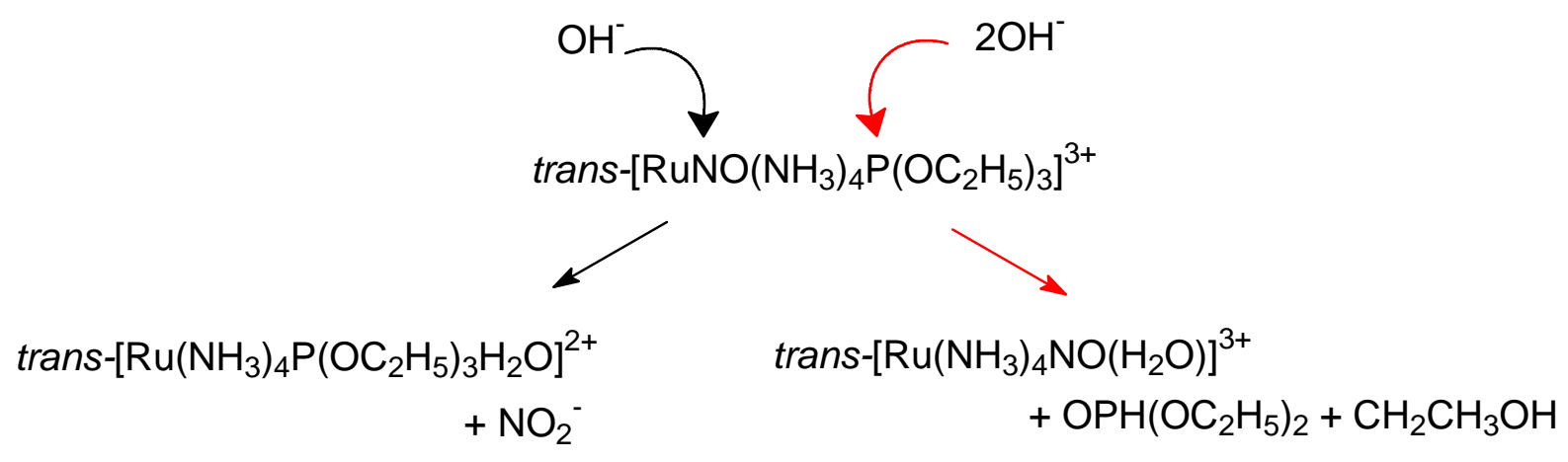

Esquema 2 - Reação entre o complexo trans-[RuNO $\left.\left(\mathrm{NH}_{3}\right)_{4} \mathrm{P}\left(\mathrm{OC}_{2} \mathrm{H}_{5}\right)_{3}\right]^{3+}$ e íons hidróxido. 
Os compostos trans-[RuNO $\left.\left(\mathrm{NH}_{3}\right)_{4} \mathrm{imN}\right]\left(\mathrm{BF}_{4}\right)_{3}$ e trans-[RuNO$\left.\left(\mathrm{NH}_{3}\right)_{4} \mathrm{py}\right]\left(\mathrm{BF}_{4}\right)_{3}$ apresentaram elevado valor de $\mathrm{IC}_{50 \mathrm{~V} 79} / \mathrm{IC}_{50 \text { pro }} 18$ e 22, respectivamente. No entanto, o composto trans-[RuNO(NH$\left.\left.)_{4}\right)_{4 m N}\right]\left(B_{4}\right)_{3}$ foi selecionado para os ensaios in vivo devido sua maior atividade antiproliferativa como observado no gráfico da Figura 7. Este composto também apresentou resultados promissores nos estudos in vivo contra o parasito T. cruzi [25].

Para os experimentos in vivo, quatro grupos de camundongos foram infectados com $1 \times 10^{5}$ formas promastigotas de L. major intradermicamente em uma orelha. O tratamento foi executado desde a terceira até a sexta semana diariamente com a dosagem de $0,5, \quad 1,0$ e $10,0 \mu \mathrm{mol} \mathrm{kg}^{-1}$ do composto trans-[RuNO $\left.\left(\mathrm{NH}_{3}\right)_{4} \mathrm{imN}\right]\left(\mathrm{BF}_{4}\right)_{3}$ e o grupo controle foi tratado apenas com PBS. A Figura 12a apresenta a evolução da lesão da orelha infectada com o parasito durante 6 semanas. Observou-se que logo após o tratamento com o complexo trans-[RuNO $\left.\left(\mathrm{NH}_{3}\right)_{4} \mathrm{imN}\right]\left(\mathrm{BF}_{4}\right)_{3}$, os grupos de animais tratados com 0,5 e 1,0 $\mu \mathrm{molkg}{ }^{-1}$ mantiveram o tamanho da lesão cutânea estável. $\mathrm{O}$ grupo tratado com $10 \mu \mathrm{mol} \mathrm{kg}^{-1}$ do nitrosilo complexo apresentou diminuição da lesão. Por outro lado, os camundongos tratados apenas com PBS apresentaram o aumento nas dimensões da lesão até a sexta semana. Após o período de seis semanas, foi realizada a contagem de parasitas em cada grupo de camundongos. Foi observado que o grupo tratado com a menor concentração $\left(0,5 \mu \mathrm{mol} \mathrm{kg}{ }^{-1}\right)$ do nitrosilo apresentou a maior inibição de crescimento (98\%) (Figura 12 b, Tabela 4). O menor efeito inibitório observado para os tratamentos com 1,0 e $10 \mu \mathrm{mol} \mathrm{kg}^{-1}$ do composto pode estar relacionado ao efeito imunossupressor provocado pelo excesso de NO liberado no organismo do animal [14]. Veja que a diminuição da lesão no grupo tratado com a maior concentração não significou menor carga parasitária. A redução da lesão pode 
estar relacionada a dois fatores: a inibição do crescimento parasitário e ao efeito antiinflamatório do óxido nítrico [76].

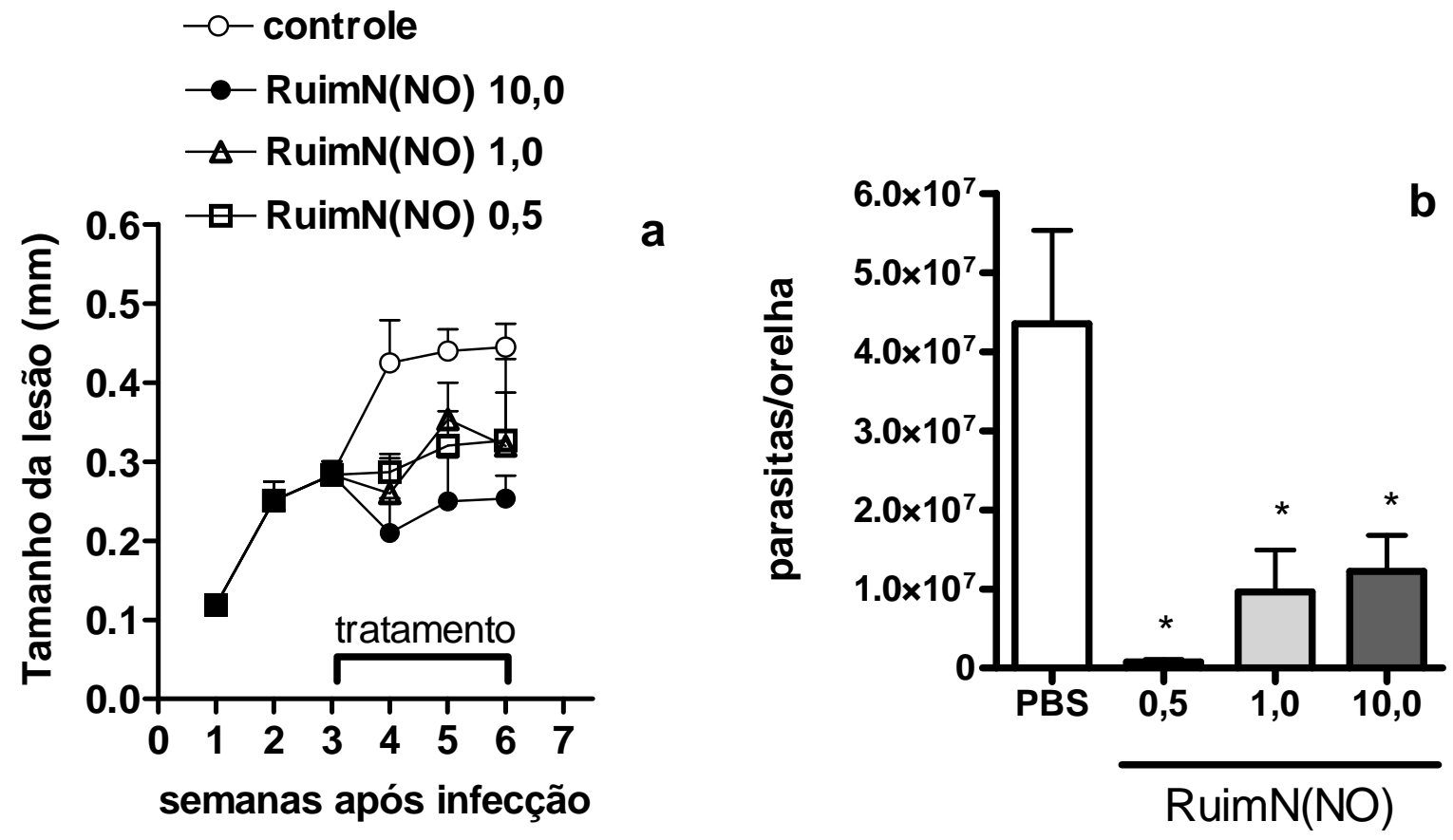

Figura 12 - a) Efeito do composto trans-[RuNO$\left.\left(\mathrm{NH}_{3}\right)_{4} \mathrm{imN}\right]\left(\mathrm{BF}_{4}\right)_{3}$ no curso de infecção de camundongos BALB/c. Grupos de 6 animais foram inoculados subcutaneamente na orelha com $1 \times 10^{5}$ de formas promastigotas de L. major e tratados subcutaneamente em dias consecutivos com o complexo na semana 3, 4, 5 e 6 de infecção ( $\square$ 0,5, $\Delta$ 1,0 e $\bullet 10 \mu \mathrm{mol} \mathrm{kg}{ }^{-1}$, o controle). Tamanho da lesão (em $\mathrm{mm}$ ) representa a diferença entre a orelha infectada e a orelha contralateral não infectada. b) carga parasitária 6 semanas após infecção de grupos de animais tratados com $\square$ PBS, - $0,5, \quad 1,0$ e $\quad 10,0 \mu \mathrm{mol} \mathrm{kg} \mathrm{kg}^{-1}$ do composto trans-[RuNO$\left.\left(\mathrm{NH}_{3}\right)_{4} \mathrm{imN}\right]\left(\mathrm{BF}_{4}\right)_{3}$. ${ }^{*}$ Valores significativamente menor que o controle $(P<0,05)$.

Outro grupo de animais foi (controle positivo) tratado com $10 \mathrm{mg} \mathrm{kg}^{-1} \mathrm{dia}^{-1} \mathrm{de}$ glucantime (droga padrão) em um período de duas semanas e comparado com o grupo tratado com a dose do composto trans-[RuNO$\left.\left(\mathrm{NH}_{3}\right)_{4} \mathrm{imN}\right]\left(\mathrm{BF}_{4}\right)_{3}$ que apresentou melhor efeito antiparasitário $\left(0,5 \mu \mathrm{mol} \mathrm{kg}{ }^{-1}\right)$. Verificou-se que os grupos tratados com o complexo trans-[RuNO$\left.\left(\mathrm{NH}_{3}\right)_{4} \mathrm{imN}\right]\left(\mathrm{BF}_{4}\right)_{3}$ apresentaram decréscimo de 70\% da carga parasitária (Tabela 4). O tratamento com a glucantime 
$\left(\mathrm{C}=33 \mu \mathrm{mol} \mathrm{kg}{ }^{-1}, 10 \mathrm{mg} \mathrm{Kg}^{-1}\right)$ apresentou atividade similar ao do nitrosilo como observado na Figura 13. É importante observar que a dose administrada da droga padrão é 66 vezes superior a dose utilizada do complexo trans-[RuNO$\left.\left(\mathrm{NH}_{3}\right)_{4} \mathrm{imN}\right]\left(\mathrm{BF}_{4}\right)_{3}$ em nossos experimentos.
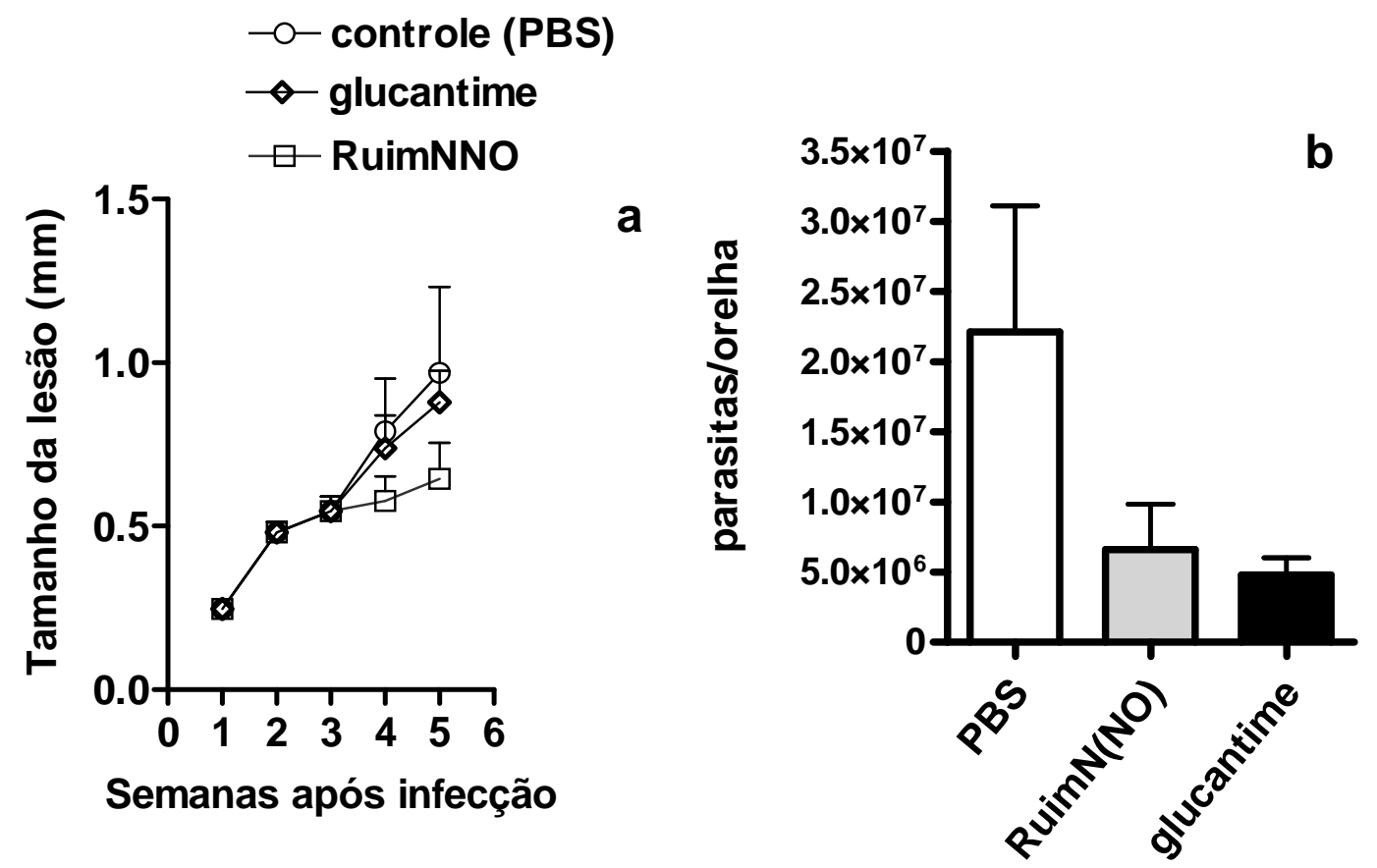

Figura 13 - a) Efeito dos compostos trans-[RuNO $\left.\left(\mathrm{NH}_{3}\right)_{4} \mathrm{imN}\right]\left(\mathrm{BF}_{4}\right)_{3}$ e glucantime no curso de infecção de camundongos BALB/c. Grupos de 6 animais foram inoculados subcutaneamente na orelha com $1 \times 10^{5}$ de formas promastigotas de L. major e tratados com o complexo $\square$ trans-[RuNO$\left.\left(\mathrm{NH}_{3}\right)_{4} \mathrm{imN}\right]\left(\mathrm{BF}_{4}\right)_{3}$ e $\diamond$ glucantime na semana 3,4 e 5 de infecção (ocontrole, PBS). Tamanho da lesão (em $\mathrm{mm}$ ) representa a diferença entre a orelha infectada e a orelha contralateral não infectada. b) carga parasitária (após a quinta semana de infecção) de grupos de animais $\square$ tratados com PBS, tratados com $0,5 \mu \mathrm{mol} \mathrm{Kg}^{-1}$ do composto trans-[RuNO$\left.\left(\mathrm{NH}_{3}\right)_{4} \mathrm{imN}\right]\left(\mathrm{BF}_{4}\right)_{3} \mathrm{e}$ - tratados com $33 \mu \mathrm{mol} \mathrm{Kg}^{-1}$ de glucantime.

Outro fator importante diz respeito a toxicidade deste nitrosilo cuja dose letal $\left(L_{50}\right)$ está na faixa de 125 a $250 \mu \mathrm{mol} \mathrm{kg}{ }^{-1}$ de peso corpóreo[25]. A dose diária $\left(0,5 \mu \mathrm{mol} \mathrm{kg}{ }^{-1}\right)$ utilizada nos experimentos foi sempre 250 vezes inferior ao valor de $\mathrm{LD}_{50}$ e a dose total fornecida a cada animal durante as três semanas de tratamento $\left(10,5 \mu \mathrm{mol} \mathrm{kg}{ }^{-1}\right)$ é 12 vezes inferior a sua dose letal. Além disto, não foi observado 
perda de peso significativa do grupo de camundongos tratado com o composto trans-[RuNO$\left.\left(\mathrm{NH}_{3}\right)_{4} \mathrm{imN}\right]\left(\mathrm{BF}_{4}\right)_{3}$ comparado ao grupo controle.

Tabela 4 - Atividade In vivo do composto trans-[RuNO $\left.\left(\mathrm{NH}_{3}\right)_{4} \mathrm{imN}\right]\left(\mathrm{BF}_{4}\right)_{3}$ contra o parasito L. major em camundogo BALB/c ${ }^{\mathrm{a}}$

\begin{tabular}{|c|c|c|c|c|}
\hline Composto & $\begin{array}{l}\text { Dosagem } \\
\left(\mu \mathrm{mol} \mathrm{kg}^{-1}\right)\end{array}$ & Dia & $\begin{array}{c}\text { Peso } \\
\text { corporal }(g)\end{array}$ & \%inibição \\
\hline \multirow[t]{2}{*}{ Controle } & - & 35 & $25,2 \pm 0,5$ & - \\
\hline & - & 42 & $25,0 \pm 1,4$ & - \\
\hline \multirow[t]{2}{*}{ trans-[RuNO $\left.\left(\mathrm{NH}_{3}\right)_{4} \mathrm{imN}\right]\left(\mathrm{BF}_{4}\right)_{3}$} & 0,5 & 35 & $23,3 \pm 1,5$ & $70 \pm 21$ \\
\hline & 0,5 & 42 & $23,3 \pm 1,3$ & $98 \pm 2$ \\
\hline \multicolumn{5}{|c|}{$\begin{array}{l}\text { a Camundongos foram inoculados com } 10^{5} \text { promastigotas de } L \text {. major (fase estacionária). } \\
\text { Camundogos foram selecionados randomicamente em grupos de } 4 \text { ou } 5 \text { animais tratados por } 2 \text { e } 3 \\
\text { semanas diariamente com trans-[RuNO }\left(\mathrm{NH}_{3}\right)_{4} \mathrm{imN}_{(}\left(\mathrm{BF}_{4}\right)_{3}\left(0,5 \mu \mathrm{mol} \mathrm{kg}^{-1} \text { de peso corpóreo, injeção }\right. \\
\text { subcutâneo). Os camundongos receberam tratamento três semanas após o desafio com } L \text {. major } \\
\text { (dia 0). Média } \pm \text { desvio padrão. * Valores significativamente menor que o valor do grupo controle } \\
(\mathrm{P}<0,05) \text {. }\end{array}$} \\
\hline
\end{tabular}

\subsection{Efeito antileishmania de sulfato complexos}

Para avaliar a atividade antipromastigota do complexo de Rutênio sem NO presente na esfera de coordenação, experimentos foram realizados com precursores dos nitrosilo complexo trans-[Ru( $\left.\left.\mathrm{NH}_{3}\right)_{4} \mathrm{~L}(\mathrm{SO})_{4}\right] \mathrm{Cl}(\mathrm{L}=$ nic, L-hist, imN, pz, py)[59]. Estes complexos apresentam efeito antipromastigota inferior aos análogos nitrosilos complexos com valores de $\mathrm{IC}_{50 \text { pro }}$ reunidos na Tabela 5. Não foi observado relação entre potencial de redução ( $\left.E_{\text {Rulll/Rull }}\right)$ destes complexos sua atividade antiparasitária. No entanto, a ordem de atividade antipromastigota neste grupo de complexo é semelhante aos nitrosilos complexos. 
Tabela 5 - Atividade antipromastigota e $\mathrm{E}_{1 / 2}$ de sulfato complexos

\begin{tabular}{|c|c|c|}
\hline Compostos & $\mathbf{I} \mathbf{C}_{50}$ & $E_{1 / 2}(V) v s E C S^{[59]}$ \\
\hline $\operatorname{trans}-\left[\mathrm{Ru}\left(\mathrm{NH}_{3}\right)_{4} \operatorname{lmN}\left(\mathrm{SO}_{4}\right)\right] \mathrm{Cl}$ & 81 & $-0,280$ \\
\hline trans-[Ru( $\left.\left(\mathrm{NH}_{3}\right)_{4} \mathrm{py}\left(\mathrm{SO}_{4}\right)\right] \mathrm{Cl}$ & 137 & $-0,048$ \\
\hline trans $-\left[\mathrm{Ru}\left(\mathrm{NH}_{3}\right)_{4} \mathrm{pz}\left(\mathrm{SO}_{4}\right)\right] \mathrm{Cl}$ & 260 & 0,246 \\
\hline trans-[Ru( $\left.\left.\mathrm{NH}_{3}\right)_{4} \mathrm{Hist}\left(\mathrm{SO}_{4}\right)\right] \mathrm{Cl}$ & 378 & $-0,418$ \\
\hline trans-[Ru( $\left.\left(\mathrm{NH}_{3}\right)_{4}(\mathrm{isn})\left(\mathrm{SO}_{4}\right)\right] \mathrm{Cl}$ & 488 & 0,047 \\
\hline $\operatorname{trans}-\left[\mathrm{Ru}\left(\mathrm{NH}_{3}\right)_{4} \mathrm{Nic}\left(\mathrm{SO}_{4}\right)\right] \mathrm{Cl}$ & 5640 & 0,014 \\
\hline
\end{tabular}

Resultados expressos como \pm s.e.m., $\mathrm{n}=3-5, \mathrm{P}<0,05 ;{ }^{a} \mathrm{IC}_{50}$ pro $=$ corresponde a concentração com $50 \%$ de atividade antiproliferativa, após $24 \mathrm{~h}$ de incubação.

Para os experimentos in vivo foi escolhido o complexo com melhor atividade antiparasitária in vitro, o complexo trans- $\left[\mathrm{Ru}\left(\mathrm{NH}_{3}\right)_{4} \mathrm{imN}\left(\mathrm{SO}_{4}\right)\right] \mathrm{Cl}$. Dois grupos de camundongos foram infectados com $1 \times 10^{5}$ formas promastigotas de L. major intradermicamente na orelha. O tratamento foi executado da terceira até a sexta semana diariamente com a dosagem de $0,5 \mu \mathrm{molkg}^{-1}$ de composto trans-[Ru(NH$)_{4}$ imN $\left.\left(\mathrm{SO}_{4}\right)\right] \mathrm{Cl}$. O grupo controle foi tratado apenas com PBS. O composto trans-[Ru(NH$\left.)_{4} i m N\left(\mathrm{SO}_{4}\right)\right] \mathrm{Cl}$ apresentou menor efeito antileishmania in vivo na concentração utilizada comparado ao nitrosilo complexo (Figura 14b). Além disto, não foi observado diminuição da lesão do grupo de animais tratados com o sulfato complexo comparado ao controle (Figura 14a). Estes resultados sugerem novamente que a ação antiparasitária dos compostos trans- $\left[\mathrm{RuNO}\left(\mathrm{NH}_{3}\right)_{4} \mathrm{~L}\right]\left(\mathrm{BF}_{4}\right)_{3}$ está relacionada a capacidade doadora de NO destes complexos. 
- Controle (PBS)

$\rightarrow$ RuimNSO$_{4}$

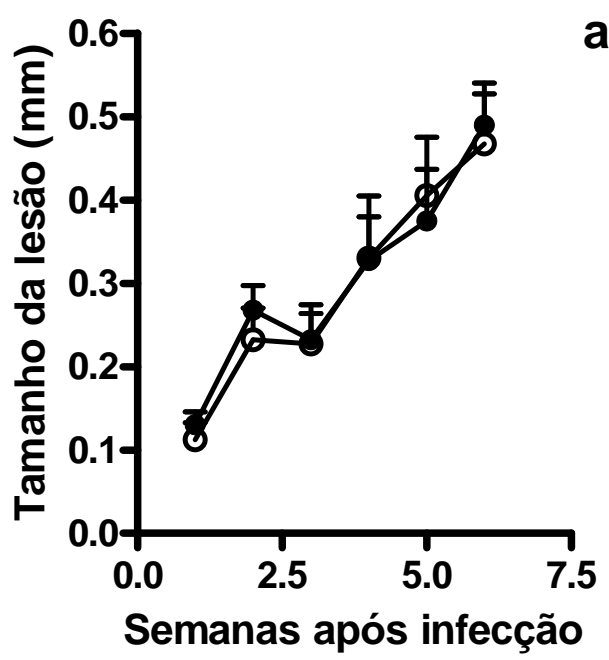

a

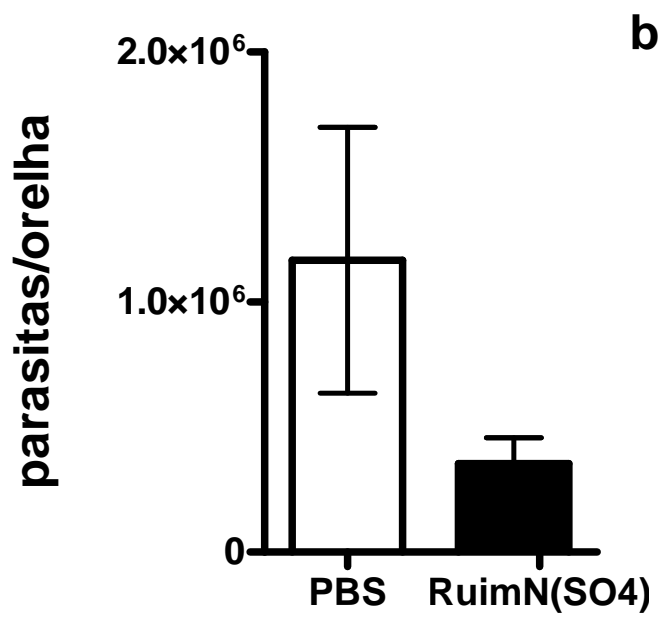

Figura 14 - a) Efeito do composto trans-[Ru( $\left.\left.\mathrm{NH}_{3}\right)_{4} i m N\left(\mathrm{SO}_{4}\right)\right] \mathrm{Cl}$ no curso de infecção de camundongos BALB/c. Grupos de 6 animais foram inoculados subcutaneamente na orelha com $1 \times 10^{5}$ de formas promastigotas de $L$. major e $\bullet$ tratados com 0 complexo na semana 3, 4, 5 e 6 de infecção. Tamanho da lesão (em $\mathrm{mm}$ ) representa a diferença entre a orelha infectada e a orelha contralateral não infectada. b) carga parasitária de grupos de animais $\square$ tratados com PBS e - tratados com $0,5 \mu \mathrm{mol} \mathrm{Kg}{ }^{-1}$ do composto trans- $\left[\mathrm{Ru}\left(\mathrm{NH}_{3}\right){ }_{4} \mathrm{imN}\left(\mathrm{SO}_{4}\right)\right] \mathrm{Cl}$. 


\subsection{Conclusão parcial}

Verificou-se que os complexos nitrosilados apresentaram efeito antiparasitário contra as formas promastigotas e amastigotas do L. major. Os dados obtidos destes experimentos indicaram a influência das características físico-químicas ( $k_{\text {-NO }}$ e $\mathrm{E}_{\left(\mathrm{NO}^{+} / \mathrm{NO}^{0}\right)}$ deste complexos sobre sua ação como agentes antiparasitários.

Analisamos também a possível ação dos produtos gerados de reações redox destes complexos sobre o parasito L.major e observamos que ambos, NO e HNO, agem sobre a forma extracelular e intracelular do parasito. Por outro lado, o complexo do tipo trans-[Ru(NH$\left.\left.)_{3}\right)_{4}\left(\mathrm{H}_{2} \mathrm{O}\right)\right]^{+2}$ exibe inibição apenas contra a forma extracelular (promastigota) do L.major in vitro.

Também foi observado que dentre os compostos estudados o complexo trans-[RuNO$\left.\left(\mathrm{NH}_{3}\right)_{4} \mathrm{imN}\right]\left(\mathrm{BF}_{4}\right)_{3}$ apresenta o melhor efeito antiproliferativo e baixa toxicidade contra células V79. Estes resultados foram utilizados como critérios através de seu incide terapêutico para a escolha deste complexo para os experimentos in vivo. Testou-se 0 potencial do complexo trans-[RuNO $\left.\left(\mathrm{NH}_{3}\right)_{4} \mathrm{imN}\right]\left(\mathrm{BF}_{4}\right)_{3}$ como agente contra a leishmaniose visto que este apresentou resultados promissores tendo em vista a dose utilizada no tratamento, 250 vezes menor que sua dose letal. Os sulfato complexos apresentaram menor efeito antiparasitário comparado aos similares nitrosilos sugerindo, portanto, que a atividade antiparasitária das tetraaminas de rutênio está relacionada principalmente a capacidade doadora de óxido nítrico. 


\subsection{Reação entre os nitrosilos complexos e a L-cisteína}

É bem conhecida a reatividade de nitrosilos de rutênio frente a agentes nucleofílicos[60]. Assim, diferentes autores propõem metodologias complementares para a previsão do ataque nucleofílico ao ligante nitrosônio[60-63]. A maior parte dos trabalhos trata da reação entre íons $\mathrm{OH}^{-}$e nitrosilos complexos[60, 63]. Estas reações de ataque nucleofílico se processam em duas etapas (Equações 17 e 18):

$$
\begin{aligned}
{[\mathrm{M}-\mathrm{NO}]^{\mathrm{n}+}+\mathrm{OH}^{-} } & \rightleftharpoons \quad\left[\mathrm{M}-\mathrm{NO}_{2} \mathrm{H}\right]^{(\mathrm{n}-1)+} \\
{\left[\mathrm{M}-\mathrm{NO}_{2} \mathrm{H}^{(\mathrm{n}-1)+}+\mathrm{OH}^{-}\right.} & \rightleftharpoons\left[\mathrm{M}-\mathrm{NO}_{2}\right]^{(\mathrm{n}-2)+}+\mathrm{H}_{2} \mathrm{O}
\end{aligned}
$$

Para os complexos do tipo trans- $\left[\mathrm{Ru}(\mathrm{NO})\left(\mathrm{NH}_{3}\right)_{4} \mathrm{~L}\right](\mathrm{X})_{3},\left(\mathrm{X}=\mathrm{BF}_{4}^{-}\right.$ou $\mathrm{PF}_{6}^{-}$e $\mathrm{L}_{=}=$ imN , 4-pic, pz, py, $\mathrm{P}(\mathrm{OEt})_{3}$, L- hist, isn, imC, nic), o caráter eletrofílico do ligante nitrosônio $\left(\mathrm{NO}^{+}\right)$é influenciado pelo caráter ácido $\pi$ do ligante trans $L[60,64]$. Quanto maior a acidez $\pi$ do ligante $L$, maior a competição pela densidade eletrônica do centro metálico e, portanto, a retrodoação do tipo $\mathrm{M} \rightarrow \mathrm{NO}^{+}$teria menor intensidade. $\mathrm{A}$ conseqüência deste fato seria o aumento do caráter eletrofílico do nitrosônio facilitando o ataque de nucleófilos frente a este ligante[60].

Com relação aos tiois, tais como a L-cisteína e a glutationa, a reação de ataque nucleofílico frente ao ligante nitrosônio envolve a transferência de elétrons como será discutido mais adiante. Em trabalhos recentes[65], foi reportado que o ataque nucleofílico dos tiois frente ao ligante $\mathrm{NO}^{+}$é mais eficiente sob a forma deprotonada (RS'). Em nossos experimentos, foi observado que os complexos do tipo trans- $\left[\mathrm{Ru}(\mathrm{NO})\left(\mathrm{NH}_{3}\right)_{4} \mathrm{~L}\right]\left(\mathrm{BF}_{4}\right)_{3},(\mathrm{~L}=\mathrm{imN}, 4$-pic, py, isn) reagem com a L-cisteína 
somente em condições de concentração hidrogeniônica menor que $1 \times 10^{-6} \mathrm{~mol} \mathrm{~L}^{-1}$, ou seja, na presença da forma deprotonada da L-cisteína cujo pKa é igual a 8,3. Por outro lado, o complexo trans-[RuNO $\left.\left(\mathrm{NH}_{3}\right)_{4} \mathrm{P}(\mathrm{OEt})_{3}\right]\left(\mathrm{PF}_{6}\right)_{3}$ reage com a L-cisteína mesmo em pH ácido $\left(\mathrm{C}_{\mathrm{H}^{+}}=1 \times 10^{-2} \mathrm{~mol} \mathrm{~L}^{-1}\right)$ em que a concentração da espécie $\mathrm{RSH}$ é muito superior a forma deprotonada deste tiol.

Portanto, com o intuito de entender o comportamento de nitrosilos de rutênio em meio biológico, foram conduzidos experimentos com os complexos trans-[RuNO $\left.\left(\mathrm{NH}_{3}\right)_{4} \mathrm{~L}\right]\left(\mathrm{BF}_{4}\right)_{3}, \quad(\mathrm{~L}=\mathrm{imN}, 4-p i c$, py, isn $)$ e a L-cisteína, aminoácido presente na glutationa. As medidas foram realizadas em soluções tamponadas em $\mathrm{pH} 7,4 \mu=0,2 \mathrm{~mol} \mathrm{~L}^{-1}, \mathrm{a} 25^{\circ} \mathrm{C}$.

A Figura 15a ilustra a evolução de $\mathrm{NO}^{0}$ gerada da reação entre o complexo trans-[RuNO $\left.\left(\mathrm{NH}_{3}\right)_{4}(\mathrm{imN})\right]\left(\mathrm{BF}_{4}\right)_{3}$ e a L-cisteína, acompanha por meio de medidas cronoamperométrica com o uso de um eletrodo seletivo para detecção de óxido nítrico (NO). Nota-se que nestas condições a evolução de NO é bem inferior ao esperado para uma reação estequiométrica. Com a adição simultânea dos compostos $\mathrm{Na}_{3}\left[\mathrm{Fe}(\mathrm{CN})_{6}\right]$ e trans-[RuNO$\left.\left(\mathrm{NH}_{3}\right)_{4}(\mathrm{imN})\right]\left(\mathrm{BF}_{4}\right)_{3}$ em uma solução contendo L-cisteína ocorreu aumento significativo na concentração de NO liberado no meio (Figura 15b). Este aumento de concentração de NO livre pode estar relacionado a oxidação do nitroxil (HNO) pelo complexo de ferro [43] como descrito na Equação 19. Estes resultados sugerem que ocorre também redução de 2 elétrons no ligante $\mathrm{NO}^{+}$gerando como produto o $\mathrm{HNO}$.

$$
\left[\mathrm{Fe}^{\mathrm{III}}(\mathrm{CN})_{6}\right]^{-3}+\mathrm{HNO} \longrightarrow\left[\mathrm{Fe}^{\prime \prime}(\mathrm{CN})_{6}\right]^{-4}+\mathrm{NO}^{0}+\mathrm{H}^{+}
$$




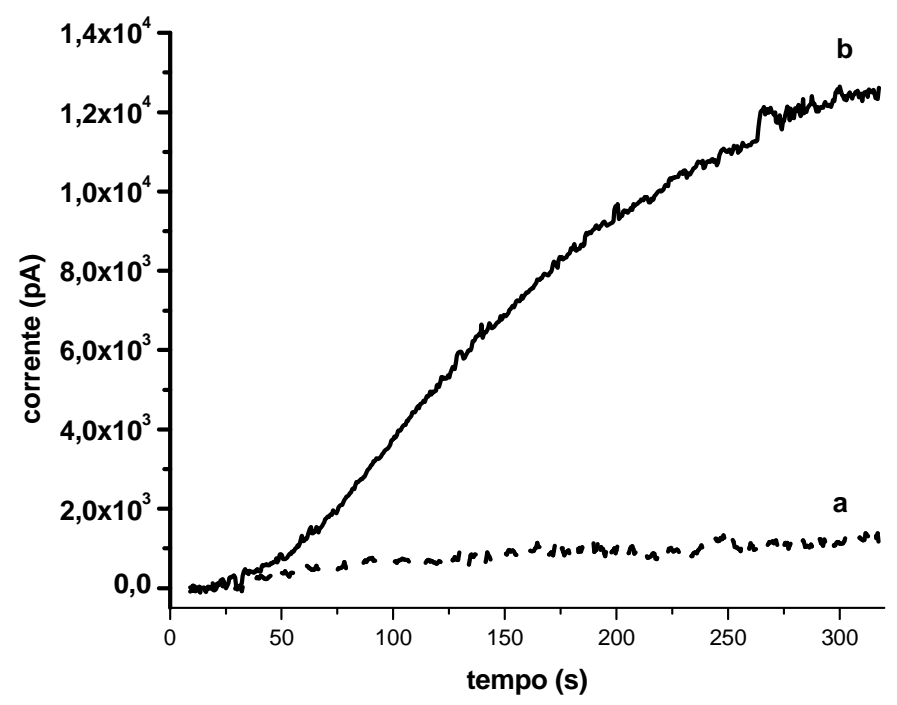

Figura 15 - Cronoamperograma da reação entre 0 complexo trans $\left[\mathrm{RuNO}\left(\mathrm{NH}_{3}\right)_{4} \mathrm{imN}\right]^{+3}$ e a L-cisteína condições: $\mathrm{pH} 7,4 ; \mu=0,2 \mathrm{~mol} \mathrm{~L}^{-1} \mathrm{~T}=25^{\circ} \mathrm{C}$. a ) $\mathrm{C}_{\mathrm{Ru}}=0,5 \times 10^{-3} \mathrm{~mol} \mathrm{~L}^{-1} \mathrm{e} \mathrm{C}_{\text {cis }}=0,5 \times 10^{-3} \mathrm{~mol} \mathrm{~L}^{-1}$. b) ) $\mathrm{C}_{\mathrm{Ru}}=0,5 \times 10^{-3} \mathrm{~mol} \mathrm{~L}^{-1}$, $\mathrm{C}_{\text {cis }}=0,5 \times 10^{-3} \mathrm{~mol} \mathrm{~L}^{-1}$ e $\mathrm{Na}_{3}\left[\mathrm{Fe}(\mathrm{CN})_{6}\right]=0,5 \times 10^{-3} \mathrm{~mol} \mathrm{~L}^{-1}$.

O nitroxil oriundo da reação entre os nitrosilos de rutênio e a L-cisteína também foi detectado espectrofotometricamente com auxílio da metmiogobina, um conhecido captador de HNO [66]. A Figura 16 mostra o espectro da solução contendo a mistura do complexo trans-[RuNO$\left.\left(\mathrm{NH}_{3}\right)_{4}(\mathrm{imN})\right]\left(\mathrm{BF}_{4}\right)_{3}$, L-cisteína e metmioglobina em $\mathrm{pH}=7,4, \mu=0,2 \mathrm{~mol} \mathrm{~L}^{-1}$ a $25^{\circ} \mathrm{C}$. Nestas condições, foi observado a formação de duas bandas centradas em $543\left(\varepsilon=1,16 \times 10^{4} \mathrm{~mol}^{-1} \mathrm{~L}^{-1} \mathrm{~cm}^{-1}\right)$ e $578 \mathrm{~nm}\left(\varepsilon=1,05 \times 10^{4} \mathrm{~mol}^{-1} \mathrm{~L}^{-1} \mathrm{~cm}^{-1}\right)$ atribuída a formação do nitrosilo ferroso $\left(\mathrm{Mb}-\mathrm{Fe}^{\prime \prime} \mathrm{NO}^{0}\right)[66,67]$ (Equação 20). É importante mencionar que a reação entre o $\mathrm{NO}^{0}$ e a metmioglobina gera o complexo $\mathrm{Mb}-\mathrm{Fe}^{\prime \prime \prime} \mathrm{NO} / \mathrm{Fe}^{\prime \prime} \mathrm{NO}^{+} \mathrm{com}$ bandas em 534nm e 567nm na região do visível. Em nossos experimentos, não foi observado a formação destas bandas sugerindo que a concentração de $\mathrm{NO}^{0}$ produzido é muito baixa.

$$
\mathrm{Fe} e^{\prime \prime \prime} \mathrm{Mb}+\mathrm{HNO} \rightarrow \mathrm{Fe}^{\prime \prime}(\mathrm{NO}) \mathrm{Mb}+\mathrm{H}^{+}
$$




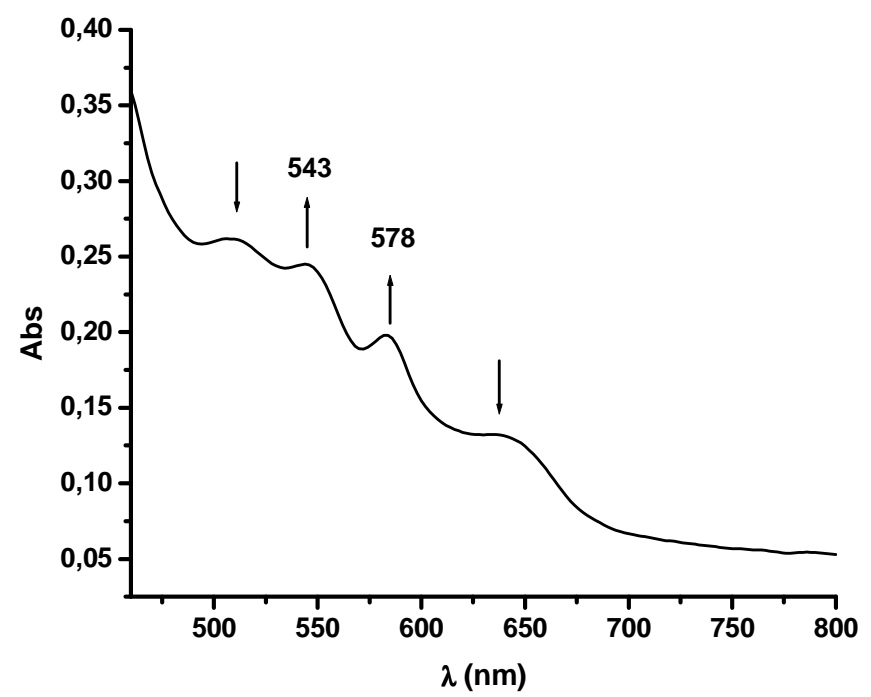

Figura 16 - Espectro eletrônico da solução contendo a mistura do complexo trans-[RuNO $\left(\mathrm{NH}_{3}\right)_{4} \mathrm{imN}^{+3}$, metmioglobina e a L-cisteína. Condições: $\mathrm{pH}$ 7,4; $\mu=0,2 \mathrm{~mol} \mathrm{~L}^{-1} \mathrm{~T}=25^{\circ} \mathrm{C}$. $\mathrm{C}_{\mathrm{Ru}}=0,5 \times 10^{-3} \mathrm{~mol} \mathrm{~L}^{-1}$ e $\mathrm{C}_{\text {cis }}=0,5 \times 10^{-2} \mathrm{~mol} . \mathrm{L}^{-1} \mathrm{e}$ $\mathrm{C}_{\text {Met }}=0,5 \times 10^{-3} \mathrm{~mol} \mathrm{~L}^{-1}$.

Portanto, os experimentos cronoamperométricos e espectrofotométricos indicam que o HNO é produto majoritário da reação entre os complexos do tipo trans-[RuNO$\left.\left(\mathrm{NH}_{3}\right)_{4} \mathrm{~L}\right]\left(\mathrm{BF}_{4}\right)_{3},(\mathrm{~L}=\mathrm{imN}, 4$-pic, py, isn $)$ e a L-cisteína na concentração hidrogeniônica utilizada nos testes biológicos $(\mathrm{pH}=7,4)$.

Com relação ao complexo trans-[Ru(NH$\left.)_{3} \mathrm{P}(\mathrm{OEt})_{3} \mathrm{NO}\right]\left(\mathrm{PF}_{6}\right)_{3}$, a reação com a Lcisteína foi monitorada em diversas condições de concentração hidrogeniônicas (faixa de $\mathrm{pH}$ de 2,0 a 7,4 ).

As medidas cronoamperométricas foram realizadas sempre nas condições de excesso de L-cisteína em relação ao complexo (10, 50 e 100 vezes), na faixa de pH variando de 2,0 a $7,4 \quad\left(\mu=0,2 \mathrm{molL}^{-1}, \quad 25^{\circ} \mathrm{C}\right)$. A adição do trans-[RuNO $\left.\left(\mathrm{NH}_{3}\right)_{4} \mathrm{P}(\mathrm{OEt})_{3}\right]\left(\mathrm{PF}_{6}\right)_{3}$ na solução contendo L-cisteína provocou imediata variação de corrente indicando liberação de $\mathrm{NO}^{0}$ no meio (Figura 17). 
Resultados e Discussão

55

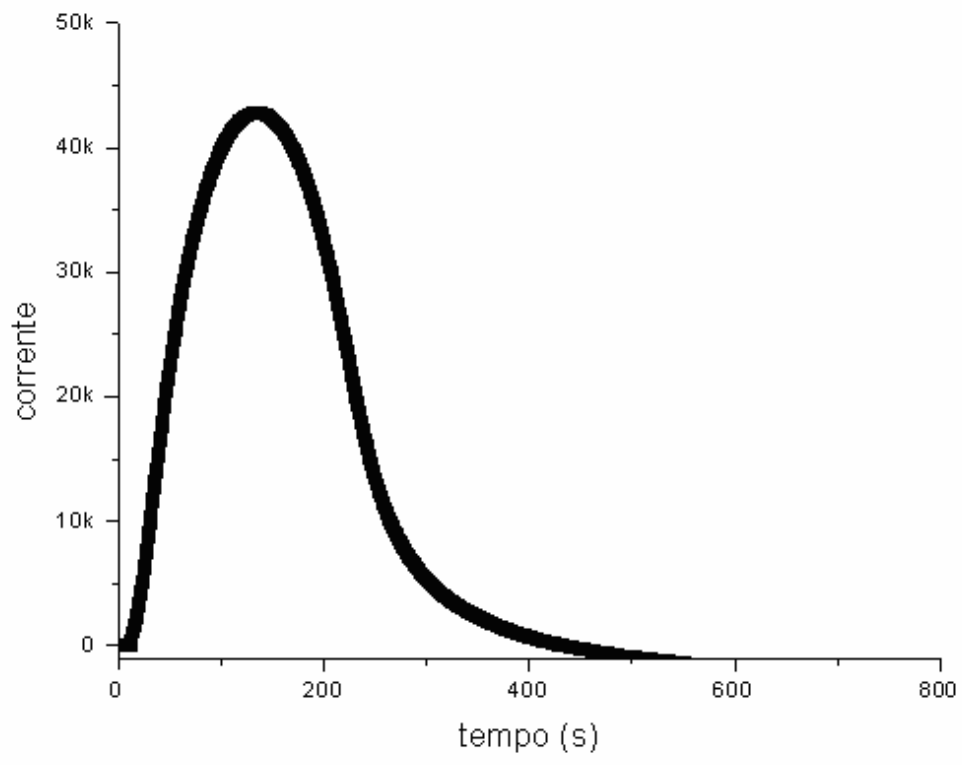

Figura $17-$ Cronoamperograma da reação entre 0 complexo trans-[RuNO$\left.\left(\mathrm{NH}_{3}\right)_{4} \mathrm{P}\left(\mathrm{OEt}_{3}\right)_{3}\right]\left(\mathrm{PF}_{6}\right)_{3}$ e a L-cisteína em pH 4,0. $\mathrm{C}_{\mathrm{Ru}}=5 \times 10^{-4} \mathrm{~mol} \mathrm{~L}^{-1} \mathrm{e}$ $\mathrm{C}_{\text {cis }}=5 \times 10^{-3} \mathrm{~mol} \mathrm{~L}^{-1} \cdot \mathrm{T}=25^{\circ} \mathrm{C}$.

Foi observado (Figura 18) que a concentração de NO livre em solução é dependente do $\mathrm{pH}$ do meio. A porcentagem de NO formado na reação do nitrosilo complexo com o tiol cresce dentro da faixa de $\mathrm{pH}$ de 2,0 a 4,0. Em concentrações hidrogeniônicas menores que $1,0 \times 10^{-4} \mathrm{~mol} \mathrm{~L}^{-1}(\mathrm{pH}>4,0)$, a presença de NO livre no meio decresce chegando a apenas $6 \%$ do esperado em $\mathrm{pH}=7,4$. Além disto, 0 aumento do excesso de L-cisteína nestas condições de pH também provoca menor concentração de NO livre. 


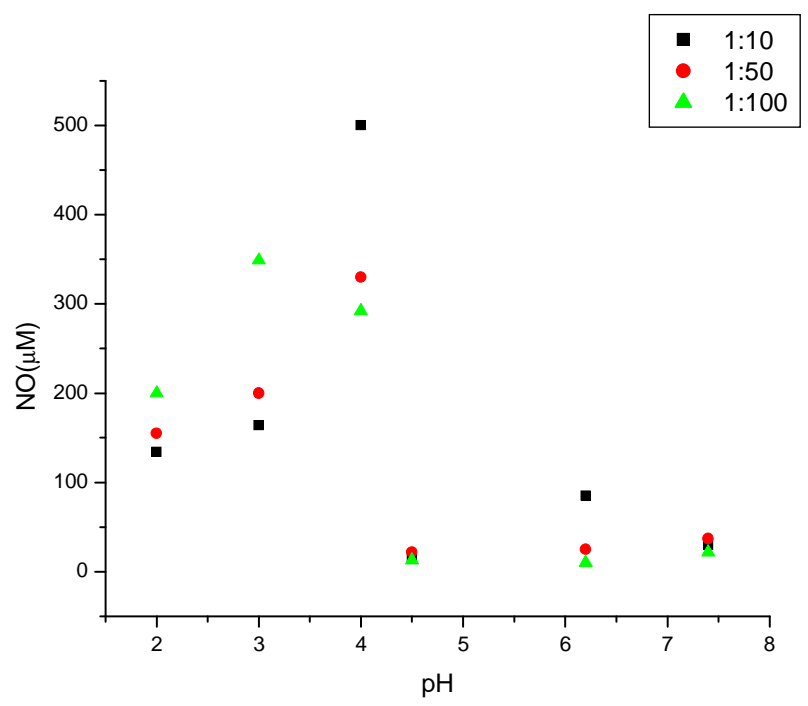

Figura 18 - Variação de concentração de $\mathrm{NO}$ em função do $\mathrm{pH}$ para a reação entre o complexo trans-[RuNO $\left.\left(\mathrm{NH}_{3}\right)_{4} \mathrm{P}(\mathrm{OEt})_{3}\right]^{+3}$ e diferentes concentrações de L-cisteína a $25{ }^{\circ} \mathrm{C}$. $\mathrm{C}_{\mathrm{Ru}}=5 \times 10^{-4} \mathrm{~mol} \mathrm{~L}^{-1}$, - $\mathrm{C}_{\text {cis }}=5 \times 10^{-3} \mathrm{~mol} \mathrm{~L}^{-1}, \cdot \mathrm{C}_{\text {cis }}=2,5 \times 10^{-2} \mathrm{~mol} \mathrm{~L}^{-1}$, $\Delta \mathrm{C}_{\text {cis }}=5 \times 10^{-2} \mathrm{~mol} \mathrm{~L}^{-1} \cdot \mathrm{T}=25^{\circ} \mathrm{C}$.

Como observado para o complexo trans-[RuNO$\left.\left(\mathrm{NH}_{3}\right)_{4}(\mathrm{imN})\right]\left(\mathrm{BF}_{4}\right)_{3}$, a adição simultânea do composto $\mathrm{Na}_{3}\left[\mathrm{Fe}(\mathrm{CN})_{6}\right]$ com 0 nitrosilo trans-[RuNO $\left.\left(\mathrm{NH}_{3}\right)_{4} \mathrm{P}(\mathrm{OEt})_{3}\right]\left(\mathrm{PF}_{6}\right)_{3}$ em uma solução contendo 10 vezes de excesso de L-cisteína em $\mathrm{pH}=7,4$ provocou aumento significativo na concentração de $\mathrm{NO}^{0}$ livre sugerindo, portanto, presença de HNO no meio como discutido anteriormente. No entanto, a presença de $\mathrm{Na}_{3}\left[\mathrm{Fe}(\mathrm{CN})_{6}\right]$ não altera a produção de $\mathrm{NO}^{0}$ da reação deste nitrosilo com a L-cisteína (10x de excesso) em condição de $\mathrm{pH}=4,0$. Nesta condição de concentração hidrogeniônica e de L-cisteína, a produção de NO corresponde a quase $100 \%$ do esperado para uma reação estequiométrica. Assim, a adição do composto de ferro não altera de modo significativo a produção de NO da reação entre este nitrosilo e a L-cisteína nesta condição de pH.

A produção de $\mathrm{HNO}$ e $\mathrm{NO}$ da reação entre 0 complexo trans-[RuNO $\left.\left(\mathrm{NH}_{3}\right)_{4} \mathrm{P}(\mathrm{OEt})_{3}\right]\left(\mathrm{PF}_{6}\right)_{3}$ a L-cisteína também foi monitora com o uso de 
metmioglobina em meio tamponado a pH 7,4 ( $\mu=0,2 \mathrm{~mol} \mathrm{~L}^{-1}$ a $\left.25^{\circ} \mathrm{C}\right)$. Foi observada a formação do espectro eletrônico referente ao nitrosilo ferroso (Figura 19). A formação desta espécie é uma forte evidência de produção de HNO oriunda da reação entre o complexo trans-[RuNO $\left.\left(\mathrm{NH}_{3}\right)_{4} \mathrm{P}(\mathrm{OEt})_{3}\right]\left(\mathrm{PF}_{6}\right)_{3}$ com a L-cisteína. As bandas de absorção da espécie $\mathrm{Mb}-\mathrm{Fe}^{\prime \prime} \mathrm{NO}^{0}$ são mais intensas com o aumento da concentração de L-cisteína no meio reacional sugerindo junto com os resultados cronoamperométricos que a presença de L-cisteína deprotonada favorece a redução de dois elétrons do ligante $\mathrm{NO}^{+}$produzindo o nitroxil (HNO).

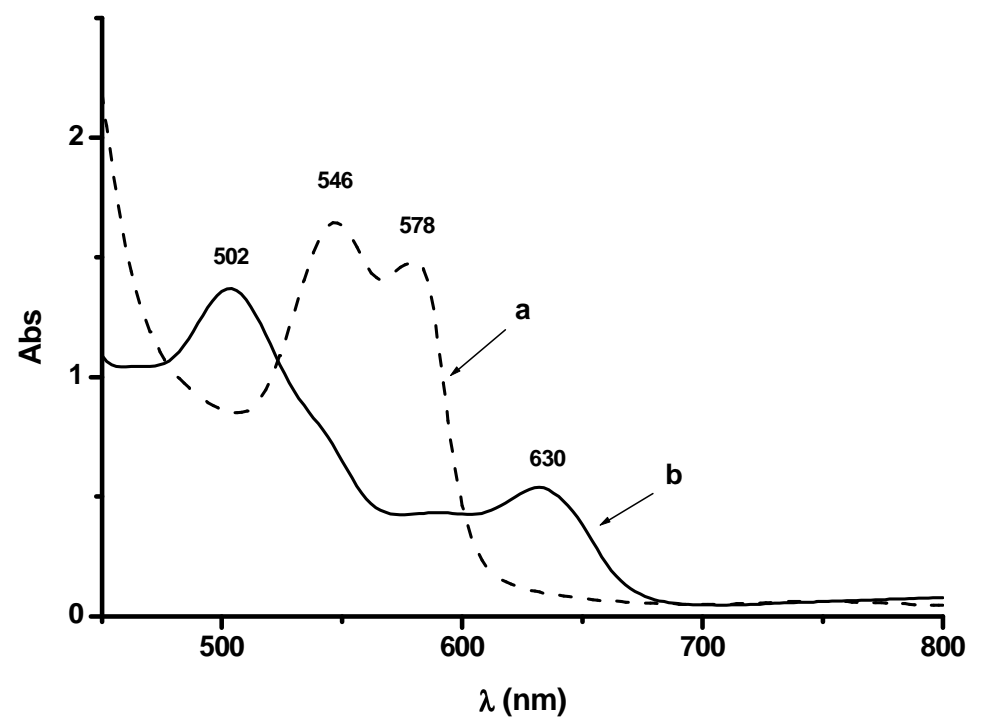

Figura $19-$ (a)espectro eletrônico da mistura das espécies trans-[RuNO $\left.\left(\mathrm{NH}_{3}\right)_{4} \mathrm{P}(\mathrm{OEt})_{3}\right]^{3+}\left(5,0 \times 10^{-5} \mathrm{~mol}^{-1} \mathrm{~L}^{-1}\right)$, L-cisteína $\left(1,0 \times 10^{-4} \mathrm{~mol} \mathrm{~L}^{-1}\right)$ e metmioglobina $\left(5,0 \times 10^{-5} \mathrm{~mol} \mathrm{~L}^{-1}\right)$. (b) Espectro eletrônico da metmioglobina. Condições: $\mathrm{pH} 7,4 ; \mu=0,2 \mathrm{~mol} \mathrm{~L}^{-1} \cdot \mathrm{T}=25^{\circ} \mathrm{C}$

O complexo nitrosilo ferroso, gerado da mistura trans-[RuNO $\left.\left(\mathrm{NH}_{3}\right)_{4} \mathrm{P}(\mathrm{OEt})_{3}\right]\left(\mathrm{PF}_{6}\right)_{3} / \mathrm{L}$-cisteína/metmioglobina, também foi detectado por ressonância paramagnética de elétrons o qual apresentou um fator $g$ anisotrópico próximo a 2,0 e 1,9[68,69], característico de $\mathrm{NO}^{0}$ coordenado ao centro metálico, $\mathrm{Mb}-\mathrm{Fe}^{\| \prime} \mathrm{NO}^{0}$ (Figura 20). 


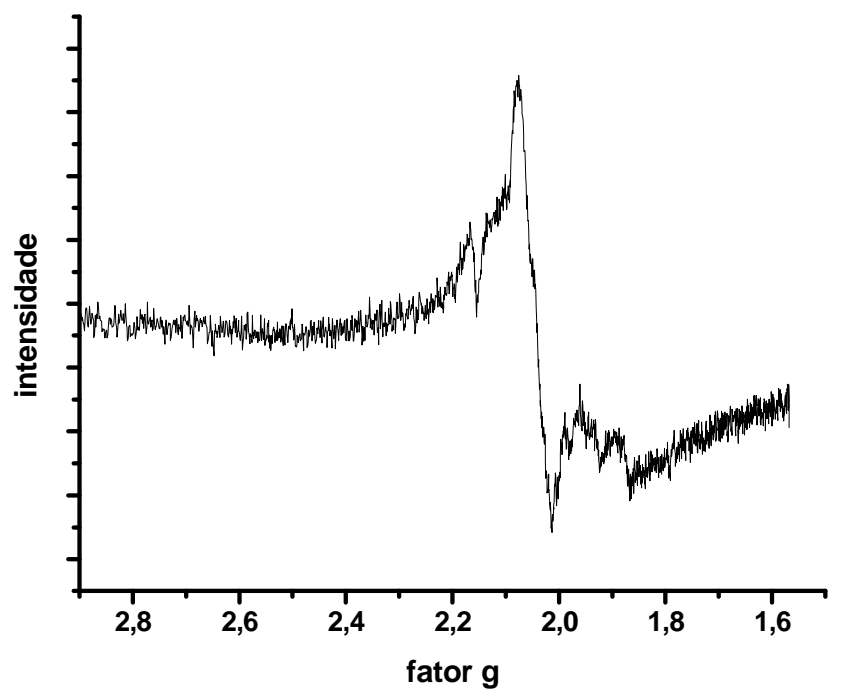

Figura 20 - Espectro de EPR da mistura da L-cisteína, do complexo trans-[RuNO $\left.\left(\mathrm{NH}_{3}\right)_{4} \mathrm{P}(\mathrm{OEt})_{3}\right]\left(\mathrm{PF}_{6}\right)_{3}$ e da metmioglobina. $\mathrm{pH} 7,4 ; \mu=0,2 \mathrm{~mol} \mathrm{~L}^{-1} ; \mathrm{T}=$ $77 \mathrm{~K}$.

Além disto, não foi observado formação do complexo $\mathrm{Mb}-\mathrm{Fe}^{\|} \mathrm{NO}^{+}$devido a baixa concentração de NO produzida nesta condições de pH concordando com os dados cronoamperométricos. Por outro lado, a forma protonada da L-cisteína parece favorecer a formação de $\mathrm{NO}^{0}$ oriundo da reação entre $\mathrm{O}$ nitrosilo trans-[RuNO $\left.\left(\mathrm{NH}_{3}\right)_{4} \mathrm{P}(\mathrm{OEt})_{3}\right]\left(\mathrm{PF}_{6}\right)_{3}$ e a L-cisteína.

Outro ponto importante é verificar se o nitrosilo ferroso $\left(\mathrm{Mb}-\mathrm{Fe}^{11} \mathrm{NO}^{0}\right)$ é formado devido a redução do complexo $\mathrm{Mb}-\mathrm{Fe}{ }^{\prime \prime} \mathrm{NO}^{+}$pela L-cisteína. O nitrosilo ferroso foi obtido por meio da reação da metmioglobina com gás NO em uma solução tampão $\mathrm{pH}=7,4, \mu=0,2 \mathrm{~mol}^{-L^{-1}}$. Não foi observado nenhuma mudança no espectro eletrônico do complexo nitrosônio $\left(\mathrm{Mb}-\mathrm{Fe}^{\prime \prime} \mathrm{NO}^{+}\right)$após a adição do tiol no tempo de escala da reação em estudo (Figura 21). Este experimento reforça o indício de formação de HNO devido a redução em dois elétrons do ligante nitrosônio pela L-cisteína. 


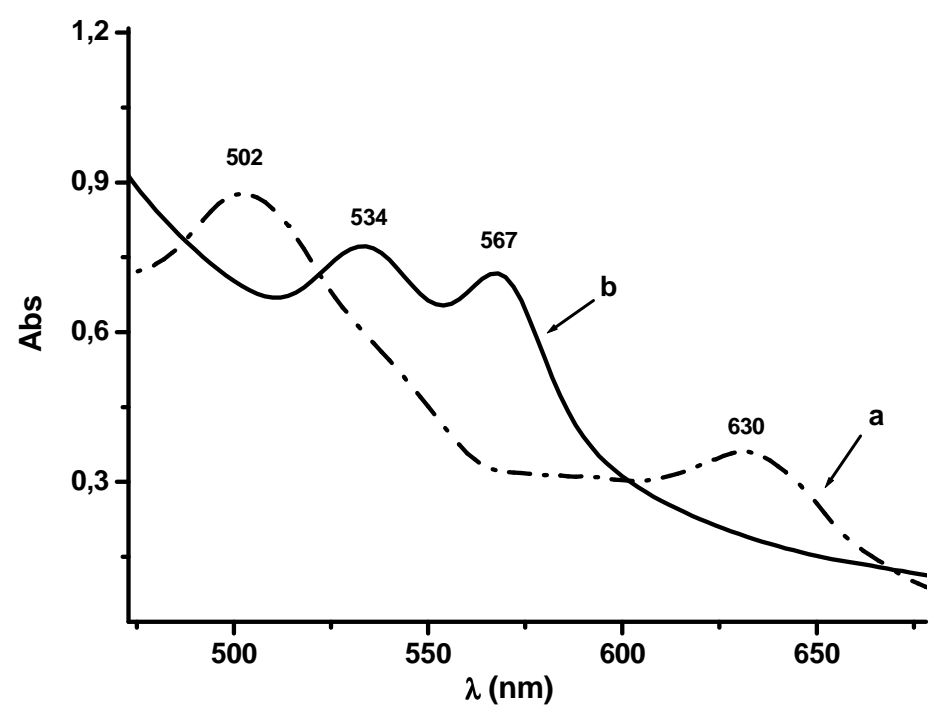

Figura 21 - (a) Espectro eletrônico da metmioglobina. (b) Espectro eletrônico do nitrosilo ferroso $\left(\mathrm{Mb}-\mathrm{Fe}^{\prime \prime} \mathrm{NO}^{0}\right)$ com adição de L-cisteína. Condições: $\mathrm{C}_{\text {metMb }}=3 \times 10^{-5}$ $\mathrm{mol} \mathrm{L}{ }^{-1} ; \mathrm{pH} 7,4 ; \mu=0,2 \mathrm{~mol} \mathrm{~L}^{-1}$. T $=25^{\circ} \mathrm{C}$.

A reação do complexo trans-[RuNO $\left.\left(\mathrm{NH}_{3}\right)_{4} \mathrm{P}(\mathrm{OEt})_{3}\right]\left(\mathrm{PF}_{6}\right)_{3}$ e a L-cisteína também foi monitorada por meio de espectroscopia vibracional na região do infravermelho. A banda em $1923 \mathrm{~cm}^{-1}$ corresponde ao modo vibracional vNO do ligante nitrosônio $\left(\mathrm{NO}^{+}\right)$. A adição da L-cisteína a solução contendo o nitrosil complexo promove imediata diminuição desta banda e o aparecimento de uma banda em $1872 \mathrm{~cm}^{-1}$ (Figura 22 a)provavelmente relativo a dissociação de $\mathrm{NO}^{0} \mathrm{em}$ solução e ocorre também a formação das bandas em 2236 e $2209 \mathrm{~cm}^{-1}$ atribuídas a formação do $\mathrm{N}_{2} \mathrm{O}[77,78]$, produto da dimerização do HNO (Figura 22 b). Este experimento indica, portanto, que a reação entre 0 complexo trans$\left[\mathrm{RuNO}\left(\mathrm{NH}_{3}\right)_{4} \mathrm{P}(\mathrm{OEt})_{3}\right]\left(\mathrm{PF}_{6}\right)_{3}$ e a L-cisteína promove a formação de $\mathrm{NO}^{0}$ e $\mathrm{HNO}$ em solução. 


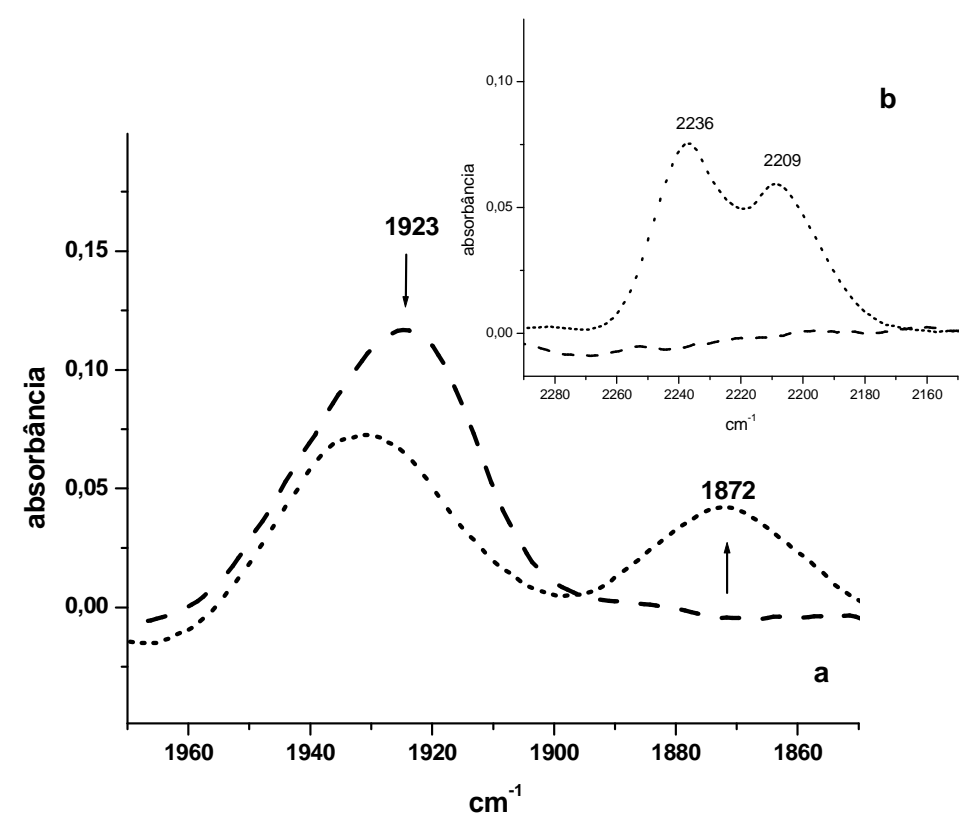

Figura 22 - Espectro vibracional na região do infravermelho da mistura do complexo trans-[RuNO $\left.\left(\mathrm{NH}_{3}\right)_{4} \mathrm{P}(\mathrm{OEt})_{3}\right]\left(\mathrm{PF}_{6}\right)_{3}$ e a L-cisteína. Condições: $\mathrm{C}_{\text {metMb }}=1 \times 10^{-1} \mathrm{~mol} \mathrm{~L}^{-1}$; $\mathrm{pH} 4,5 ; \mu=0,2 \mathrm{~mol} \mathrm{~L}^{-1}$. $\mathrm{T}=25^{\circ} \mathrm{C}$.

Assim, os resultados reportados neste trabalho indicam que o ataque nucleofílico da L-cisteina no ligante nitrosôsio é seguido por sua redução de um ou dois elétrons provocando sua dissociação do centro metálico e oxidando o tiol. A dissociação do $\mathrm{NO}$ e do HNO do centro de coordenação também foi comprovada pela identificação e quantificação do complexo trans-[Ru(NH$\left.\left.)_{3}\right)_{4} \mathrm{P}(\mathrm{OEt})_{3} \mathrm{H}_{2} \mathrm{O}\right]^{+2}$ como produto final da reação entre o nitrosilo trans- $\left[\mathrm{RuNO}\left(\mathrm{NH}_{3}\right)_{4} \mathrm{P}(\mathrm{OEt})_{3}\right]\left(\mathrm{PF}_{6}\right)_{3}$ e a L-cisteína.

$\mathrm{O}$ espectro de ressonância magnética nuclear de ${ }^{31} \mathrm{P}$ da mistura entre $\mathrm{O}$ complexo nitrosilo trans-[RuNO $\left.\left(\mathrm{NH}_{3}\right)_{4} \mathrm{P}(\mathrm{OEt})_{3}\right]\left(\mathrm{PF}_{6}\right)_{3}$ e a L-cisteína em pH ácido $(4,0)$ apresentou apenas um singleto em 148 ppm referente ao ligante trietilfosfito 
coordenado ao composto trans- $\left[\mathrm{Ru}\left(\mathrm{NH}_{3}\right)_{4} \mathrm{P}\left(\mathrm{OC}_{2} \mathrm{H}_{5}\right)_{3}\left(\mathrm{H}_{2} \mathrm{O}\right)\right]^{2+}$ como mostrado na Figura 23 [41].

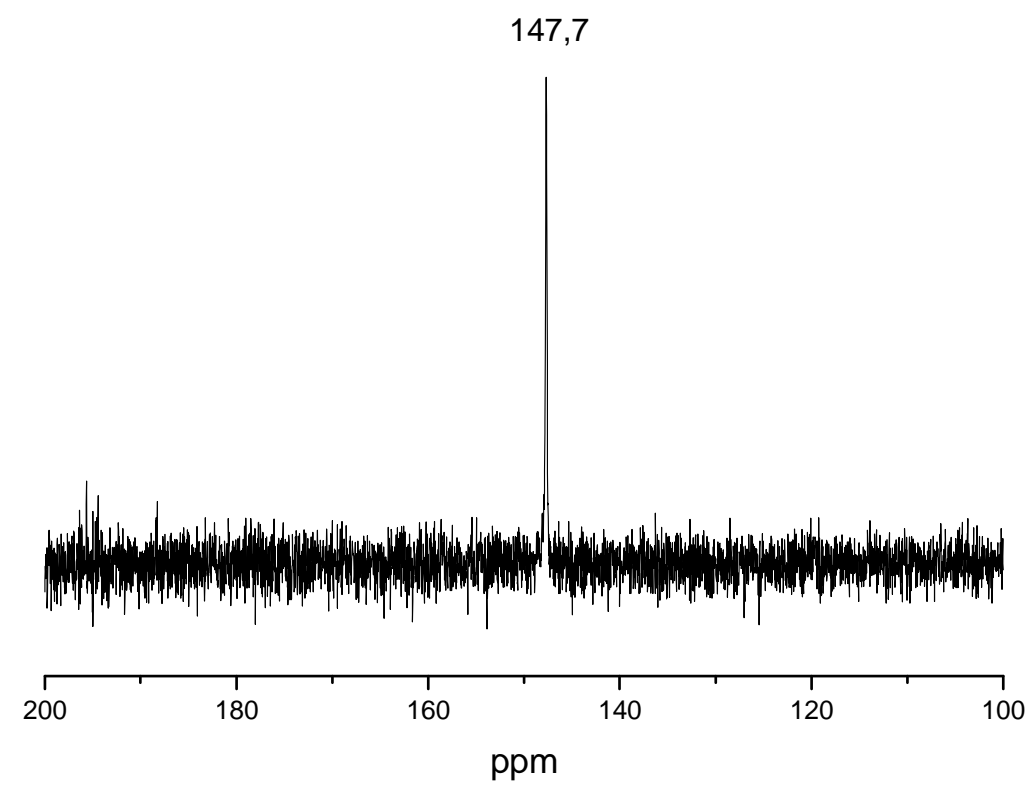

Figura 23 - Espectro de ressonância magnética nuclear de ${ }^{31} \mathrm{P}$ da reação entre o complexo trans-[RuNO $\left.\left(\mathrm{NH}_{3}\right)_{4} \mathrm{P}(\mathrm{OEt})_{3}\right]^{+3}$ e a L-cisteína em $\mathrm{D}_{2} \mathrm{O}(\mathrm{pH}=4,0)$.

Conforme mencionado anteriormente, a identificação do complexo trans- $\left[\mathrm{Ru}\left(\mathrm{NH}_{3}\right)_{4} \mathrm{P}\left(\mathrm{OC}_{2} \mathrm{H}_{5}\right)_{3}\left(\mathrm{H}_{2} \mathrm{O}\right)\right]^{2+}$ também foi realizada por meio de adição de excesso de pirazina (1000x) após a reação entre o nitrosilo e o tiol (10×) entrar em equilíbrio. A mistura entre o aquo complexo e o ligante pz gera o produto trans- $\left[\mathrm{Ru}\left(\mathrm{NH}_{3}\right)_{4} \mathrm{P}\left(\mathrm{OC}_{2} \mathrm{H}_{5}\right)_{3}(\mathrm{pz})\right]^{2+}$ (Equação 21) o qual apresenta uma intensa banda do tipo MLCT centrada em $366 \mathrm{~nm}\left(\varepsilon=4,2 \times 10^{3} \mathrm{~mol}^{-1} \mathrm{~L}^{-1} \mathrm{~cm}^{-1}\right)$ [70] (Figura 24).

trans- $\left[\mathrm{Ru}\left(\mathrm{NH}_{3}\right)_{4} \mathrm{P}(\mathrm{OEt})_{3} \mathrm{H}_{2} \mathrm{O}\right]^{2+}+\mathrm{pz} \rightleftharpoons$ trans- $\left[\mathrm{Ru}\left(\mathrm{NH}_{3}\right)_{4} \mathrm{P}(\mathrm{OEt})_{3} \mathrm{pz}\right]^{2+}+\mathrm{H}_{2} \mathrm{O}$ 


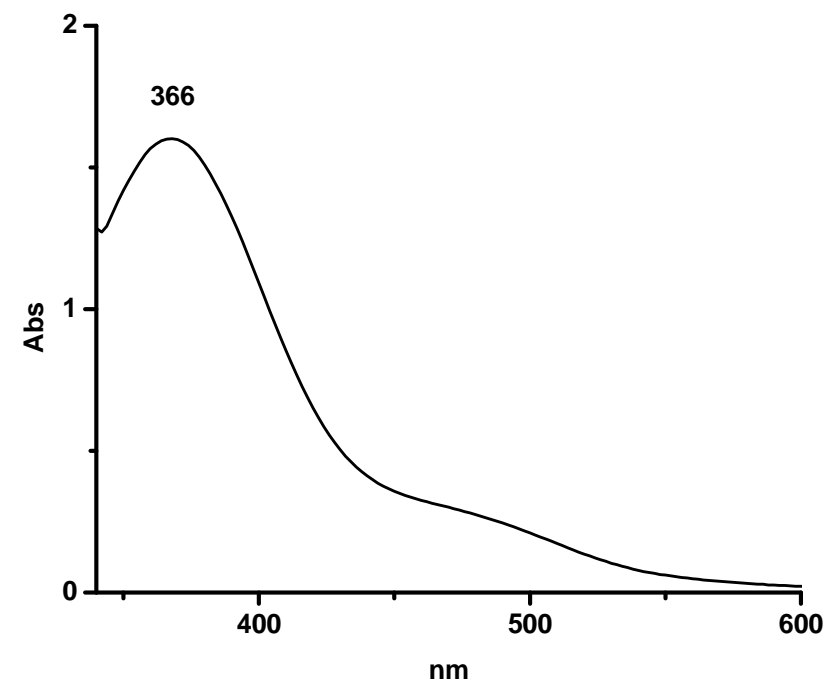

Figura $24-$ Espectro eletrônico da mistura das espécies trans-[Ru $\left.\left(\mathrm{NH}_{3}\right)_{4} \mathrm{P}(\mathrm{OEt})_{3} \mathrm{NO}\right]^{3+}\left(5,0 \times 10^{-4} \mathrm{~mol}^{-1} \mathrm{~L}^{-1}\right)$, L-cisteína $\left(5,0 \times 10^{-3} \mathrm{~mol} \mathrm{~L}^{-1}\right)$ e pirazina $\left(5,0 \times 10^{-1} \mathrm{~mol} \mathrm{~L}^{-1} \mathrm{~mol} \mathrm{~L}^{-1}\right) . \mathrm{T}=25^{\circ} \mathrm{C}$.

Por meio da formação deste complexo em solução foi possível quantificar a formação do complexo trans- $\left[\mathrm{Ru}\left(\mathrm{NH}_{3}\right)_{4} \mathrm{P}\left(\mathrm{OC}_{2} \mathrm{H}_{5}\right)_{3}\left(\mathrm{H}_{2} \mathrm{O}\right)\right]^{2+}$ o qual apresentou conversão quantitativa nas condições de $\mathrm{pH}=4,0$. Nesta mesmas condições a evolução de NO foi de $95 \%$ de conversão indicando, portanto, uma dissociação completa do óxido nítrico da esfera de coordenação.

Medidas de voltametria cíclica da mistura do complexo trans- $\left[\mathrm{Ru}\left(\mathrm{NH}_{3}\right)_{4} \mathrm{P}(\mathrm{OEt})_{3} \mathrm{NO}\right]^{3+}\left(5,0 \times 10^{-4} \mathrm{~mol}^{-\mathrm{L}^{-1}}\right)$ e da L-cisteína $\left(5,0 \times 10^{-3} \mathrm{~mol}^{-1} \mathrm{~L}^{-1}\right)$ em $\mathrm{pH} 4,0$ indicaram diminuição do processo em $-0,108 \mathrm{~V} v s \mathrm{ECS}$ referente ao par redox $\mathrm{RuNO}^{+} / \mathrm{RuNO}^{0}$ e aumento do processo em $0,52 \mathrm{VvsECS}$ referente a formação do complexo trans- $\left[\mathrm{Ru}\left(\mathrm{NH}_{3}\right)_{4} \mathrm{P}\left(\mathrm{OC}_{2} \mathrm{H}_{5}\right)_{3}\left(\mathrm{H}_{2} \mathrm{O}\right)\right]^{2+}$ (Figura 25) [41]. 


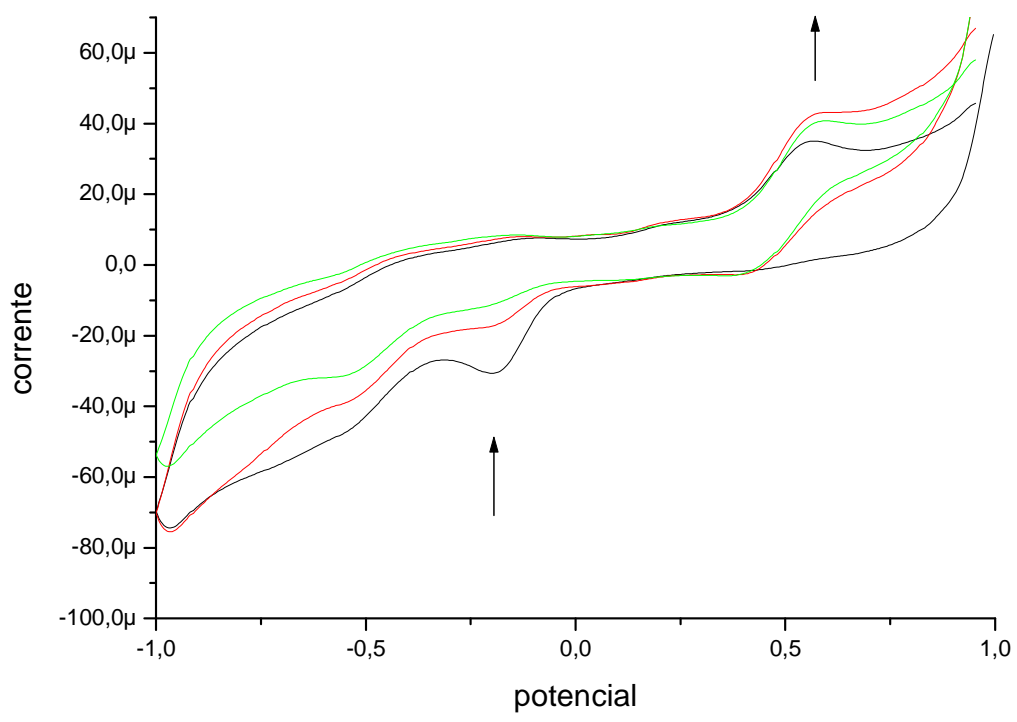

Figura 25: Voltamogramas cíclicos referente a mistura entre o complexo rutênio $t$ $\left[\mathrm{Ru}\left(\mathrm{NH}_{3}\right)_{4} \mathrm{P}(\mathrm{OEt})_{3} \mathrm{NO}\right]^{+3}$ e a L-cisteína em pH 4,0 e $\mu=0,2 \mathrm{M}$. T $=25^{\circ} \mathrm{C}$.

A identificação da cistina também comprovou a reação redox entre a cisteína e os nitrosilos complexos. Experimentos em $\mathrm{pH} 4,0$, utilizando cromatografia líquida acoplada a detector de massa (HPLC/MS/MS), permitiu a identificação e quantificação de cistina como produto da reação entre trans-[RuNO(NH$\left.\left.{ }_{3}\right)_{4} \mathrm{P}(\mathrm{OEt})_{3}\right]^{+3}$ e a L-cisteína. Considerando a razão massa/carga $(\mathrm{m} / \mathrm{z}=241)$ da cistina, foi realizada uma curva de calibração utilizando solução de cistina em diferentes concentrações no mesmo pH da reação entre o complexo nitrosilado e a L-cisteína. Para uma solução contendo $1,0 \times 10^{-4}$ mol $\mathrm{L}^{-1}$ do complexo trans-[RuNO $\left.\left(\mathrm{NH}_{3}\right)_{4} \mathrm{P}(\mathrm{OEt})_{3}\right]\left(\mathrm{PF}_{6}\right)_{3}$ e $2,0 \times 10^{-4}$ mol. L ${ }^{-1}$ de L-cisteína, a concentração de cistina calcula foi de $3 \times 10^{-5} \mathrm{~mol} \mathrm{~L}^{-1}$ similar ao encontrado para o $\mathrm{NO}^{0}$ nas mesmas condições experimentais. 


\subsection{Aspectos ligados a cinética da reação entre 0 complexo trans-[RuNO $\left.\left(\mathrm{NH}_{3}\right)_{4} \mathrm{P}(\mathrm{OEt})_{3}\right]\left(\mathrm{PF}_{6}\right)_{3}$ e a L-cisteína}

A reação entre o complexo trans-[RuNO $\left.\left(\mathrm{NH}_{3}\right)_{4} \mathrm{P}(\mathrm{OEt})_{3}\right]\left(\mathrm{PF}_{6}\right)_{3}$ e a L-cisteína foi monitorada por espectrofotometria na região do UV-Vis, utilizando a técnica de stopped flow. Observou-se uma banda centrada em 455 nm (Figura 26a) a qual, por analogia a sistemas similares[65, 71], foi atribuída a formação da espécie trans-[Ru(NH$\left.)_{3} \mathrm{P}(\mathrm{OEt})_{3} \mathrm{~N}(\mathrm{O}) \mathrm{SR}\right]^{\mathrm{n}-1} \quad$ (Apêndice, Figura 3A). Esta espécie seria formada, em uma escala de tempo de milisegundos, por meio da interação do enxofre da L-cisteína com o nitrogênio do ligante nitrosônio [71](Equação 22). Conforme se observa na Figura 26b, a curva obtida pela variação de absorbância a 455nm em função do tempo apresenta um traçado bem definido.

$$
\operatorname{trans}-\left[\mathrm{RuNO}\left(\mathrm{NH}_{3}\right)_{4} \mathrm{LP}(\mathrm{OEt})_{3}\right]^{+3}+\mathrm{RS}^{-} \frac{\mathrm{k}_{1}}{\frac{\mathrm{k}_{-1}}{二}} \operatorname{trans}-\left[\mathrm{Ru}\left(\mathrm{NH}_{3}\right)_{4}\left(\mathrm{P}(\mathrm{OEt})_{3} \mathrm{~N}(\mathrm{O}) \mathrm{SR}\right]^{\mathrm{n}-1}\right.
$$

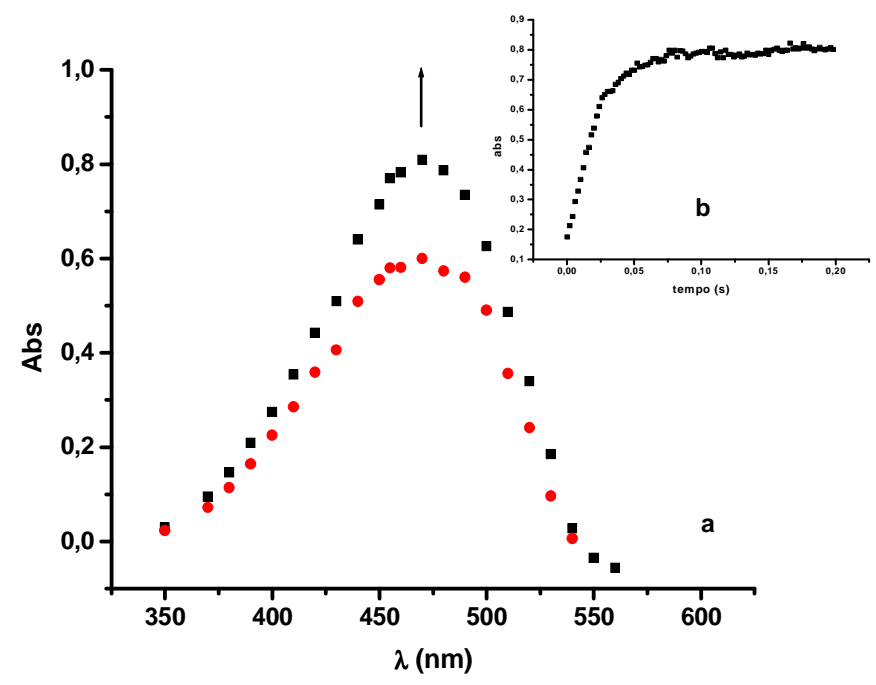

Figura 26 - a) Espectro obtido utilizando stopped flow para a solução resultante da mistura do complexo trans-[RuNO $\left.\left(\mathrm{NH}_{3}\right)_{4} \mathrm{P}(\mathrm{OEt})_{3}\right]^{+3}\left(5,0 \times 10^{-4} \mathrm{~mol}^{-\mathrm{L}^{-1}}\right)$ e a L-cisteína $\left(4,0 \times 10^{-3} \mathrm{~mol} \mathrm{~L}^{-1}\right)$. b) Variação de absorbância a $455 \mathrm{~nm}$ para a mistura do complexo trans-[RuNO $\left.\left(\mathrm{NH}_{3}\right)_{4} \mathrm{P}(\mathrm{OEt})_{3}\right]^{+3}$ e a L-cisteína. Condições: $\mathrm{pH}=3,0$ e $\mu=0,2 \mathrm{~mol} \mathrm{~L}^{-1}$. - $\mathrm{t}=20 \mathrm{~ms} \quad \mathrm{t}=40 \mathrm{~ms}$. $\mathrm{T}=25^{\circ} \mathrm{C}$. 
A partir dos gráficos $\ln \left(A_{\text {inf }}-A_{t}\right)$ em função do tempo (s), foram calculados os valores de $\mathrm{k}_{\mathrm{obs}}$ para várias concentrações de L-cisteína. A Figura 27 ilustra um exemplo de gráfico para determinação de $\mathrm{k}_{\mathrm{obs}}$ correspondente a Figura 26 b.

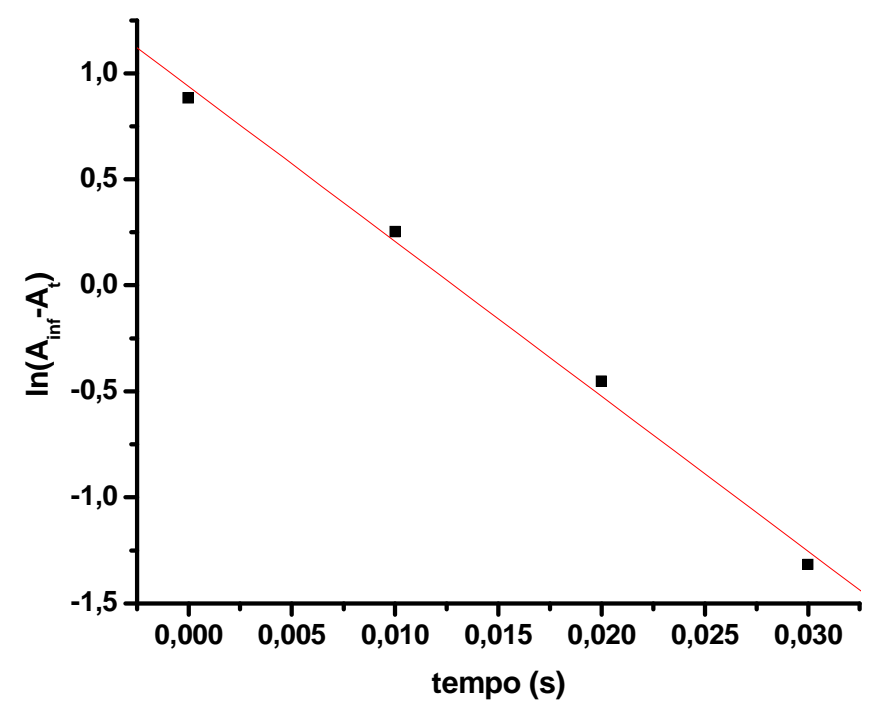

Figura 27 - $\ln \left(A_{\text {inf }}-A_{t}\right)$ em função do tempo (s) para a reação entre complexo trans-[RuNO $\left.\left(\mathrm{NH}_{3}\right)_{4} \mathrm{P}(\mathrm{OEt})_{3}\right]^{+3}$ e a L-cisteína. Condições: $\mathrm{pH}=3,0$ e $\mu=0,2 \mathrm{~mol} \mathrm{~L}^{-1}$. $\mathrm{C}_{\mathrm{Ru}}=5,0 \times 10^{-4} \mathrm{~mol} \mathrm{~L}^{-1} ; \mathrm{C}_{\text {cis }}=4,0 \times 10^{-3} \mathrm{~mol} \mathrm{~L}^{-1} ;$ onde $\mathrm{C}_{\text {cis }}=\left[\mathrm{RS}^{-}\right]+[\mathrm{RSH}] . \mathrm{T}=25^{\circ} \mathrm{C}$.

A Figura 28 apresenta uma relação linear entre os valores de $k_{\text {obs }}$ e a concentração de L-cisteína. Por meio da análise desta reta, segundo a equação $\mathrm{k}_{\mathrm{obs}}$ $=\mathrm{k}_{1} \mathrm{C}_{\text {cis }}+\mathrm{k}_{-1}$, foram calculados os valores para as constantes de velocidades específica $k_{1}$ e $k_{-1}$ para a formação da espécie trans-[Ru( $\left.\left(\mathrm{NH}_{3}\right)_{4} \mathrm{P}(\mathrm{OEt})_{3} \mathrm{~N}(\mathrm{O}) \mathrm{SR}\right]^{\mathrm{n}-1}$ (Equação 22). 


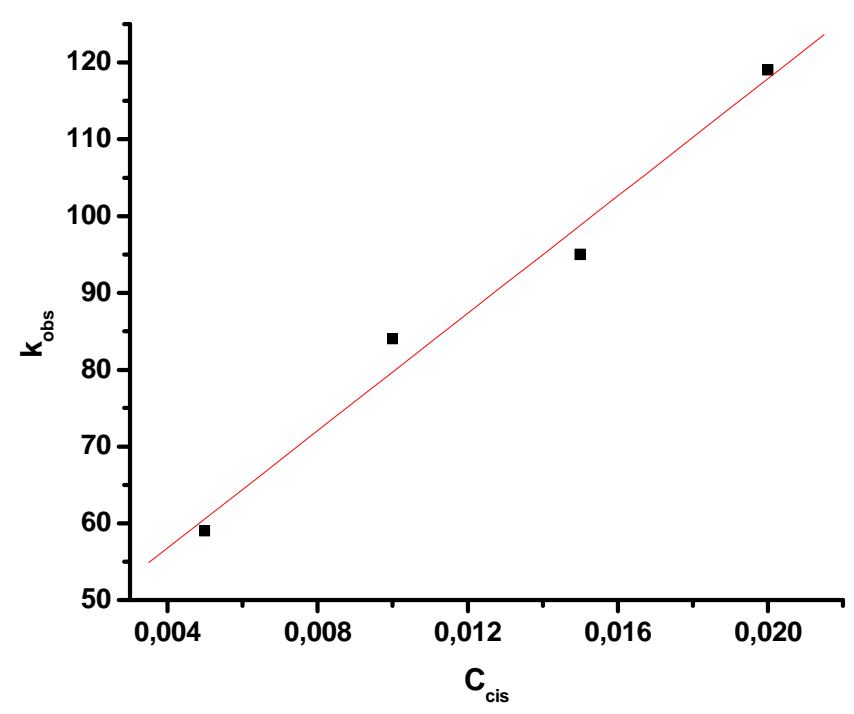

Figura 28 - Dependência de $\mathrm{k}_{\mathrm{obs}}$ em função de concentração de L-cisteína. $\mathrm{pH}$ = 3,$5 ; \mu=0,2 \mathrm{~mol} \mathrm{~L}^{-1} . \mathrm{T}=25^{\circ} \mathrm{C}$.

Foi observado que o valor numérico de $k_{1}$ para formação da espécie trans-[Ru( $\left.\left(\mathrm{NH}_{3}\right)_{4} \mathrm{P}(\mathrm{OEt})_{3} \mathrm{~N}(\mathrm{O}) \mathrm{SR}\right]^{\mathrm{n}-1}$ aumenta com a diminuição da concentração hidrogeniônica, $7,2 \times 10^{2} \mathrm{~mol}^{-1} \mathrm{Ls}^{-1} \mathrm{em} \mathrm{pH}=3,0$ e $3,5 \times 10^{3} \mathrm{~mol}^{-1} \mathrm{Ls}^{-1} \mathrm{em} \mathrm{pH}=3,5$. Esta dependência da constante de velocidade específica com o pH é esperada[71] e deve estar relacionada ao equilíbrio das espécies protonada (RSH) e desprotonada (RS') da cisteína (equação 23).

$$
\begin{aligned}
& \mathrm{RSH} \rightleftharpoons \mathrm{RS}^{-}+\mathrm{H}^{+} \quad \mathrm{K}_{\mathrm{a}}
\end{aligned}
$$

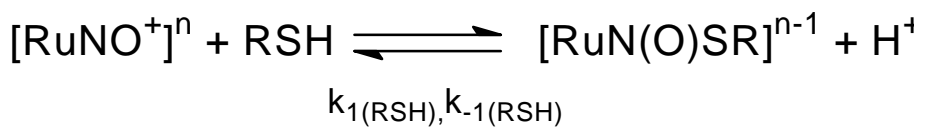

$$
\begin{aligned}
& {\left[\mathrm{RuNO}^{+}\right]^{\mathrm{n}}+\mathrm{RS}^{-} \underset{\mathrm{k}_{1\left(\mathrm{RS}^{-}\right), \mathrm{k}_{-1\left(\mathrm{RS}^{-}\right)}}^{\rightleftharpoons}}{\rightleftharpoons}[\mathrm{RuN}(\mathrm{O}) \mathrm{SR}]^{\mathrm{n}-1}} \\
& \mathrm{k}_{\mathrm{i}}=\frac{\mathrm{k}_{1\left(\mathrm{RS}^{-}\right)} \mathrm{k}_{\mathrm{a}}+\mathrm{k}_{1(\mathrm{RSH})}\left[\mathrm{H}^{+}\right]}{\mathrm{k}_{\mathrm{a}}+\left[\mathrm{H}^{+}\right]} \\
& \mathrm{k}_{-1}=\mathrm{k}_{-1(\mathrm{RS}-)}+\mathrm{k}_{-1(\mathrm{RSH})}\left[\mathrm{H}^{+}\right]
\end{aligned}
$$


Segundo a literatura[71], a reação de complexos nitrosilados com a L-cisteína desprotonada é mais favorável visto que esta espécie é um nucleófilo mais forte comparado a forma protonada, RSH (Equação 24 e 25). Os valores de $k_{1}\left(1,7 \times 10^{7}\right.$ $\left.\mathrm{mol}^{-1} \mathrm{~L} \mathrm{~s}^{-1}\right)$ e $\mathrm{k}_{-1}\left(47 \mathrm{~s}^{-1}\right)$ para a interação do complexo trans-[RuNO $\left.\left(\mathrm{NH}_{3}\right)_{4} \mathrm{P}(\mathrm{OEt})_{3}\right]^{+3}$

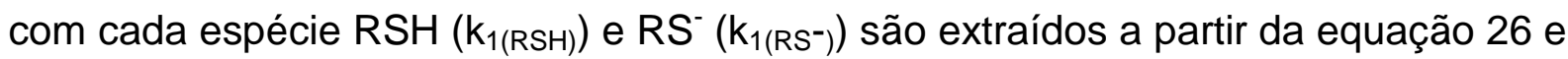
27 em que uma relação linear pode ser obtido em um gráfico de valores de $k_{1}$ versus $1 /\left[H^{+}\right][71]$.

Após a rápida formação da banda centrada em $455 \mathrm{~nm}$ devido a geração da espécie trans-[Ru( $\left.\left.\mathrm{NH}_{3}\right)_{4} \mathrm{P}(\mathrm{OEt})_{3} \mathrm{~N}(\mathrm{O}) \mathrm{SR}\right]^{\mathrm{n}-1}$, nota-se seu decréscimo e o simultâneo aumento de uma banda em $316 \mathrm{~nm}$ (Figura 29 a) com um ponto isosbéstico em 418nm. Existe uma considerável diferença de escalas de tempo em que ocorrem estas duas etapas da reação sendo possível monitorar o decréscimo de absorbância em 455 e aumento a $316 \mathrm{~nm}$, utilizando espectrofotometria UV-visível convencional (Figura 29 b).

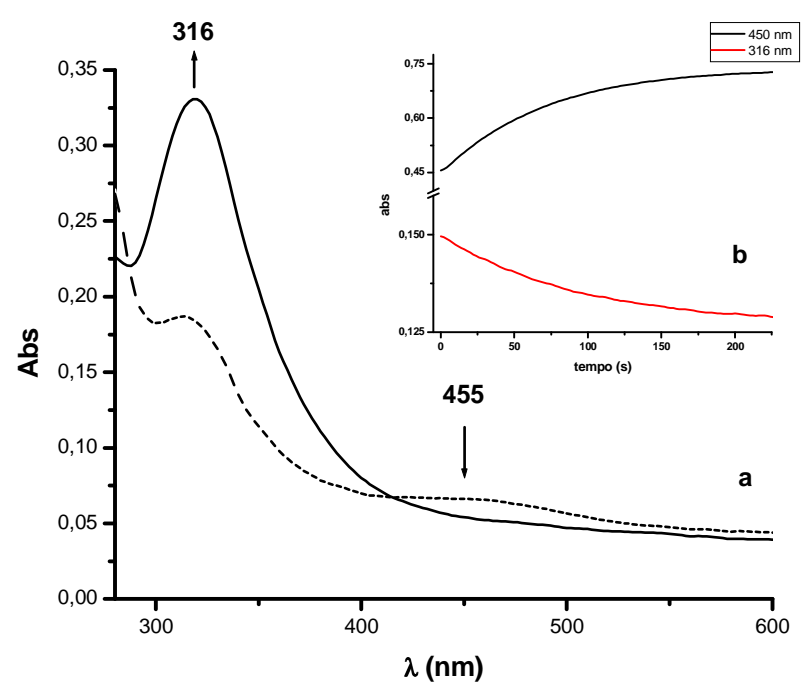

Figura 29 - a) Variações dos espectros para a reação entre o complexo trans-[RuNO $\left.\left(\mathrm{NH}_{3}\right)_{4} \mathrm{P}(\mathrm{OEt})_{3}\right]^{+3}$ e a L-cisteína b) Variações de absorbância nos comprimentos de onda 450 e $316 \mathrm{~nm}$ em função do tempo (s). Condições: $\mathrm{C}_{\mathrm{Ru}}=$ $5,0 \times 10^{-4} \mathrm{~mol} \mathrm{~L}^{-1} ; \mathrm{C}_{\text {cis }}=5,0 \times 10^{-4} \mathrm{~mol} \mathrm{~L}^{-1} ; \mathrm{pH}=2,0 ; \mu=0,2 \mathrm{~mol} \mathrm{~L}^{-1} ; \mathrm{T}=25^{\circ} \mathrm{C}$. 
Os valores numéricos para as constantes de velocidade $\mathrm{k}_{\mathrm{obs}}$, calculados a partir dos gráficos $\ln \left(A_{\text {inf }}-A_{t}\right)$ em função de $t(s)$, estão reunidas na Tabela 6 para 0 $\mathrm{pH} 2,0$. Podemos observar que os valores calculados para estas constantes, nos dois comprimentos de onda, não apresentam diferenças significativas sugerindo a inexistência de reações paralelas nestas condições experimentais. Foi observado também que os valores de $\mathrm{k}_{\mathrm{obs}}$ variam com a concentração de L-cisteína e que a absorbância a $316 \mathrm{~nm}$ corresponde a formação de trans- $\left[\mathrm{Ru}\left(\mathrm{NH}_{3}\right)_{4} \mathrm{P}(\mathrm{OEt})_{3} \mathrm{H}_{2} \mathrm{O}\right]^{+2}$. Este aquo complexo foi identificado por $\operatorname{RMN}{ }^{31} \mathrm{P}(\delta=148 \mathrm{ppm})$ e pela formação do complexo trans-[Ru(NH$\left.)_{3} \mathrm{P}(\mathrm{OEt})_{3} \mathrm{pz}\right]^{+2}$ na presença do ligante pirazina $(\mathrm{pz})$.

Tabela 6 - Valores de kobs em função da concentração de cisteína

\begin{tabular}{ccc}
\hline $\mathrm{C}_{\text {cis }}\left(\mathrm{molL}^{-1}\right)$ & $\mathrm{k}_{\text {obs }}\left(\mathrm{s}^{-1}\right)$ & $\mathrm{k}_{\text {obs }}\left(\mathrm{s}^{-1}\right)$ \\
& $(316 \mathrm{~nm})$ & $(450)$ \\
\hline $2,0 \times 10^{-2}$ & $1,2 \times 10^{-2}$ & $1,0 \times 10^{-2}$ \\
$1,5 \times 10^{-2}$ & $7,0 \times 10^{-3}$ & $7,0 \times 10^{-3}$ \\
$1,0 \times 10^{-2}$ & $5,0 \times 10^{-3}$ & $6,0 \times 10^{-3}$ \\
$0,5 \times 10^{-2}$ & $3,0 \times 10^{-3}$ & $3,0 \times 10^{-3}$ \\
a) reação realizada em pH 2,0; $\mu=0,2 \mathrm{~mol} \mathrm{~L}^{-1} \mathrm{~T}=25^{\circ} \mathrm{C}$
\end{tabular}

Por meio do gráfico $\mathrm{k}_{\mathrm{obs}}$ versus $\mathrm{C}_{\mathrm{cis}}$, foram calculadas as constantes de velocidade específica direta $\mathrm{k}_{2}\left(4,4 \times 10^{-1} \mathrm{~mol}^{-1} \mathrm{Ls}^{-1}\right)$ e reversa $\mathrm{k}_{-2}\left(1,0 \times 10^{-3} \mathrm{~s}^{-1}\right)$ (Figura 30). 


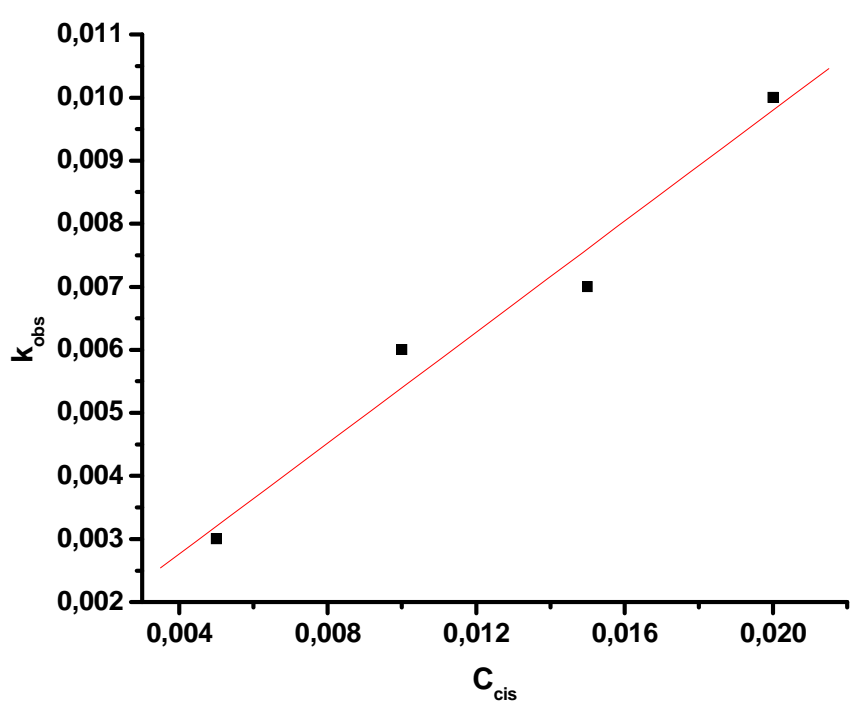

Figura 30 - Dependência de $\mathrm{k}_{\mathrm{obs}}$ em função de concentração de L-cisteína. Condições: (455nm) pH 2,0 $\mu=0,2 \mathrm{~mol} \mathrm{~L}^{-1} ; \mathrm{T}=25^{\circ} \mathrm{C}$.

A dependência da constante $k_{2}$, a uma mesma concentração hidrogeniônica, com a concentração da L-cisteína sugere interação deste tiol com a espécie trans-[Ru(NH$\left.\left.)_{3}\right)_{4} \mathrm{P}(\mathrm{OEt})_{3} \mathrm{~N}(\mathrm{O}) \mathrm{SR}\right]^{\mathrm{n}-1} \quad$ (Equação 28). Também foi observado a dependência de $\mathrm{k}_{2}$ em relação ao pH do meio, como observado na Figura 31, sugerindo que a interação da trans-[Ru( $\left.\left(\mathrm{NH}_{3}\right)_{4} \mathrm{P}(\mathrm{OEt})_{3} \mathrm{~N}(\mathrm{O}) \mathrm{SR}\right]^{\mathrm{n}-1}$ com a L-cisteína desprotonada é mais favorável (Equação 28).

$$
\begin{aligned}
& t-\left[\mathrm{Ru}\left(\mathrm{NH}_{3}\right)_{4} \mathrm{P}(\mathrm{OEt})_{3} \mathrm{~N}(\mathrm{O}) \mathrm{SR}\right]^{(\mathrm{n}-1)}+\mathrm{RS}^{-} \frac{\mathrm{k}_{2}}{\mathrm{k}_{-2}} t-\left[\mathrm{Ru}\left(\mathrm{NH}_{3}\right)_{4} \mathrm{P}(\mathrm{OEt})_{3} \mathrm{~N}(\mathrm{O})(\mathrm{SR})_{2}\right]^{(\mathrm{n}-2)} \\
& t-\left[\mathrm{Ru}\left(\mathrm{NH}_{3}\right)_{4} \mathrm{P}(\mathrm{OEt})_{3} \mathrm{~N}(\mathrm{O})(\mathrm{SR})_{2}\right]^{(\mathrm{n}-2)} \longrightarrow t-\left[\mathrm{Ru}\left(\mathrm{NH}_{3}\right)_{4} \mathrm{P}(\mathrm{OEt})_{3} \mathrm{NO}^{0}\right]^{+2}+\mathrm{RSSR}^{\bullet}
\end{aligned}
$$




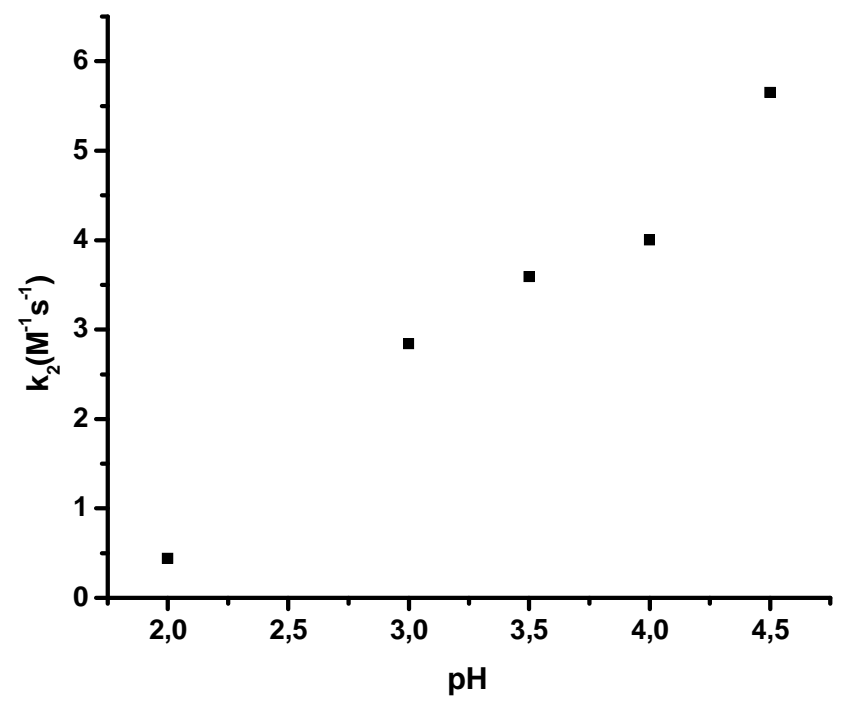

Figura 31 - Valores de $\mathrm{k}_{2}$ versus $\mathrm{pH}$ para a reação entre o complexo trans-[Ru( $\left.\left(\mathrm{NH}_{3}\right)_{4} \mathrm{P}(\mathrm{OEt})_{3} \mathrm{NO}\right]^{+3}$ e a L-cisteína; $\mu=0,2 \mathrm{~mol} \mathrm{~L}^{-1} . \mathrm{T}=25^{\circ} \mathrm{C}$.

Após a formação do complexo trans-[Ru( $\left.\left.\mathrm{NH}_{3}\right)_{4} \mathrm{P}(\mathrm{OEt})_{3} \mathrm{NO}^{0}\right]^{+2}$ (Equação 8), podem ocorrer a dissociação do NO da esfera de coordenação como observado por medidas cronoamperométrica (equação 30).

$$
\text { trans- } \left.\left[\mathrm{Ru}\left(\mathrm{NH}_{3}\right)_{4} \mathrm{P}(\mathrm{OEt})_{3} \mathrm{NO}^{0}\right]^{+2}+\mathrm{H}_{2} \mathrm{O} \stackrel{\mathrm{k}_{-\mathrm{NO}}}{\longrightarrow} \text { trans-[Ru(}\left(\mathrm{NH}_{3}\right)_{4} \mathrm{P}(\mathrm{OEt})_{3} \mathrm{H}_{2} \mathrm{O}\right]^{+2}+\mathrm{NO}^{0}
$$

A dissociação do $\mathrm{NO}$ do fragmento trans-[Ru(NH$\left.)_{3} \mathrm{P}(\mathrm{OEt})_{3}\right]^{+2}$ apresenta uma constante de velocidade específica igual a $0,98 \mathrm{~s}^{-1}$ [41], superior aos valores de constante de velocidade reunidos na Tabela 2. Este fato sugere que a etapa lenta nestas condições experimentais $(\mathrm{pH} 2,0)$, onde $\mathrm{C}_{\mathrm{RS}}{ }^{-}<\mathrm{C}_{\mathrm{Ru}}$, corresponde a equação 28. O espectro eletrônico final obtido para a solução onde ocorre a reação é similar ao espectro do complexo trans-[Ru( $\left.\left(\mathrm{NH}_{3}\right)_{4} \mathrm{P}(\mathrm{OEt})_{3} \mathrm{H}_{2} \mathrm{O}\right]^{+2}$ corroborando com a reação da Equação 30. 
$\mathrm{O}$ aumento dos valores numérico de $\mathrm{k}_{2} \mathrm{o}$ qual expressa o desaparecimento da espécie trans-[Ru( $\left.\left(\mathrm{NH}_{3}\right)_{4} \mathrm{P}(\mathrm{OEt})_{3} \mathrm{~N}(\mathrm{O}) \mathrm{SR}\right]^{\mathrm{n}-1}$ com o $\mathrm{pH}$ do meio esta de acordo com o aumento de concentração de NO no meio na faixa de $\mathrm{pH}$ 2,0-4,0 (Figura 18) e, portanto, indicando aumento da produção do complexo trans$\left[\mathrm{Ru}\left(\mathrm{NH}_{3}\right)_{4} \mathrm{P}(\mathrm{OEt})_{3} \mathrm{NO}^{0}\right]^{+2}$ (Equação 30). Em pH =4,0, atinge-se o máximo de produção de $\mathrm{NO}$ e de formação do complexo trans-[Ru( $\left.\left(\mathrm{NH}_{3}\right)_{4} \mathrm{P}(\mathrm{OEt})_{3} \mathrm{H}_{2} \mathrm{O}\right]^{+2}$. Porém, em soluções cujo valores de pH estão acima de 4,0, a concentração de NO formado diminui conforme se observa na Figura 18. Além disto, foi detectado formação de HNO em pH 7,4 sugerindo que outra reação possa estar ocorrendo. Em condições de $\mathrm{pH} \geq 3,0$, a banda centrada em $316 \mathrm{~nm}$ sofre um deslocamento para $320 \mathrm{~nm}$ com simultâneo diminuição da banda em 455 nm(Figura 32).

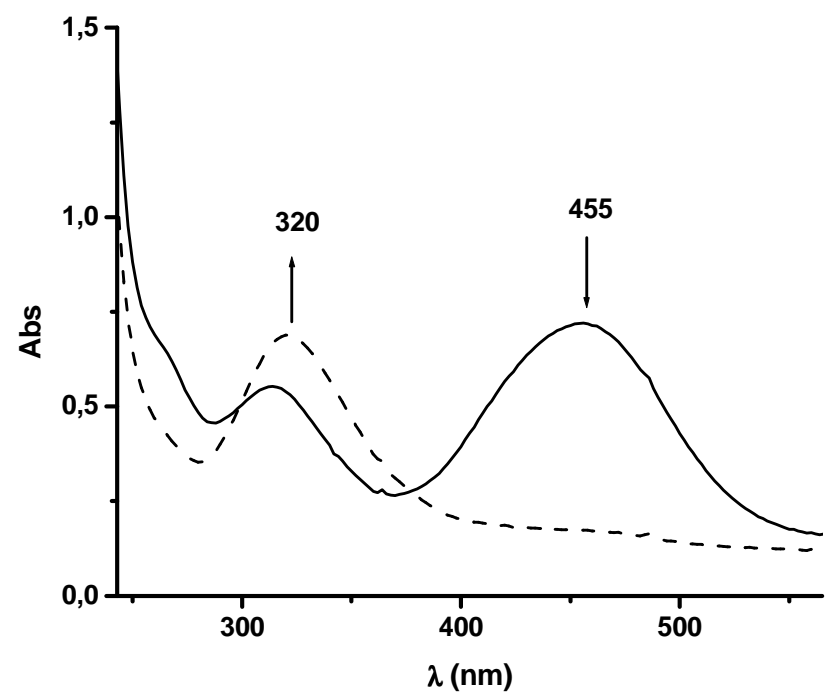

Figura 32 - Variações dos espectros da reação entre 0 complexo trans- $\left[\mathrm{RuNO}\left(\mathrm{NH}_{3}\right)_{4} \mathrm{P}(\mathrm{OEt})_{3}\right]^{+3}$ e a cisteína em $\mathrm{pH}=4,5 . \mathrm{C}_{\mathrm{Ru}}=5 \times 10^{-4} \mathrm{~mol} \mathrm{~L}^{-1}$; $\mathrm{C}_{\mathrm{RS}}=5 \times 10^{-4} \mathrm{~mol} \mathrm{~L}^{-1} ; \mu=0,2 \mathrm{~mol} \mathrm{~L}^{-1} ; \mathrm{T}=25^{\circ} \mathrm{C}$.

O conjunto de resultados sugere que ocorre primeiro a decomposição da espécie trans-[Ru( $\left.\left(\mathrm{NH}_{3}\right)_{4} \mathrm{P}(\mathrm{OEt})_{3} \mathrm{~N}(\mathrm{O}) \mathrm{SR}\right]^{\mathrm{n}-1}$ formando 0 complexo 
trans- $\left[\mathrm{Ru}\left(\mathrm{NH}_{3}\right)_{4} \mathrm{P}(\mathrm{OEt})_{3} \mathrm{NO}^{0}\right]^{+2}$, e que o mesmo pode interagir com $\mathrm{RS}^{-}$, sofrendo transferência eletrônica e gerando HNO (equações 31 e 32).

$$
\begin{aligned}
& \text { trans-[Ru(NH} \left.\left.)_{4} \mathrm{P}(\mathrm{OEt})_{3} \mathrm{NO}^{0}\right)\right]^{+2}+\mathrm{RS}^{-} \rightleftharpoons \operatorname{trans}-\left[\mathrm{Ru}\left(\mathrm{NH}_{3}\right)_{4} \mathrm{P}(\mathrm{OEt})_{3} \mathrm{~N}(\mathrm{O}) \mathrm{SR}\right]^{\mathrm{n}-2} \\
& \left.\operatorname{trans}-\left[\mathrm{Ru}\left(\mathrm{NH}_{3}\right)_{4} \mathrm{P}(\mathrm{OEt})_{3} \mathrm{~N}(\mathrm{O}) \mathrm{SR}\right]^{\mathrm{n}-2} \longrightarrow \operatorname{trans}-\left[\mathrm{Ru}\left(\mathrm{NH}_{3}\right)_{4} \mathrm{P}(\mathrm{OEt})_{3} \mathrm{H}_{2} \mathrm{O}\right)\right]^{+2}+\mathrm{HNO}+\mathrm{RS}
\end{aligned}
$$

Isto torna-se evidente em condições onde $\mathrm{C}_{\mathrm{H}}+>1,0 \times 10^{-4} \mathrm{molL}^{-1}$; em que a concentração de equilíbrio de $\mathrm{RS}^{-}$é inferior a do complexo metálico. À medida que diminui a concentração hidrgeniônica, aumenta a [RS] e, portanto, a associação da segunda L-cisteína com o complexo trans- $\left[\mathrm{Ru}\left(\mathrm{NH}_{3}\right)_{4} \mathrm{P}(\mathrm{OEt})_{3} \mathrm{NO}^{0}\right]^{+2}$ formando a espécie trans-[Ru(NH$\left.\left.)_{3}\right)_{4} \mathrm{P}(\mathrm{OEt})_{3} \mathrm{~N}(\mathrm{O}) \mathrm{SR}\right]^{\mathrm{n}-2}$ (Equação 31) torna-se competitivo com a reação 30.

A conseqüência da formação do complexo trans-[Ru(NH$\left.)_{3} \mathrm{P}(\mathrm{OEt})_{3} \mathrm{~N}(\mathrm{O}) \mathrm{SR}\right]^{\mathrm{n}-2}$ é uma menor concentração de NO livre no meio como evidenciado na Figura 18. Foi observado também que o aumento de excesso de concentração de equilíbrio de L-cisteína também diminui a concentração de NO livre.

Após a formação da espécie trans-[Ru(NH$\left.)_{4} \mathrm{P}(\mathrm{OEt})_{3} \mathrm{~N}(\mathrm{O}) \mathrm{SR}\right]^{\mathrm{n}-2}$, foi observado sua decomposição por meio do monitoramento da banda em 320nm o qual apresenta diminuição de absorbânia e deslocamento para 316nm (Figura 33). 


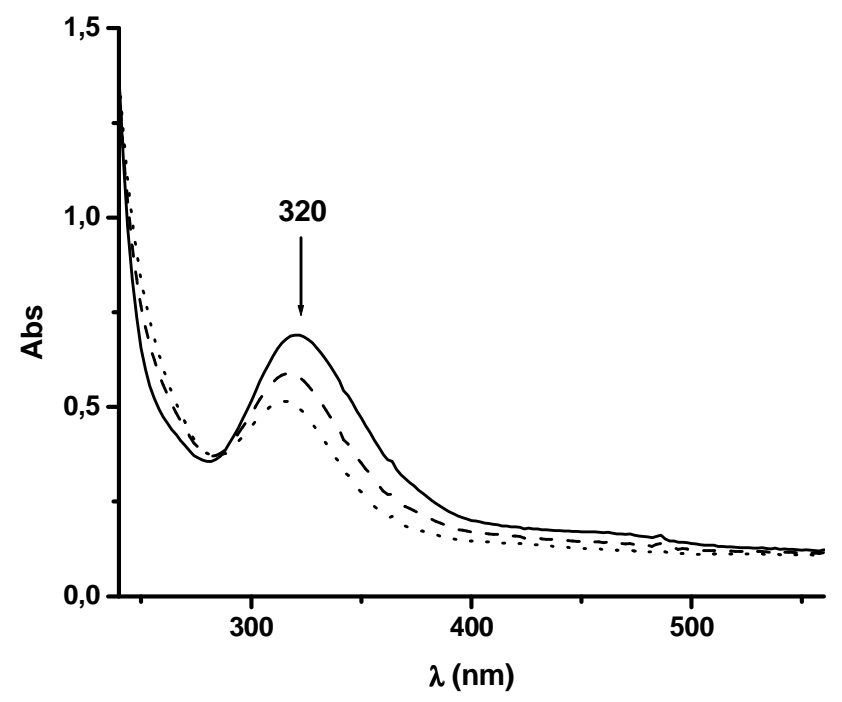

Figura 33 - Variações dos espectros do complexo trans- $\left[\mathrm{Ru}\left(\mathrm{NH}_{3}\right)_{4} \mathrm{P}(\mathrm{OEt})_{3} \mathrm{~N}(\mathrm{O}) \mathrm{SR}\right]^{\mathrm{n}-2}$ Condições: $\mathrm{pH}=4,5 \mathrm{C}_{\mathrm{Ru}}=5,0 \times 10^{-4} \mathrm{~mol} \mathrm{~L}^{-1}$; $\mathrm{C}_{\mathrm{RS}}=5,0 \times 10^{-4} \mathrm{~mol} \mathrm{~L}^{-1} ; \mu=0,2 \mathrm{~mol} \mathrm{~L}^{-1} ; \mathrm{T}=25^{\circ} \mathrm{C}$.

A Figura 34 apresenta o gráfico de $\ln \left(A_{\text {inf }}-A_{t}\right)$ em função de $t$ (s) o qual foi utilizado para calcular os valores de $k_{3}$ referente a esta etapa da reação.

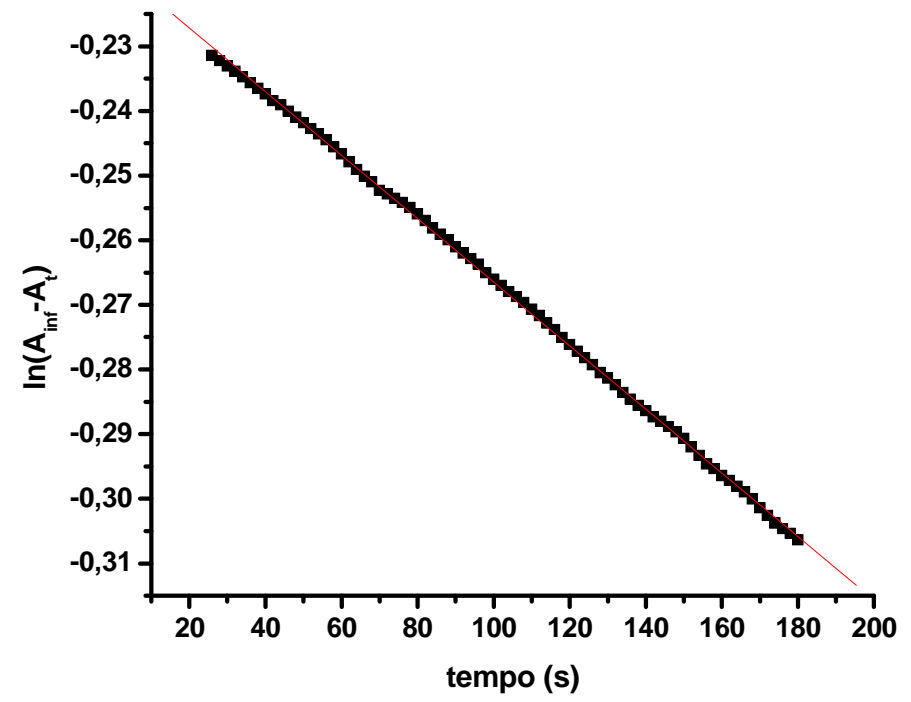

Figura $34-\ln \left(A_{\text {inf }}-A_{t}\right)$ em função de $t(s)$ para a reação de decaimento do complexo trans- $\left[\mathrm{Ru}\left(\mathrm{NH}_{3}\right)_{4} \mathrm{P}(\mathrm{OEt})_{3} \mathrm{~N}(\mathrm{O}) \mathrm{SR}\right]^{\mathrm{n}-2}$. Condições: $\mathrm{pH}=4,5 \mathrm{C}_{\mathrm{Ru}}=5,0 \times 10^{-4} \mathrm{~mol} \mathrm{~L}^{-1}$; $\mathrm{C}_{\mathrm{RS}}=5,0 \times 10^{-4} \mathrm{~mol} \mathrm{~L}^{-1} ; \mu=0,2 \mathrm{~mol} \mathrm{~L}^{-1} ; \mathrm{T}=25^{\circ} \mathrm{C}$. 
Foi observado que este decaimento é independente da concentração de cisteína e que se processa com $\mathrm{k}_{\mathrm{obs}}$ igual a $4,9 \times 10^{-4} \mathrm{~s}^{-1}$. Esta etapa da reação corresponde, portanto, a formação do complexo trans-[Ru( $\left.\left(\mathrm{NH}_{3}\right)_{4} \mathrm{P}(\mathrm{OEt})_{3} \mathrm{H}_{2} \mathrm{O}\right]^{+2}$, do $\mathrm{HNO}$ e da cistina (RSSR) a partir do complexo trans-[Ru( $\left.\left(\mathrm{NH}_{3}\right)_{4} \mathrm{P}(\mathrm{OEt})_{3} \mathrm{~N}(\mathrm{O}) \mathrm{SR}\right]^{\mathrm{n}-2}$ como descrito na Equação 32.

\subsection{Aspectos ligados a cinética da reação entre a L-cisteína e complexos de rutênio do tipo trans-[RuNO $\left.\left(\mathrm{NH}_{3}\right)_{4} \mathrm{~L}\right]^{+3}$, onde $\mathrm{L}=$ piridina (py), isonicotinamida (isn), 4-picolina (4-pic).}

A reação entre o complexo trans- $\left[\mathrm{RuNO}\left(\mathrm{NH}_{3}\right)_{4} \mathrm{P}(\mathrm{OEt})_{3}\right]^{+3}$ e a L-cisteína foi investigada em diferentes concentrações hidrogeniônicas e as constantes de velocidade para cada etapa desta reação foram calculadas. Porém, em pH fisiológico $(7,4)$, o estudo da reação deste complexo e a L-cisteína apresenta limitações devido ao ataque nucleofílico de íons hidroxilas no ligante $\mathrm{NO}^{+} \mathrm{e}$ $\mathrm{P}(\mathrm{OEt})_{3}[72]$ podendo ocorrer, portanto, alguma limitação nas medidas cinéticas.

Para buscar uma melhor compreensão da reação entre complexos nitrosilados e a L-cisteína em pH 7,4, ampliamos os estudos da investigação da reação deste tiol com outras tetraaminas de rutênio do tipo trans- $\left[\mathrm{Ru}\left(\mathrm{NH}_{3}\right)_{4} \mathrm{LNO}\right]^{+3}$, onde $L=p y$, isn, 4-pic.

De forma semelhante ao observado paro 0 complexo trans-[RuNO $\left.\left(\mathrm{NH}_{3}\right)_{4} \mathrm{P}(\mathrm{OEt})_{3}\right]^{+3}$, a reação da L-cisteína com os complexos trans-[Ru(NH$)_{4} \mathrm{LNO}^{+3}(\mathrm{~L}=$ py, isn, 4-pic) gera uma banda intensa na região do visível atribuída a formação da espécie trans- $\left[\mathrm{Ru}\left(\mathrm{NH}_{3}\right)_{4} \mathrm{LN}(\mathrm{O}) \mathrm{SR}\right]^{\mathrm{n}-1}$ (Equação 33 e 34) como observado na Figura 35. 


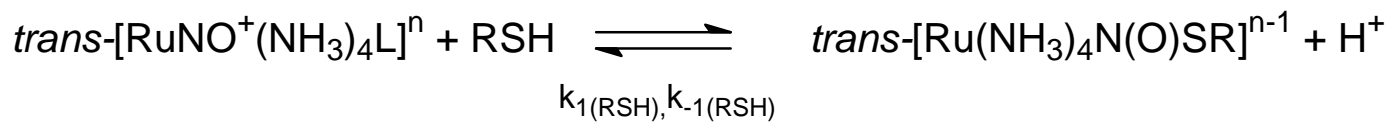

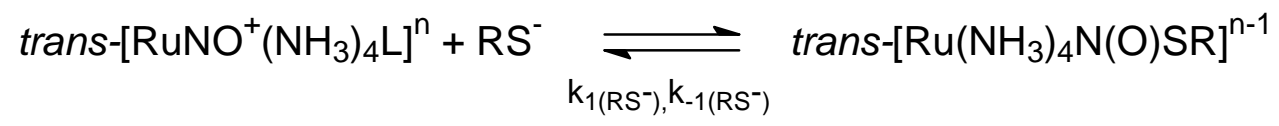

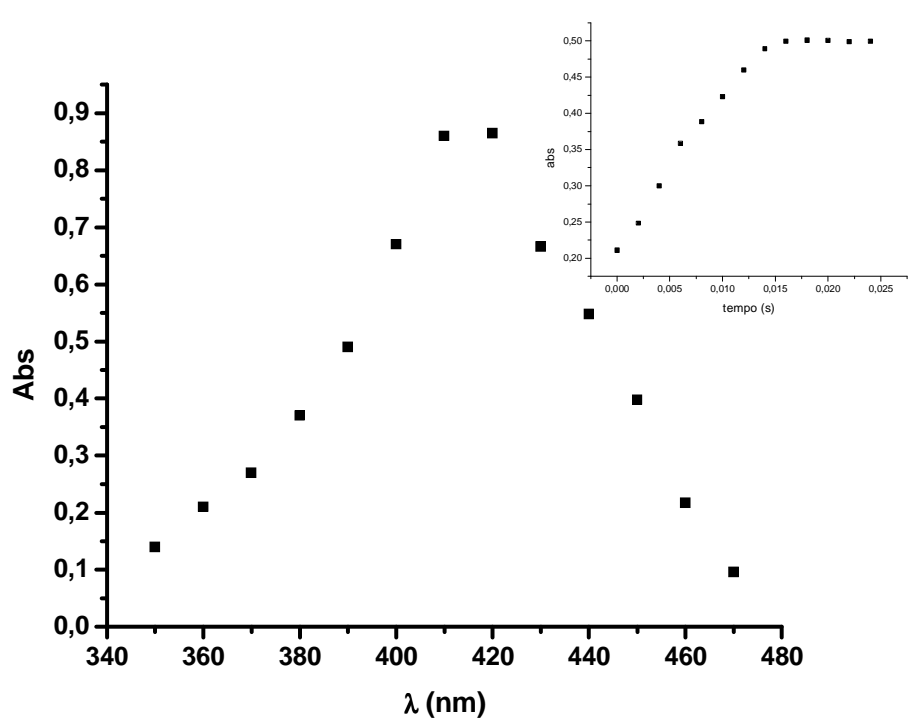

Figura 35 - Espectro eletrônico para a solução contendo o complexo trans- $\left[\mathrm{RuNO}\left(\mathrm{NH}_{3}\right)_{4}(4 \text {-pic) }]^{+3}\right.$ e a L-cisteína, $\mathrm{pH}=7,4, \mathrm{C}_{\mathrm{Ru}}=5,0 \times 10^{-4} \mathrm{~mol} \mathrm{~L}^{-1} ; \mathrm{C}_{\text {cis }}=$ $5,0 \times 10^{-3} \mathrm{~mol} \mathrm{~L}^{-1} \mu=0,2 \mathrm{~mol} \mathrm{~L}^{-1} . \mathrm{T}=25^{\circ} \mathrm{C}$.

Os valores de $k_{1 \text { (cis) }}$ e $k_{-1 \text { (cis) }}$ foram calculados para a formação da espécie trans- $\left[\mathrm{Ru}\left(\mathrm{NH}_{3}\right)_{4} \mathrm{LN}(\mathrm{O}) \mathrm{SR}\right]^{\mathrm{n}-1}(\mathrm{~L}=\mathrm{py}$, isn, 4-pic) de forma análoga ao discutido anteriormente para $\mathrm{L}=\mathrm{P}(\mathrm{OEt})_{3}$ e estão reunidos na Tabela 7 . 


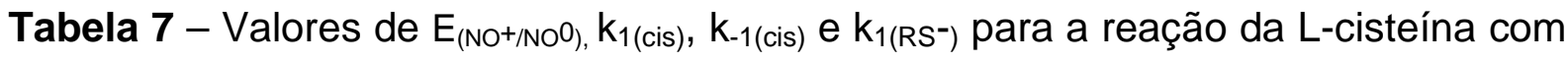
nitrosilos de rutênio trans-[RuNO $\left.\left(\mathrm{NH}_{3}\right)_{4} \mathrm{~L}\right]^{+3}$ onde $\mathrm{L}=\mathrm{P}(\mathrm{OEt})_{3}, \mathrm{pz}$, isn, py e 4-pic Reação: $\quad$ trans-[RuNO $\left.{ }^{+}\left(\mathrm{NH}_{3}\right)_{4} \mathrm{~L}\right]^{\mathrm{n}}+\mathrm{RS}^{-} \rightleftharpoons \operatorname{trans}_{-}^{-}\left[\mathrm{Ru}\left(\mathrm{NH}_{3}\right)_{4} \mathrm{~N}(\mathrm{O}) \mathrm{SR}\right]^{\mathrm{n}-1}$

\begin{tabular}{|c|c|c|c|c|}
\hline complexo & $\mathrm{k}_{1 \text { (cis) }}\left(\mathrm{mol}^{-1} \mathrm{Ls}^{-1}\right)$ & $\mathrm{k}_{-1(\mathrm{cis})}\left(\mathbf{s}^{-1}\right)$ & $\mathrm{K}_{1\left(\mathrm{RS}^{-}\right)}\left(\mathrm{mol}^{-1} \mathrm{Ls}^{-1}\right)$ & $\begin{array}{l}\mathrm{E}_{(\mathrm{NO}+\mathrm{NO} \mathrm{O})} \\
\text { (V)vsENH }\end{array}$ \\
\hline trans $-\left[\mathrm{RuNO}\left(\mathrm{NH}_{3}\right)_{4} \mathrm{P}(\mathrm{OEt})_{3}\right]^{+3}$ & $3,5 \times 10^{3}$ a & 47 & $1,7 \times 10^{7}$ & 0,132 \\
\hline trans-[RuNO$\left.\left(\mathrm{NH}_{3}\right)_{4} \mathrm{pz}\right]^{+3}$ & $1,6 \times 10^{5} \mathrm{c}$ & 110 & $3,2 \times 10^{6} \mathrm{c}$ & 0,11 \\
\hline trans-[RuNO$\left.\left(\mathrm{NH}_{3}\right)_{4} \mathrm{isn}\right]^{+3}$ & $8,04 \times 10^{3}$ b & 23 & $7,2 \times 10^{4}$ & 0,052 \\
\hline trans-[RuNO$\left.\left(\mathrm{NH}_{3}\right)_{4} \mathrm{py}\right]^{+3}$ & $3,2 \times 10^{3} \mathrm{~b}$ & 57 & $2,8 \times 10^{4}$ & 0,012 \\
\hline Trans-[RuNO $\left(\mathrm{NH}_{3}\right)_{4}(4-$ pic $\left.)\right]^{+3}$ & $2,5 \times 10^{3} b$ & 78 & $2,2 \times 10^{4}$ & $-0,008$ \\
\hline
\end{tabular}

a) $\mathrm{pH}=3,5$. b) $\mathrm{pH}=7,4$.c $) \mathrm{pH}=7,0[71] \mu=0,2 \mathrm{~mol} \mathrm{~L}^{-1}$. Erro estimado $=0,015 \mathrm{~V}$ [42]. $\mathrm{T}=25^{\circ} \mathrm{C}$. Valores calculados a partir da equação 5 usando pKa $=8,3$.

A dependência dos valores de $\mathrm{k}_{1 \text { (cis) }}$ em relação ao $\mathrm{pH}$ do meio descrito para a formação da espécie trans- $\left[\mathrm{Ru}\left(\mathrm{NH}_{3}\right)_{4} \mathrm{P}(\mathrm{OEt})_{3} \mathrm{~N}(\mathrm{O}) \mathrm{SR}\right]^{\mathrm{n}-1}$ e para outros nitrosilos de rutênio[65] também deve ocorrer para os complexos trans-[Ru(NH$\left.)_{4} \mathrm{LN}(\mathrm{O}) \mathrm{SR}\right]^{\mathrm{n}-1}$ onde $L=$ py, isn, 4-pic. Portanto, a partir da equação 26, foram calculados os valores numéricos de $\mathrm{k}_{1\left(\mathrm{RS}^{-}\right)}$para a formação destas espécies. Os valores de $\mathrm{k}_{1 \text { (cis) }}$ obtidos experimentalmente para os diversos complexos não podem ser diretamente comparados entre si devido as diferentes condições de $\mathrm{pH}$ em que foram utilizados os experimentos. Estes valores calculados de $\mathrm{k}_{1\left(\mathrm{RS}^{-}\right)}$, no entanto, apresenta como esperado[71] uma relação direta com o potencial de redução $\mathrm{NO}^{+} / \mathrm{NO}^{0}$.

O caráter ácido $\pi$ do ligante (L) trans ao íon nitrosônio influência seu potencial

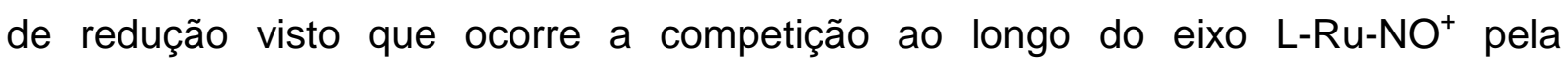
densidade eletrônica[33]. Portanto, no sistema trans-[RuNO $\left.\left(\mathrm{NH}_{3}\right)_{4} \mathrm{~L}\right]^{3+}$, o potencial de redução do par $\mathrm{NO}^{+} / \mathrm{NO}^{0}$ é um indicador do caráter eletrofílico deste ligante[42]. Isto também se reflete para a reação entre L-cisteína e os nitrosilo complexos e para a 
reação de ataque nucleofílico de íons hidroxilas no sistema trans- $\left[\mathrm{RuNO}\left(\mathrm{NH}_{3}\right)_{4} \mathrm{~L}\right]^{+3}[60]$.

Após a formação da espécie trans-[Ru(NH$\left.)_{3} \mathrm{LN}(\mathrm{O}) \mathrm{SR}\right]^{\mathrm{n}-1}$, foi também observada a variação do espectro eletrônico como ilustrado na Figura 36.
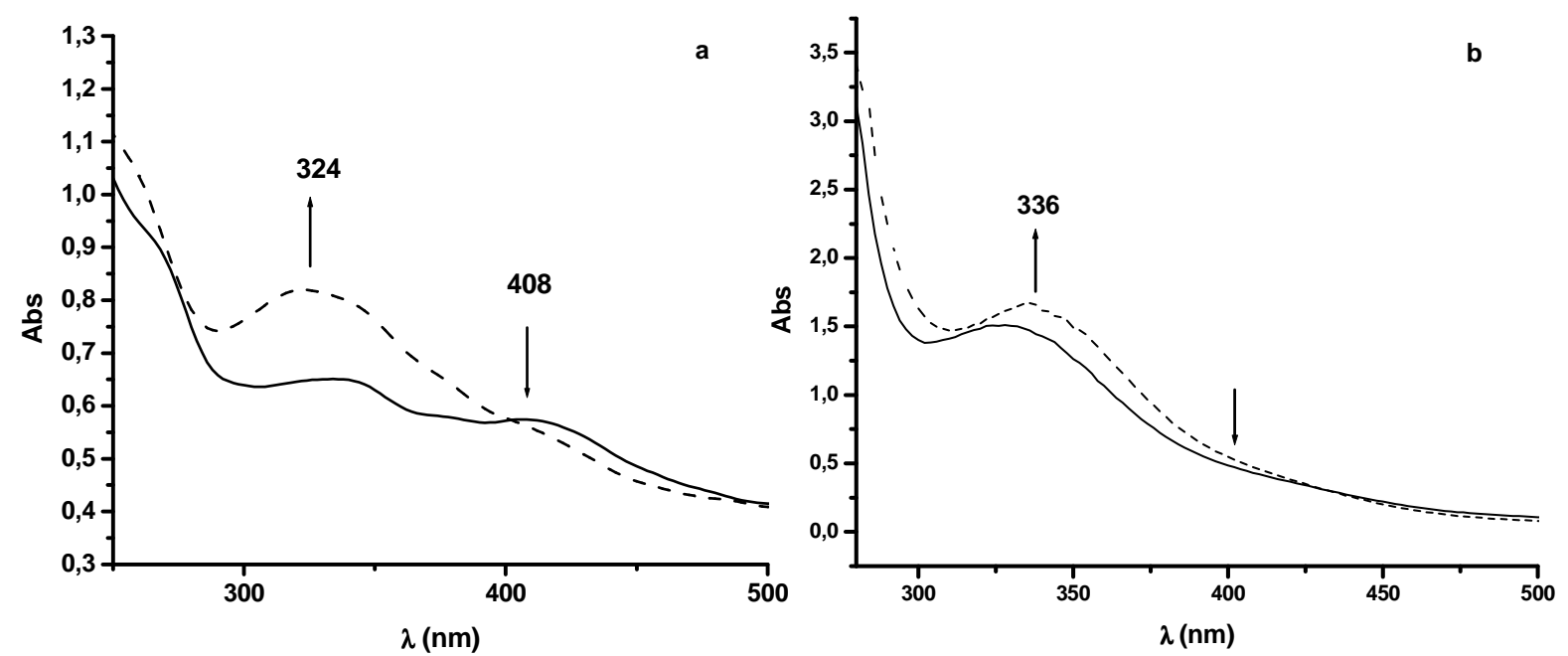

Figura 36 - Variações dos espectros do complexo (a) trans-[Ru( $\left.\left.\mathrm{NH}_{3}\right)_{4} \mathrm{pyN}(\mathrm{O}) \mathrm{SR}\right]^{\mathrm{n}-1}$, (b) trans- $\left[\mathrm{Ru}\left(\mathrm{NH}_{3}\right)_{4} 4-\mathrm{PicN}(\mathrm{O}) \mathrm{SR}\right]^{\mathrm{n}-1}$ Condições: $\mathrm{pH}=7,4 \mathrm{C}_{\mathrm{Ru}}=5,0 \times 10^{-4} \mathrm{~mol} \mathrm{~L}^{-1}$; $\mathrm{C}_{\text {cis }}=5,0 \times 10^{-4} \mathrm{~mol} \mathrm{~L}^{-1} ; \mu=0,2 \mathrm{~mol} \mathrm{~L}^{-1} ; \mathrm{T}=25^{\circ} \mathrm{C}$.

Os valores de $k_{\text {obs }}$, calculados a partir dos gráficos $\ln \left(A_{\text {inf }}-A_{t}\right)$ em função de tempo(s),variam com a concentração de L-cisteína como ilustrado na Figura 37. Este fato sugere, portanto, interação da L-cisteína com o complexo trans$\left[\mathrm{Ru}\left(\mathrm{NH}_{3}\right)_{4} \mathrm{LN}(\mathrm{O}) \mathrm{SR}\right]^{\mathrm{n}-1}$ provavelmente de acordo com:

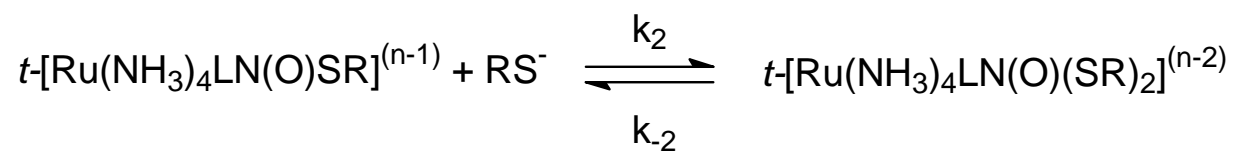



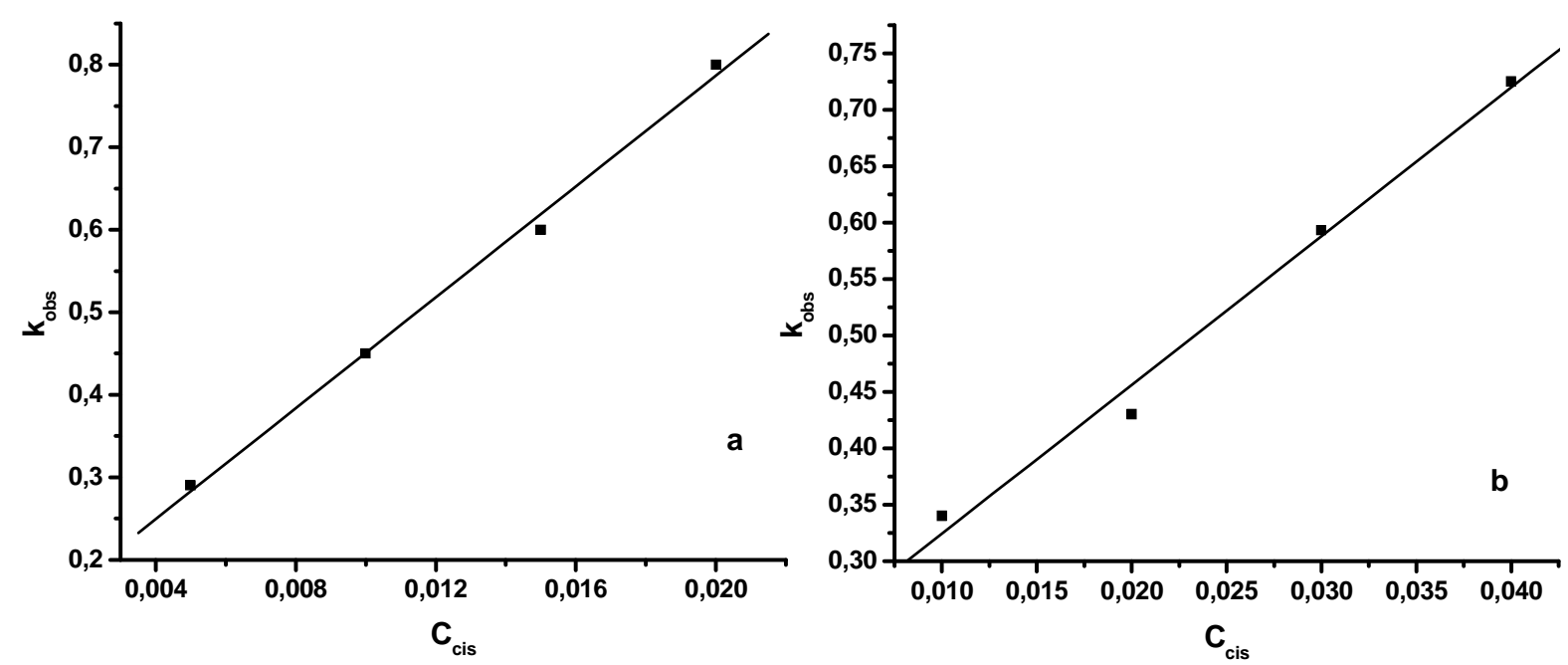

Figura 37 - Dependência de $\mathrm{k}_{\mathrm{obs}}$ em função de concentração de L-cisteína para a formação das espécies: (a) trans-[Ru( $\left.\left.\mathrm{NH}_{3}\right)_{4} \mathrm{pyN}(\mathrm{O}) \mathrm{SR}\right]^{\mathrm{n}-1}$, (b) trans- $\left[\mathrm{Ru}\left(\mathrm{NH}_{3}\right)_{4} 4-\mathrm{picN}(\mathrm{O}) \mathrm{SR}\right]^{\mathrm{n}-1} \cdot \mathrm{pH}=7,4 ; \mathrm{C}_{\mathrm{Ru}}=5,0 \times 10^{-4} \mathrm{~mol} \mathrm{~L}^{-1}$; $\mathrm{C}_{\text {cis }}=5,0 \times 10^{-4} \mathrm{~mol} \mathrm{~L}^{-1} \mu=0,2 \mathrm{~mol} \mathrm{~L}^{-1}$. $\mathrm{T}=25^{\circ} \mathrm{C}$.

Os valores numéricos de $\mathrm{k}_{2 \text { (cis) }}$ foram calculados a partir do gráfico $\mathrm{k}_{\mathrm{obs}}$ em função da concentração de L-cisteína $\left(\mathrm{C}_{\text {cis }}\right)$ (Figura 37 ) e reunidos na Tabela 8. Novamente, os valores de $\mathrm{k}_{2\left(\mathrm{RS}^{-}\right)}$foram calculados a partir da equação 26 para íon trans- $\left[\mathrm{RuNO}\left(\mathrm{NH}_{3}\right)_{4} \mathrm{~L}\right]^{3+}$ onde $\mathrm{L}=4$-pic, py e isn. 
Tabela 8 - Valores de constante de velocidade $\left(\mathrm{K}_{2}\right)$ para $t-\left[\mathrm{Ru}\left(\mathrm{NH}_{3}\right)_{4} \mathrm{LNO}\right]^{+3}$

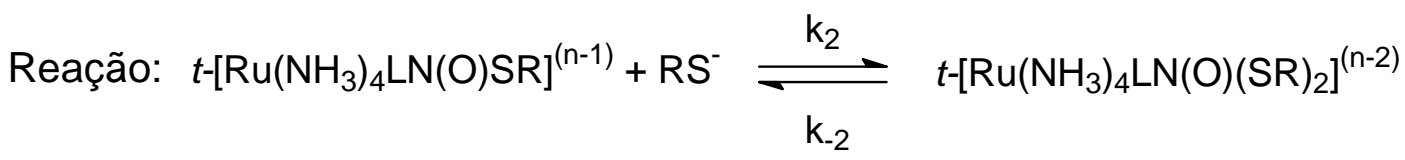

\begin{tabular}{|c|c|c|c|c|}
\hline L= ligante & $\mathrm{K}_{2}\left(\mathrm{~mol}^{-1} \mathrm{Ls}^{-1}\right)$ & $\mathrm{k}_{-2}\left(\mathrm{~mol}^{-1} \mathrm{Ls}^{-1}\right)$ & $\mathrm{K}_{2 \mathrm{rs}}{ }^{-}\left(\mathrm{mol}^{-1} \mathrm{Ls}^{-1}\right)$ & $\begin{array}{l}\mathrm{E}_{(\mathrm{NO}+\mathrm{NO} O)} \\
(\mathrm{V}) v s E N H\end{array}$ \\
\hline $\mathrm{P}(\mathrm{OET})_{3}$ & $5,65^{\mathrm{a}}$ & $4,4 \times 10^{-2}$ & $3,3 \times 10^{4}$ & 0,132 \\
\hline pirazina & $60^{\mathrm{b}}$ & 2,8 & $1,2 \times 10^{3}$ & 0,11 \\
\hline piridina & $31^{\mathrm{c}}$ & 0,6 & $2,78 \times 10^{2}$ & 0,012 \\
\hline 4-picolina & $13,2^{\mathrm{c}}$ & 0,2 & $4,9 \times 10^{1}$ & $-0,008$ \\
\hline
\end{tabular}

a) $\mathrm{pH} 4,5$ b) $\mathrm{pH} \mathrm{7,0} \mathrm{c)} \mathrm{pH} \mathrm{7,4}$

A Figura 38 ilustra a variação de $\operatorname{lnk}_{1\left(\mathrm{RS}^{-}\right)}$em função de $\mathrm{E}_{(\mathrm{NO}+\mathrm{NO})}$. Este gráfico sugere uma correlação entre estes parâmetros. Nota-se um comportamento semelhante ao observado para a formação da primeira espécie da reação, indicando a existência de interação do complexo trans-[Ru( $\left.\left(\mathrm{NH}_{3}\right)_{4} \mathrm{LN}(\mathrm{O}) \mathrm{SR}\right]^{\mathrm{n}-1}$ com a L-cisteína formando a espécie trans-[Ru(NH$\left.)_{4} \mathrm{LN}(\mathrm{O})(\mathrm{SR})_{2}\right]^{\mathrm{n}-2}$.

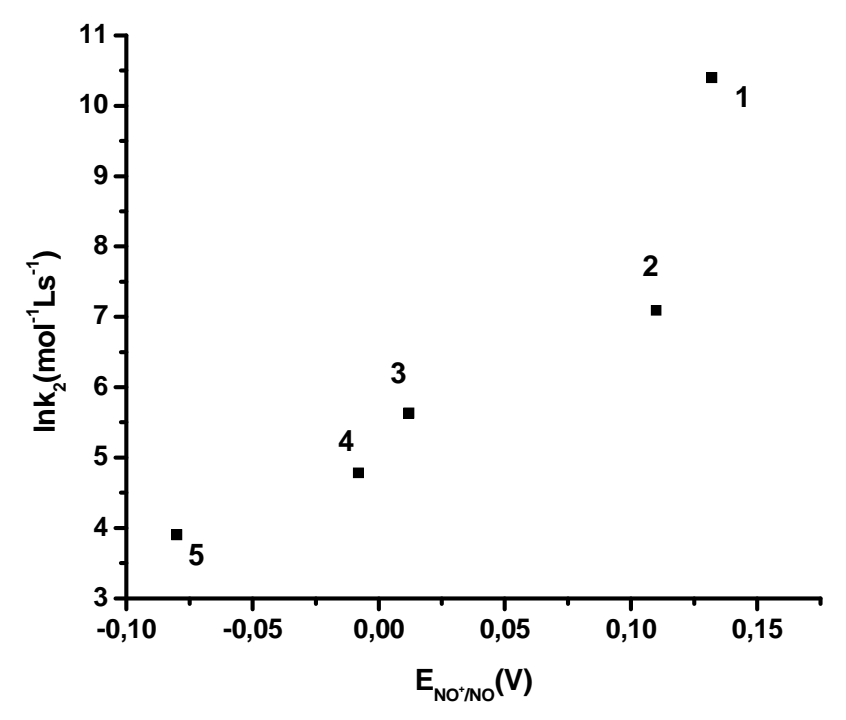

Figura 38 - Valores de $\ln _{\mathrm{k}_{2}\left(\mathrm{RS}^{-}\right)}$versus $\mathrm{E} \mathrm{NO}^{+} / \mathrm{NO}_{0}$ de complexos nitrosilos. 1. trans-[RuNO $\left.\left(\mathrm{NH}_{3}\right)_{4} \mathrm{P}(\mathrm{OEt})_{3}\right]^{+3} ; \quad 2$. trans-[RuNO$\left.\left(\mathrm{NH}_{3}\right)_{4}(\mathrm{pz})\right]^{+3} ; \quad 3 . \quad$ trans$\left[\mathrm{RuNO}\left(\mathrm{NH}_{3}\right)_{4} \mathrm{py}\right]^{+3}$; 4. trans-[RuNO$\left.\left(\mathrm{NH}_{3}\right)_{4}(4-\mathrm{pic})\right]^{+3}$; 5 . $t$-[RuNO(Hedta)]; 
Como discutido anteriormente, a espécie trans-[Ru( $\left.\left(\mathrm{NH}_{3}\right)_{4} \mathrm{LN}(\mathrm{O})(\mathrm{SR})_{2}\right]^{\mathrm{n}-2}$ pode decair formando o complexo que em parte dissocia o óxido nítrico dando origem ao complexo trans-[Ru(NH$\left.\left.)_{3}\right)_{4} \mathrm{LH}_{2} \mathrm{O}\right]^{+2}$ (36 e 37). Por outro lado, em uma reação paralela, a espécie trans-[Ru( $\left.\left(\mathrm{NH}_{3}\right)_{4} \mathrm{LNO}^{0}\right]^{+2}$ também pode interage com o tiol formando o complexo trans-[Ru(NH$)_{4} \mathrm{LN}(\mathrm{O}) \mathrm{SR}^{\mathrm{n}-2}(38)$.

$$
\begin{array}{ccc}
\text { trans }-\left[\mathrm{Ru}\left(\mathrm{NH}_{3}\right)_{4} \mathrm{LN}(\mathrm{O})(\mathrm{SR})_{2}\right]^{\mathrm{n}-2} \longrightarrow & \text { trans- }\left[\mathrm{Ru}\left(\mathrm{NH}_{3}\right)_{4} \mathrm{LNO}^{0}\right]^{+2}+\mathrm{RSSR} \cdot(36) \\
\operatorname{trans}-\left[\mathrm{Ru}\left(\mathrm{NH}_{3}\right)_{4} \mathrm{LNO}^{0}\right]^{+2} \longrightarrow & \text { trans- }\left[\mathrm{Ru}\left(\mathrm{NH}_{3}\right)_{4} \mathrm{LH}_{2} \mathrm{O}\right]^{+2}+\mathrm{NO} \\
\operatorname{trans}-\left[\mathrm{Ru}\left(\mathrm{NH}_{3}\right)_{4} \mathrm{LNO}^{0}\right]^{+2}+\mathrm{RS}^{-} \longrightarrow & \text { trans- }\left[\mathrm{Ru}\left(\mathrm{NH}_{3}\right)_{4} \mathrm{LN}(\mathrm{O}) \mathrm{SR}\right]^{\mathrm{n}-2}
\end{array}
$$

Para a reação da L-cisteína com complexos trans- $\left[\mathrm{Ru}\left(\mathrm{NH}_{3}\right)_{4}(4-\text { pic }) \mathrm{NO}^{0}\right]^{+2}$, trans- $\left[\mathrm{Ru}\left(\mathrm{NH}_{3}\right)_{4} \mathrm{pyNO}^{0}\right]^{+2}$, trans- $\left[\mathrm{Ru}\left(\mathrm{NH}_{3}\right)_{4} \mathrm{pzNO}^{0}\right]^{+2}$ e trans- $\left[\mathrm{Ru}\left(\mathrm{NH}_{3}\right)_{4} \mathrm{isnNO}^{0}\right]^{+2}$, a dissociação do NO é menos favorecida visto que os valores de $\mathrm{K}_{\text {-NO }}$ variam de 0,043 a $0,09 \mathrm{~s}^{-1}[32]$, muito inferior ao complexo trans- $\left[\mathrm{Ru}\left(\mathrm{NH}_{3}\right)_{4} \mathrm{P}(\mathrm{OEt})_{3} \mathrm{NO}^{0}\right]^{+2}$. Assim, podemos supor que a via que envolve a formação da espécie trans- $\left[\mathrm{Ru}\left(\mathrm{NH}_{3}\right)_{4} \mathrm{LN}(\mathrm{O}) \mathrm{SR}\right]^{\mathrm{n}-2}$ é predominante para estes complexos $(\mathrm{L}=$ N-heterocíclico, Equação 38).

A etapa subseqüente da reação entre os complexos trans-[RuNO $\left.\left(\mathrm{NH}_{3}\right)_{4} \mathrm{~L}\right]^{+3}$, onde $\mathrm{L}=\mathrm{N}$-heterocíclico, e a L-cisteína corresponderia a produção de HNO por meio da decomposição da espécie trans-[Ru( $\left.\left(\mathrm{NH}_{3}\right)_{4} \mathrm{LN}(\mathrm{O})(\mathrm{SR})_{2}\right]^{\mathrm{n}-2} \quad$ ou trans-[Ru(NH$\left.)_{4} \mathrm{LN}(\mathrm{O}) \mathrm{SR}\right]^{\mathrm{n}-2}$ como observado nas equações 39 e 40:

$$
\begin{aligned}
& \text { trans }-\left[\mathrm{Ru}\left(\mathrm{NH}_{3}\right)_{4} \mathrm{LN}(\mathrm{O})(\mathrm{SR})_{2}\right]^{\mathrm{n}-2} \longrightarrow \mathrm{HNO}+\text { trans- }\left[\mathrm{Ru}\left(\mathrm{NH}_{3}\right)_{4} \mathrm{LH}_{2} \mathrm{O}\right]^{+2}+\mathrm{RSSR}(39) \\
& \text { trans- }\left[\mathrm{Ru}\left(\mathrm{NH}_{3}\right)_{4} \mathrm{LN}(\mathrm{O}) \mathrm{SR}^{\mathrm{n}-2} \longrightarrow \mathrm{HNO}+\text { trans- }\left[\mathrm{Ru}\left(\mathrm{NH}_{3}\right)_{4} \mathrm{LH}_{2} \mathrm{O}\right]^{+2}+\mathrm{RS} \cdot(40)\right.
\end{aligned}
$$


A Tabela 9 apresenta valores de $\mathrm{k}_{\mathrm{obs}}$ para alguns nitrosilos complexos. Foi observado que a constante de velocidade não depende da concentração de Lcisteína sendo, portanto, uma reação de primeira ordem. Até o momento, não conseguimos evidências que nos permitam afirmar qual das reações é prodominante (Equação 39 ou 40).

Tabela 9 - Valores de constante de velocidade para a decomposição do complexo trans- $\left[\mathrm{Ru}\left(\mathrm{NH}_{3}\right)_{4} \mathrm{LN}(\mathrm{O}) \mathrm{SR}\right]^{\mathrm{n}-2}$ ou do trans-[Ru(NH$\left.)_{4} \mathrm{LN}(\mathrm{O})(\mathrm{SR})_{2}\right]^{\mathrm{n}-2}$

\begin{tabular}{cc}
\hline L= ligante & $\mathrm{K}_{\mathrm{obs}}\left(\mathbf{s}^{-1}\right)$ \\
\hline isonicotinamida & $4,5 \times 10^{-3}$ \\
piridina & $2,7 \times 10^{-2}$ \\
4-picolina & $6 \times 10^{-3}$ \\
\hline
\end{tabular}


Em linhas gerais, os resultados sugerem o seguinte esquema:

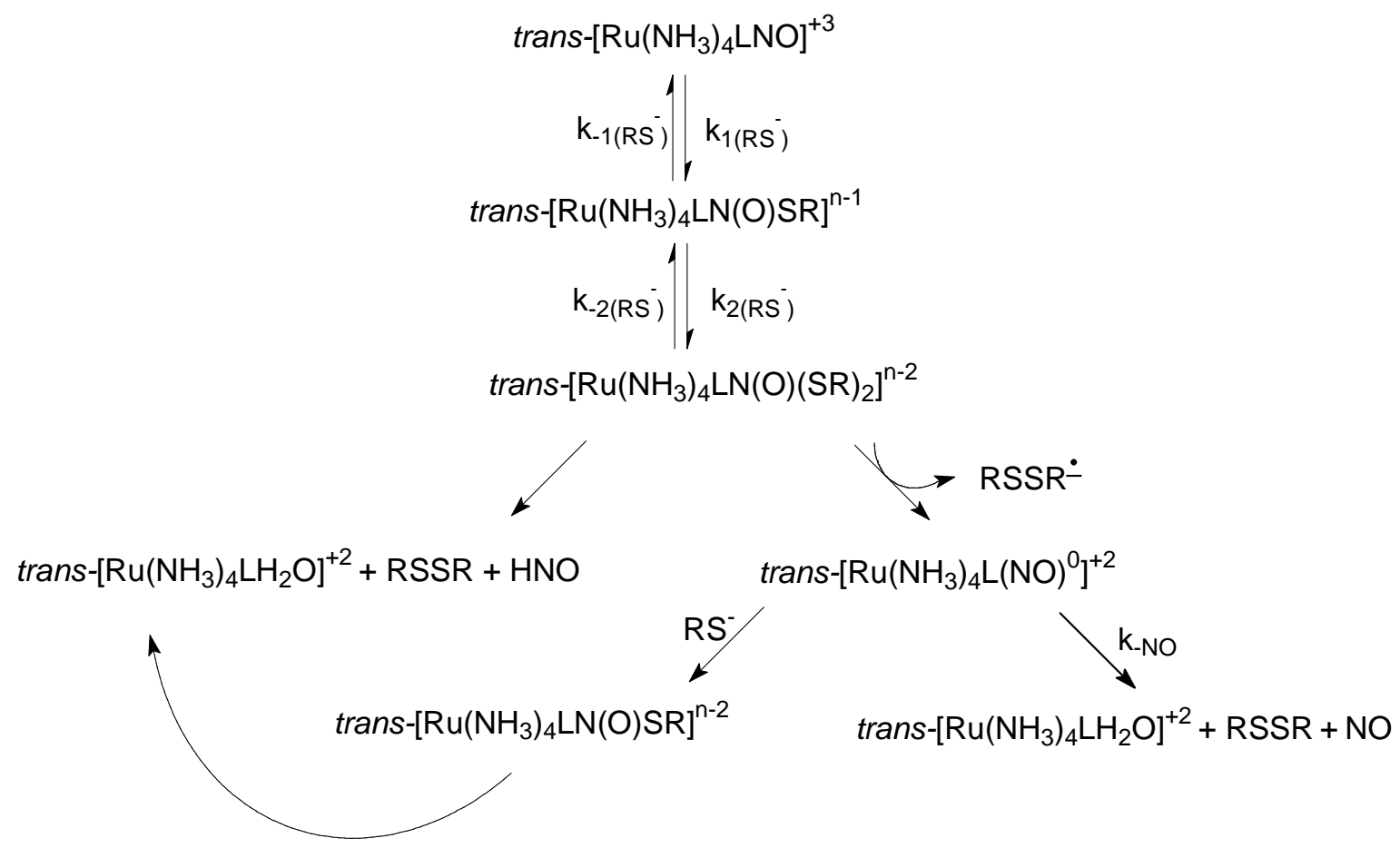

Esquema geral para a reação entre nitrosilo complexos e a L-cisteína 


\subsection{Conclusão parcial}

Embora muitos aspectos da reação entre 0 nitrosilo trans-[RuNO $\left.\left(\mathrm{NH}_{3}\right)_{4} \mathrm{~L}\right]\left(\mathrm{BF}_{4}\right)_{3},(\mathrm{~L}=\mathrm{imN}$, 4-pic, py, isn) e a L-cisteína, ainda devam ser esclarecidos, os experimentos sugerem que em solução onde $\mathrm{pH}=7,4$, o principal produto da redução do ligante nitrosônio $\left(\mathrm{NO}^{+}\right)$é o nitroxil (HNO).

A reação entre a L-cisteína e o complexo trans- $\left[\mathrm{Ru}\left(\mathrm{NH}_{3}\right)_{4} \mathrm{P}(\mathrm{OEt})_{3} \mathrm{NO}\right]^{+3}$ nas mesma condições de $\mathrm{pH}$ se processa da mesma forma que foi observado para os outros nitrosilos complexos. Por outro lado, quando a reação ocorre em meio ácido ( $\mathrm{pH}=4,0)$, a redução monoeletrônica do ligante nitrosônio é predominante. A reação entre trans-[RuNO $\left.\left(\mathrm{NH}_{3}\right)_{4} \mathrm{~L}\right]^{+3}$ e a L-cisteína se processa em uma primeira etapa pela formação da espécie trans-[Ru( $\left.\left(\mathrm{NH}_{3}\right)_{4} \mathrm{LN}(\mathrm{O}) \mathrm{SR}\right]^{\mathrm{n}-1}$ o qual depende da concentração de cisteína deprotonada $\left(\mathrm{RS}^{-}\right)$. Em seguida, ocorrre uma segunda interação da espécie $\mathrm{RS}^{-}$com o complexo trans-[Ru(NH$\left.)_{4} \mathrm{LN}(\mathrm{O}) \mathrm{SR}\right]^{\mathrm{n}-1}$ formando a espécie trans$\left[\mathrm{Ru}\left(\mathrm{NH}_{3}\right)_{4} \mathrm{LN}(\mathrm{O})(\mathrm{SR})_{2}\right]^{\mathrm{n}-2}$. Aqui poderia ocorre dois caminhos reacionais: a) a dissociação do trans-[Ru(NH$\left.\left(\mathrm{NH}_{3}\right)_{4} \mathrm{LN}(\mathrm{O})(\mathrm{SR})_{2}\right]^{\mathrm{n}-2}$ gerando o nitroxil (HNO) ou b) geração do complexo trans-[Ru(NH$\left.)_{3} \mathrm{LNO}^{0}\right]^{+2}$ e a espécie RSSR $\cdot$. O complexo trans$\left[\mathrm{Ru}\left(\mathrm{NH}_{3}\right)_{4} \mathrm{LNO}^{0}\right]^{+2}$ pode dissociar o $\mathrm{NO}^{0}$ formando também o trans- $\left[\mathrm{Ru}\left(\mathrm{NH}_{3}\right)_{4} \mathrm{LH}_{2} \mathrm{O}\right]^{+2}$ ou reagir com a espécie $\mathrm{RS}^{-}$gerando HNO. Portanto, os diferentes caminhos reacionais descritos neste trabalho levam a diferentes produtos (NO ou HNO) sendo dependente da concentração de L-cisteína deprotonada, do $\mathrm{pH}$ do meio e da capacidade de dissociar NO (k-NO) de cada nitrosilo complexo. 


\section{Considerações finais}

Experimentos in vitro demonstraram que os compostos trans- $\left[\mathrm{Ru}(\mathrm{NO})\left(\mathrm{NH}_{3}\right)_{4} \mathrm{~L}\right](\mathrm{X})_{3}\left(\mathrm{X}=\mathrm{BF}_{4}^{-}\right.$ou $\mathrm{PF}_{6}^{-}$and $\mathrm{L}=\mathrm{imN}$, 4-pic, isn, py, pz, $\mathrm{L}-$ hist, nic, imC, $\left.\mathrm{P}\left(\mathrm{OEt}_{3}\right), \mathrm{SO}_{3}{ }^{-2}\right)$ e $[\mathrm{Ru}(\mathrm{NO})$ Hedta $\left.)\right]$ apresentaram atividade antileishmania. Os complexos trans-[Ru(NO) $\left.\left(\mathrm{NH}_{3}\right)_{4} \mathrm{~L}\right](\mathrm{X})_{3}$ onde $\mathrm{L}=\mathrm{imN}, \mathrm{P}(\mathrm{OEt})_{3}$ e py apresentam índice terapêutico $>15$ indicando baixa toxicidade frente a células V79. Destes

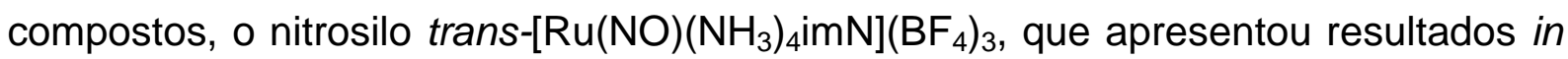
vitro mais promissores, foi escolhido para os experimentos in vivo. Estes foram realizados com camundongos infectados com o parasita Leishmania major. O tratamento foi realizado com uma dose diária de $0,5 \mu \mathrm{molKg}^{-1}$ do composto trans$\left[\mathrm{Ru}(\mathrm{NO})\left(\mathrm{NH}_{3}\right)_{4} \mathrm{imN}\right]\left(\mathrm{BF}_{4}\right)_{3}$ em um período de três semanas. Este complexo conduziu a estabilidade da lesão e inibição da carga parasitária relativo ao controle. É interessante mencionar que a dose diária do composto trans-[Ru(NO)(NH$\left.)_{4} i m N\right]\left(\mathrm{BF}_{4}\right)_{3}$, utilizada para o tratamento, é 125 vezes menor que o valor de $\mathrm{LD}_{50}$ obtido para este complexo. Experimentos in vitro com os complexos trans- $\left[\mathrm{Ru}\left(\mathrm{NH}_{3}\right)_{4} \mathrm{imN}(\mathrm{SO})_{4}\right]^{+}$e trans- $\left[\mathrm{Ru}\left(\mathrm{H}_{2} \mathrm{O}\right)\left(\mathrm{NH}_{3}\right)_{4} i m N\right]^{+2}$ apresentaram menor atividade antileishmania comparados ao análogo trans- $\left[\mathrm{Ru}(\mathrm{NO})\left(\mathrm{NH}_{3}\right)_{4} \mathrm{imN}\right]^{+3}$ sugerindo, portanto, que a atividade antiparasitária dos nitrosilos de rutênio foi atribuída em parte a capacidade de liberarem NO em meio biológico. Foi observado que a redução deste ligante é condição necessária, mas não suficiente para explicar a diferença de efeito antiparasitário destes complexos. A velocidade de dissociação do NO da esfera de coordenação ( $k_{-N o}$ ) também parece exercer influência na atividade antiparasitária dos nitrosilos trans- $\left[\mathrm{Ru}(\mathrm{NO})\left(\mathrm{NH}_{3}\right)_{4} \mathrm{~L}\right](\mathrm{X})_{3}$. Apesar de termos, no início, atribuído principalmente ao NO a capacidade leishmanicida destes 
nitrosilos, a atividade antiparasitária do HNO não pode ser negligenciada visto que na presença de excesso de L-cisteína e em $\mathrm{pH}=7,4$, o íon complexo trans$\left[\mathrm{Ru}(\mathrm{NO})\left(\mathrm{NH}_{3}\right)_{4} \mathrm{~L}\right]^{+3}$ pode sofrer redução de dois elétrons centrada no ligante nitrosônio, liberando nitroxilo no meio. Os complexos trans-[Ru(NO)(NH$\left.)_{4} \mathrm{~L}\right]^{+3}$ podem reagir com a L-cisteína (RS') formando a espécie trans- $\left[R u N(O) S R\left(N_{3}\right)_{4} L^{+3}\right.$ no tempo de escala de milisegundos. Esta espécie pode se associar a L-cisteína desprotonada (RS') gerando o complexo trans- $\left[\mathrm{Ru}\left(\mathrm{NO}^{0}\right)\left(\mathrm{NH}_{3}\right)_{4} \mathrm{~L}\right]^{+2}$. Este complexo pode liberar $\mathrm{NO}^{0}$ em meio ácido, condição de baixa concentração da espécie $\mathrm{RS}^{-}$, e em condição próxima a neutralidade reagir com L-cisteína desprotonada gerando HNO como produto. Assim, NO e HNO podem ser formadas em reações paralelas em função da concentração de L-cisteína. Por outro lado, a produção de HNO também é favorecida em complexos trans-[Ru(NO$\left.\left.{ }^{0}\right)\left(\mathrm{NH}_{3}\right)_{4} \mathrm{~L}\right]^{+2}$ onde a liberação de NO se efetua lentamente. Portanto, a capacidade do complexo trans-[Ru(NO) $\left.\left(\mathrm{NH}_{3}\right)_{4} \mathrm{~L}\right]^{+3}$ de liberar $\mathrm{NO}$ ou HNO depende das condições de $\mathrm{pH}$, da concentração de L-cisteína desprotonada no meio e dos valores de constante de velocidade específica de cada nitrosilo complexo. É importante observar que a ordem relativa de efeito trans e de influência trans do ligante auxiliar $\mathrm{L}$, relacionada diretamente com a capacidade do complexo reduzido liberar $\mathrm{NO}$ ou $\mathrm{HNO}$, seria a mesma. Portanto, em meio biológico ( $\mathrm{pH} 7,4)$, a atividade dos nitrosilos seria dependente da produção de $\mathrm{NO}$ e HNO, cujas proporções relativas seriam determinadas pela condições de pH e de concentração de redutor. 


\section{VI - Referências Bibliográficas}

1. SANTOS, D.O.; COUTINHO, C.E.R.; MADEIRA, M.F.; BOTTINO, C.G.; VIEIRA, R.T.; NASCIMENTO, S. B.; BERNARDINO, A.; BOURGUIGNON, S.C.; CORTE-REAL, S.; PINHO, R.T.; RODRIGUES, C.R.; CASTRO, H.C. Leishmaniasis treatment-a challenge that remains: a review. Parasitolgy Research, v. 103, p. 1-10, 2008.

2. REITHINGER, R.; DUJARDIN, J.C.; LOUZIR, H.; PIRMEZ, C.; ALEXANDER, B.; BROOKER, S. Cutaneous leishmaniasis. The Lancet Infectious Diseases, v. 7, p. 581-596, 2007.

3. MINODIERA P.; PHILIPPE, P. Cutaneous leishmaniasis treatment. Travel Medicine and Infectious Disease, v. 5, p. 150-158, 2007.

4. a)CROFT, S.L.; SUNDAR, S.; FAIRLAMB, A.H. Drug resistance in leishmaniasis. Clinical Microbiology Reviews, v.19, p. 111-126, 2006.

b) BERMAN, J. D., D. WADDELL, AND B. D. HANSON. Biochemical mechanisms of the antileishmanial activity of sodium stibogluconate.

Antimicrob. Agents Chemother, v. 27,p.916-920, 1985.

5. RENSLO, A.R.; MCKERROW, J.H. Drug discovery and development for neglected parasitic diseases. Nature chemical Biology, v. 2, 701-710, 2006.

6. CLARKE, M.J. Ruthenium metallopharmaceuticals. Coordination Chemistry Reviews, v. 232, p. 69-93, 2002.

7. VISBAL, G.; MARCHA'N, E.; MALDONADO, A.; SIMONI, Z.; NAVARRO,M. Synthesis and characterization of platinum-sterol hydrazone complexes with biological activity against Leishmania (L.) mexicana. Journal of Inorganic Biochemistry, v. 102, p. 547-554, 2008.

8. FARRELL, N.P.; WILLIAMSON, J.; DIANE, J.M.; MCLAREN, J.M. Trypanocidal and antitumour activity of platinum-metal and platinum-metaldrug dual-function complexes. Biochemical Pharmacology, v. 33, p. 961$971,1984$.

9. KINNAMON, K.E.; STECK, E.A.; RAN, D.S. Activity of Antitumor Drugs Against African Trypanosomes Antimicrobial agents and chemotherapy, $v$. 15, p. 157-160, 1979.

10.LOWE, G.; DROZ, A.S.; VILAIVAN, T.; WEAVER, G.W.; TWEEDALE, L.; JPRATT, .M.; ROCK, P.; YARDLEY, V.; CROFT, S.L. Cytotoxicity of $\left(2,2^{‘}: 6^{`}, 2^{\prime}\right.$ '-Terpyridine)platinum(II) Complexes to Leishmania donovani, Trypanosoma cruzi, and Trypanosoma brucei. Journal of Medical Chemistry, v. 42, p. 999-1006, 1999.

11.SA`NCHEZ-DELGADO, R.A.; LAZARDI, K.; RINCO’N, L.; URBINA, J.A.; HUBERT, A.J.;. NOELS, A.F. Toward a novel metal-based chemotherapy against tropical diseases. 1. Enhancement of the efficacy of clotrimazole 
against Trypanosoma cruzi by complexation to ruthenium in $\mathrm{RuCl}_{2}$ (clotrimazole) 2 . Journal of Medical Chemisty, v.36, p. 2041-2043, 1993.

12.SA'NCHEZ-DELGADO, R.A.; NAVARRO, M.; LAZARDI, K.; ATENCIO, R.; CAPPARELLI, M.; VARGAS, F.; URBINA, J.A. ; BOUILLEZ, A.; HUBERT, A.J.; NOELS, A.F. Inorganic Chimica Acta, v. 275, p. 528-540, 1998.

13. NAVARRO, M.; LEHMANN, T.; CISNEROS-FAJARDO, E.J.; FUENTES, A.; SANCHEZ-DELGADO, R.A.; SILVA, P. ; URBINA, J.A. Toward a novel metalbased chemotherapy against tropical diseases.: Part 5. Synthesis and characterization of new $\mathrm{Ru}(\mathrm{II})$ and $\mathrm{Ru}$ (III) clotrimazole and ketoconazole complexes and evaluation of their activity against Trypanosoma cruzi. Polyhedron, v. 19, p. 2319-2325, 2000.

14.SILVA, J.J.N.; PAVANELLI, W.R.; PEREIRA, J.C.M.; SILVA, J.S.;FRANCO, D.W. Experimental chemotherapy against Trypanosoma cruzi infection using ruthenium NO-donors. Antimicrobial agents and chemotherapy, 2009.

15.SOUSA, E.H.S.; PONTES, D.L.; DIÓGENES, I.C.N.; LOPES, L.G.F.; OLIVEIRA, J.S.; BASSO, L.A.; SANTOS, D.S.; MOREIRA, I. S.Electron transfer kinetics and mechanistic study of the thionicotinamide coordinated to the pentacyanoferrate(III)/(II) complexes: a model system for the in vitro activation of thioamides anti-tuberculosis drugs. Journal of Inorganic Biochemistry, 2005. 99: p. 368-375

16. SHARQUIE, K.E.; FARJOU, N.R.; AL-TIMIMI, D.J. Oral zinc sulphate in the treatment of acute cutaneous leishmaniasis. Clinical and Experimental Dermatolgy, v. 26, p. 21-26, 2001.

17. GIL, E.S.; CUNHA, L.C.; GONÇALVES, A.L.S.; SOUZA, A.R.;. NEGRÓN, A.C.V. Importancia de los Compuestos Inorgánicos en el Tratamiento de la Leishmaniasis. Latin American Journal of Pharmacy, v. 26, p. 454-461, 2007.

18. LANCASTER, J.R. The physiological properties of nitric oxide.

Determinants of the dynamics of NO in tissue. Nitric Oxide.

NovaYork/Londres: Academic Press, 2000, 209-223.

19. MATEO, A.O.; ARTIÑANO, M.A.A. Nitric Oxide Reactivity And Mechanisms Involved In Its Biological Effects. Pharmacological Research, v. 42, p. 421 427, 2000.

20. SALVATI, L.; MATTU, M.; COLASANTI, M.; SCALONE, A.; VENTURINI, G.; GRADONI, L.; ASCENZI, P. NO donors inhibit Leishmania infantum cysteine proteinase activity. Biochimica \& Biophysica Acta, v. 1545, p. 357-366, 2001 
21. ZEINA, B.; BANFIELD, C.; all.-Assad,S. Topical glyceryl trinitrate: a possible treatment for cutaneous leishmaniasis Clinical and Experimental Dermatology, v.22, p. 244-245, 1997.

22.SOUZA, G.F.P; YOKOYAMA-YASUNAKA, J.K.U.; SEABRA, A.B.; MIGUEL,D.C.; OLIVEIRA, M.G.; ULIANA, S.R.B. Leishmanicidal activity of primary S-nitrosothiols against Leishmania major and Leishmania amazonensis: Implications for the treatment of cutaneous leishmaniasis. Nitric Oxide: Biology and Chemistry, v. 15, p. 209-216, 2006.

23. MAUËL, J.; RANSIJN,A. Leishmania spp.: Mechanisms of Toxicity of Nitrogen Oxidation Products. Experimental Parasitology, v. 87, p. 98-111, 1997.

24. VALDEZ, C.A.; SAAVEDRA, J.E;. SHOWALTER, B.M.; DAVIES, K.M.;. WILDE, T.C.; CITRO, M.L.; BARCHI, J.J.; DESCHAMPS J. R.; PARRISH, D.; EL-GAYAR, S.; SCHLEICHER, U.; BOGDAN, C.; KEEFER, L.K. Hydrolytic Reactivity Trends among Potential Prodrugs of the O2-Glycosylated Diazeniumdiolate Family. Targeting Nitric Oxide to Macrophages for Antileishmanial Activity. Journal of Medical Chemistry, v. 51, p. 3961-3970, 2008.

25. SILVA, J. N.; OSAKABE, A. L.; PAVANELLI, W. R.; SILVA, J .S.; FRANCO, D. W.In vitro and in vivo antiproliferative and trypanocidal activities of ruthenium NO donors. British Journal of Pharmacology, v.152, p. 112-121, 2007.

26. GOMES, A.J.; BARBOUGLI, P. A.; ESPREAFICO, E. M.; TFOUN, E. trans[Ru(NO)(NH3)4(py)](BF4)3.H2O encapsulated in PLGA microparticles for delivery of nitric oxide to B16-F10 cells: Cytotoxicity and phototoxicity. Journal of Inorganic Biochemistry, v.102, p. 757-766, 2008.

27. LUNDBERG, J.O.; WEITZBERG, E.; GLADWIN, M.T. The nitrate-nitrite-nitric oxide pathway in physiology and therapeutics. Nature Reviews Drug Discovery AOP., 2008

28.BOGDAN, C.R.L. M.; DIEFENBACH, A.; FANG, F. C. Nitric Oxide in Leishmaniasis In Nitric Oxide and Infection. Editor. 1999: New York: A.P. Publishers, 1999, p. 361-377.

29. BOGDAN, C.; RÖLLINGHOFF, M. How do Protozoan Parasites Survive inside Macrophages? Parasitology Today, v. 15, p. 22-28,1999.

30.ZANICHELLI, P.G.; ESTRELA, H.F.G; SPADARI-BRATFISCH, R.C.; GRASSI-KASSISSE, D.M.; FRANCO, D.W. The effects of ruthenium compounds on vascular smooth muscle. Nitric Oxide: Biology and Chemistry, v. 16, p. 189-196, 2007.

31. TOLEDO, J.C. ; GONZAGA, F.L.L.; ANTONIO, A. A.; PEREIRA, S.L. ; FRANCO, D.W. Release of NO by a nitrosyl complex upon activation by the 
mitochondrial reducing power. Journal of Inorganic Biochemistry , v 89, p. 267-271, 2002.

32.TOLEDO,J.C.; SILVA, H.A.S.; SCARPELLINI, M; MORI, V.; CAMARGO, A.J.; BERTOTTI,M.; FRANCO, D.W. Ruthenium tetraamine as a model of nitric oxide donor compounds. European Journal of Inorganic Chemistry, v.9, p. 1879-1885, 2004.

33. TOLEDO, J.C.; B.S. LIMA NETO; FRANCO, D.W. Mutual effects in the chemical properties of the ruthenium metal center and ancillary ligands upon coordination. Coordination Chemistry Reviews, v. 249, p. 419-431, 2005.

34.TFOUNI, E.; KRIEGER, M.; MCGARVEY, B.R.; FRANCO, D.W. Structure, chemical and photochemical reactivity and biological activity of some ruthenium nitrosyl complexes. Coordination Chemistry Reviews, v. 236, p. 57-69, 2003.

35. WIERASZKO, A.; CLARKE, M.J.; LANG, D.R.; LOPES, L.G.F.; FRANCO, D.W. The influence of NO-containing ruthenium complexes on mouse hippocampal evoked potentials in vitro Life Sciences, v. 68, p. 1535-1544, 2001.

36. MARCONDES F.G.; FERRO, A.A.; SOUZA-TORSONI, A.; SUMITANI, M.; CLARKE, M.J.; FRANCO, D. W. ; TFOUNI, E.; KRIEGE, M.H In vivo effects of the controlled NO donor/scavenger ruthenium cyclam complexes on blood pressure. Life Science, v. 70, p. 2735-2752, 2002.

37. TORSONI A.S.; BARROS, B.F.; TOLEDO, J.C., HAUN, M.; KRIEGER, M.H.; TFOUNI, E.; FRANCO, D.W. Hypotensive properties and acute toxicity of trans-[Ru(NH3)4P(OEt)3(NO)](PF6)3, a new nitric oxide donor. Nitric Oxide: Biology and Chemistry, v. 6, p. 247-354, 2002.

38. RODRIGUEZ, J. A.; SOUZATORSONI, A. ; HAUN, M. ; Franco DW . Cytotoxic Evaluation Of New Synthesized Ruthenium Nitrosyl Compounds.. In: XXVI Reunião Anual da Sociedade Brasileira de Bioquímica e Biologia Molecular, 1997, Caxambú. Livro de Resumos da XXVI Reunião Anual da Sociedade Brasileira de Bioquímica e Biologia Molecular, 1997, p. 32-32.

39. PERRIN, D.D.; ARMAREGO, W.L.F.; PERRIN, D.R. Purification of Laboratory Chemicals. P.Press 1999: Elmsford USA.

40. VOGT, J.R.; L.H., J.L. KATZ, AND S. WIBERLY, The crystal and molecular structure of ruthenium-sulfur dioxide coordination compounds. I. Chlorotetraammine(sulfur dioxide)ruthenium (II) chloride. Inorganic Chemistry, v. 4, p. 1157-1160, 1965.

41. LOPES, L. G. F. ; CASTELLANO, E. E. ; FERREIRA, A. G. ; DAVANZO, C.U. ; CLARKE, M. J. ; FRANCO, D. W Reactivity of trans- 
[Ru(NH3)4P(OEt)3NO]X3, (X = PF6-, CF3COO-): modulation of the release of NO by the trans effect. Inorganic Chimica Acta, v. 358, p. 2883-2890, 2004.

42.BORGES, S.S.; DAVANZO, C.U.; CASTELLANO. E.E.; Z-SCHPECTOR, J.; SILVA, S.C.; FRANCO, D.W.; Ruthenium nitrosyl complexes with Nheterocyclic ligands. Inorganic Chemistry, v. 37, p. 2670-2677, 1998.

43. WINK, D.A.; FEELISCH, M.; FUKUTO, J.; CHISTODOULOU, D.; JOURD'HEUIL, D.; GRISHAM,M.B.; VODOVOTZ,Y.; COOK, J.A.; KRISHNA,M.; DeGRAFF, W.G.; KIM, S.; GAMSON, J.; MITCHELL, J.B.The Cytotoxicity of Nitroxyl: Possible Implications for the Pathophysiological Role of NO. Archives of Biochemistry and Biophysics, v. 351, p. 66-74, 1998.

44. PAOLOCCI, N., JACKSON, M. I, LOPEZ, B.E., MIRANDA, K., TOCCHETTI, C.G., WINK D.A., HOBBS, A.J., FUKUTO, JON. M. The pharmacology of nitroxyl (HNO) and its therapeutic potential: Not just the janus face of NO. Pharmacology Therapeutics, v. 113, p. 442-458, 2007.

45. NIMS, R.W., DARBYSHIRE, J. F., SAAVEDRA, J. E., CHRISTODOULOU, D., HANBAUER, I., COX, G. W., GRISHAM, M. B., LAVAL, F., COOK, J. A., KRISHNA, M. C., WINK, D. A. Colorimetric methods for the determination of nitric oxide concentration in neutral aqueous solutions. Methods: A Companion to Methods in Enzimology, v. 7, p. 48-54, 1995.

46. WANG, H.W., BABIC, A.M., MITCHELL, H.A., LIU, K., WAGNER, D.D. Elevated soluble ICAM-1 levels induce immune deficiency and increase adiposity in mice. FASEB Journal, v. 19, p. 1018-1020, 2005.

47.POINT, K.; SILVA, A.A.F.; SANTOS, F.F.; SILVA, M.L.; CUNHA, W.R.; NANAYAKKARA, N.P.; BASTOS, J.K.; ALBURQUEUQE, S. In vitro and in vivo antileishmanial activities of a Brazilian green propolis extract.

Parasitology research, v.103, p. 487-492, 2008.

48. LOPES, L.G.F.; WIERASZKO, A.; EL-SHERIF, Y.; CLARKE, M. J. The translabilization of nitric oxide in Ru-II- complexes by C-bound imidazoles. Inorganic Chimica Acta, v. 312, p. 15-22, 2001.

49. GENESTRA, M.E.A; CYSNE-FINKELSTEIN, L.; VIGNÓLIO-ALVES, L.; LEON, L.L. Effest of amidine deivatives on nitric oxide production by Leishmania amazonensis promastigotes and axenic amastigotes. Nitric Oxide: Biology and Chemistry, v. 8, p. 1-6, 2003.

50. GENESTRA, M.G.-S., D.;SOUZA, W.J.S.; CYSNE-FINKESLSTEIN, L.; SOARES-BEZERRA, R.J.; MONTEIRO, F.P.; LEON, L.L. Nitric Oxide Synthase (NOS) characterization in Leishmania amazonensis axenic amastigotes. Archives of Medical Research, v. 37, p. 328-333, 2006.

51.Zanichellil, P. G. ; FRANCO, D. W. ; SERNAGLIA, R. L. Immobilization of the $[\text { Rull(edta)NO }]^{+}$íon on surface of functionalized silica gel, Langmuir, v. 22, p. 203-208, 2006. 
52. OSTI, RZ; FRANCO, DW. Aspects of nitrite association with trans[Ru(NH3)4P(OEt)3(H2O)](2+) Polyhedron, v. 26, p. 4746-4750, 2007

53. MIRANDA, K.M. The chemistry of nitroxyl (HNO) and implications in biology Coordination Chemistry Reviews, v. 249, p. 433-455, 2005.

54. ASCENZI, P.S., L; BOLOGNESI, M; COLASANTI,M; POLTICELLI, F ;VENTURINI., Inhibition of Cysteine Protease Activity by NO-donors. Current Protein and Peptide Science, v. 2, p. 137-153, 2001.

55.BOCED, A.L.G.; MENEGATTI,E.; ASCENZI, P. Kinetics of parasite cysteine proteinase inactivation by NO-donors. Biochemical and Biophysical Research Communications, v. 315, p. 710-718, 2004.

56. STOYANOVSKY, D.A.; SCHOR,N.F.; NYLANDER, K.D.; SALAMA,G. Effects of $\mathrm{pH}$ on the Cytotoxicity of Sodium Trioxodinitrate (Angeli's Salt). Journal of Medicinal Chemistry, v. 47, p. 210-217, 2004.

57.SHIVA, S.; CRAWFORD, J.H.; RAMACHANDRAN, A.; CEASER, E.K.; HILLSON,T.; BROOKES, P.S.; PATEL, R.P.; DARLEY-USMAR, V.M. Mechanisms of the interaction of nitroxyl with mitochondria. The Biochemical Journal, v. 379, p. 359-366, 2004.

58. METZKER, G.; Toledo, J.C.; LIMA, F.C.A. ; MAGALHÃES, A.; CARDOSO, D.R.; FRANCO, D.W. Nitric oxide as an activation agent for nucleophilic attack in trans-[Ru(NO)(NH3)4P(OEt)3](PF6)3: a solid state study. (em preparação), 2009.

59. SILVA, H.A.D.; MCGARVEY, B.R.; SANTOS, R.H.D.; BERTOTTI, M.; MORI, V.; FRANCO, D.W. Sulfate as a ligand in ruthenium(II) and (III) ammines Canadian Journal of Chemistry-Revue Canadienne de Chimie, v, 79, p. 679-687, 2001.

60. RONCAROLI, F.; RUGGIERO, M.E.; FRANCO, D.W.; ESTIU, G.L.; OLABE, J.A. Kinetic, Mechanistic, and DFT Study of the Electrophilic Reactions of Nitrosyl Complexes with Hydroxide Inorganic Chemistry, v. 41, p. 57605769, 2002.

61. SWINEHART, J.H. The nitruprusside ion. Coordination Chemistry Reviews, v.2, p. 385-402, 1967.

62. FELTHAM, J.H.E. Principles of structure, bonding, and reactivity for metal nitrosyl complexes. Coordination Chemistry Reviews, v.13, p. 339406,1974. 
63. McCLEVERTY, J.A. Reactions of nitric oxide coordinated to transition metals. Chemical Reviews, v. 79, p. 53-76, 1979.

64. BOTTOMLEY, F. Electrophilic Behavior of Coordinated Nitric Oxide. Accounts of Chemical Research, v.11, p. 158-163, 1978.

65. RONCAROLI, F.; VIDELA, M.; SLEP, L.D.; OLABE, J.A. New features in the redox coordination chemistry of metal nitrosyls $\left\{\mathrm{M}-\mathrm{NO}^{+} ; \mathrm{M}^{-\mathrm{NO}^{0}}{ }^{0} \mathrm{M}-\mathrm{NO}^{-}\right.$ (HNO)\}. Chemical Reviews, v. 251, p. 1903-1930, 2007.

66. OENNINGTON, L.R.; SHA, X.; King, B. N-hydroxy sulfonimidamides as new nitroxyl (HNO) donors. Bioorganic and Medicinal Chemistry Letters, v.15, p. 2331-2334, 2005.

67. FURKUTO, J.M.; CRISTOPHER, H.S.; Miranda, K. M.; WINK, D.A. Nitroxyl (HNO): Chemistry, Biochemistry, and Pharmacology. Annual Review of Pharmacology and Toxicology, v. 45, p. 335-355, 2005

68. MOLLER, J.K.S; SKIBSTED, L.H. Nitric Oxide and Myoglobins. Chemistry Reviews, v. 102, p. 1167-1178, 2002.

69. JASZEWSKI, A.R.; FANN, Y.C.; CHEN, Y.R.; SATO, K.; CORBETT, J.; MASON, R.P. EPR spectroscopy studies on the structural transition of nitrosyl hemoglobin in the arterial-venous cycle of deanotreated rats as it relates to the proposed nitrosyl hemoglobin/nitrosothiol hemoglobin exchange. Free Radical Biology \& Medicine, v. 35, p. 444-451, 2003.

70. NASCIMENTO FILHO, J.C., REZENTE, J.M.; LIMA NETO,B.S. Ruthenium (II) tetraamines a useful model to compare trans-effect and trans-influence of phosphanes. Inorganica Chimica Acta, v. 145, p. 115-115,1988.

71. RONCAROLI, F.; OLABE, J.A. The Reactions of Nitrosyl Complexes with Cysteine. Inorganic Chemistry, v. 44. p. 4719-4727, 2005.

72. JUNIOR, J.C.T. Aspectos da reatividade de complexos de rutênio contendo óxido nítrico como ligante, 2004, 131p., Tese (Doutorado) - Instituto de Química de São Carlos, Universidade de São Paulo.

73. TITUS, R. G.; MARCHAND, M.; BOON, T.; LOUIS, J. A. A limiting dilution assay for quantifying Leishmania major in tissues of infected mice. Parasite Immunology, v. 7, p. 545-555,1985.

74. TASWELL, C. Cell Separation: Methods and Selected Applications: Limiting dilution assays for the separation, characterization and quantification of biologically active particles and their clonal progeny. Nova lorque, TC Pretlow \& TP Pretlow , 1986. p. 109-145. 
75. GAZZINELLI, R.T.; OSWALD, I.P.; HIENY, S.; JAMES, S.L.; SHER, A. The microbicidal activity of interferon-gamma-treated macrophages against Trypanosoma cruzi involves an L-arginine-dependent, nitrogen oxidemediated mechanism inhibitable by interleukin-10 and transforming growth factor-beta. European Journal of Immunology, v. 22(10), p. 2501-6, 1992.

76. HYUN, E.; BOLLA, M.; STEINHOFF, M; WALLACE, J.L.; SOLDATO, P.; VERGNOLLE, N. Anti-inflammatory effects of nitric oxide-releasing hydrocortisone NCX 1022, in a murine model of contact dermatitis. British Journal of Pharmacology, v. 143, p. 618-625, 2004.

77.MARHENKE, J.; JOSEPH, C.A. CORLISS, M.Z.; TIM J. DUNN, T.J.; FORD, P.C. Thermal and photochemical reactivity of $\mathrm{Os}(\mathrm{HNO})(\mathrm{CO}) \mathrm{Cl} 2(\mathrm{PPh} 3) 2$ : Evidence for photochemical HNO generation,Polyhedron, v.26, p. 46384644, 2007.

78. RORY MELENKIVITZ, R; GREGORY L. HILLHOUSE, G.L. Synthesis, structure, and reactions of a nitroxyl complex of iridium(III), cis, trans$\mathrm{IrHCl}_{2}(\mathrm{NH}=\mathrm{O})\left(\mathrm{PPh}_{3}\right)_{2}$. Chem. Commun. , p. 660-661,2002 


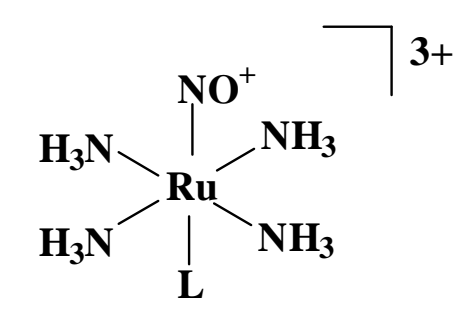

trans- $\left[\mathrm{Ru}(\mathrm{NO})\left(\mathrm{NH}_{3}\right)_{4}(\mathrm{~L})\right]^{3+}$<smiles>c1ccncc1</smiles>

Piridina (py)

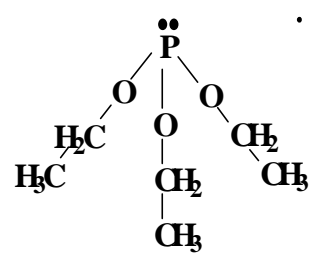

Trietilfosfito $\mathrm{P}(\mathrm{OEt})_{3}$<smiles>Cc1ccncc1</smiles>

4-Picolina (pic)<smiles>c1c[nH]cn1</smiles>

Imidazol (ImN)<smiles>COC(=O)CN(CCN(CC(=O)O)CC(=O)O)CC(=O)OC</smiles>

Hedta<smiles>NC(=O)c1cccnc1</smiles>

Nicotinamida (nic)<smiles>NC(=O)c1ccncc1</smiles>

Isonicotinamida (isn)

Figura 1A: Estruturas químicas do complexo do tipo trans-[RuNO $\left.\left(\mathrm{NH}_{3}\right)_{4} \mathrm{~L}\right]^{3+}$ e dos ligantes, $\mathrm{P}(\mathrm{OEt})_{3}$, imN, py, 4-pic, nic, isn e Hedta. 

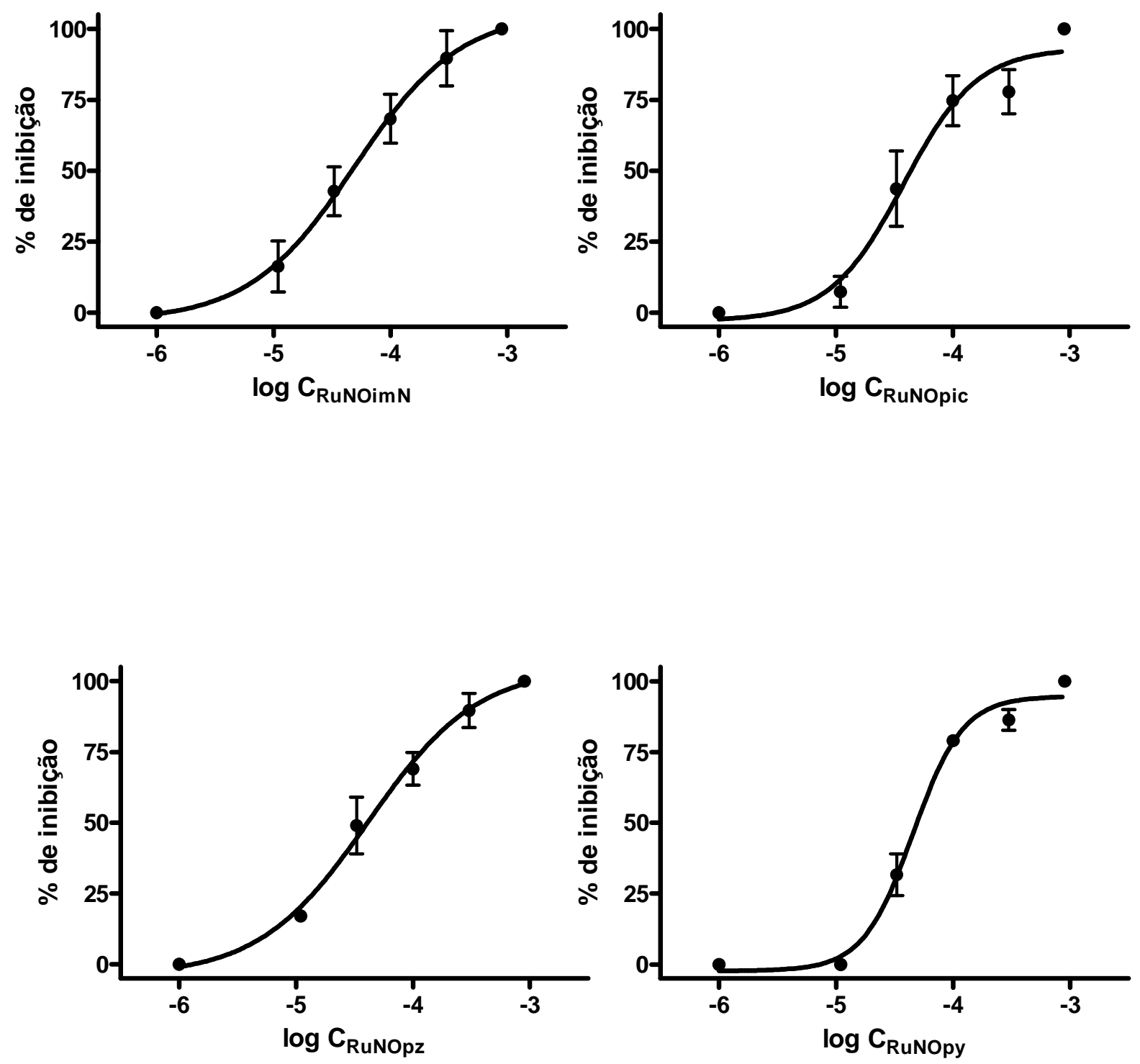

Figura 2A: porcentagem de inibição de crescimento em função do log da concentração de alguns nitrosilos de rutênio : trans- $\left[\mathrm{RuNO}\left(\mathrm{NH}_{3}\right)_{4} \mathrm{~L}\right]^{+3}$ onde $\mathrm{L}=\mathrm{imN}$, 4-pic, pz e py. 


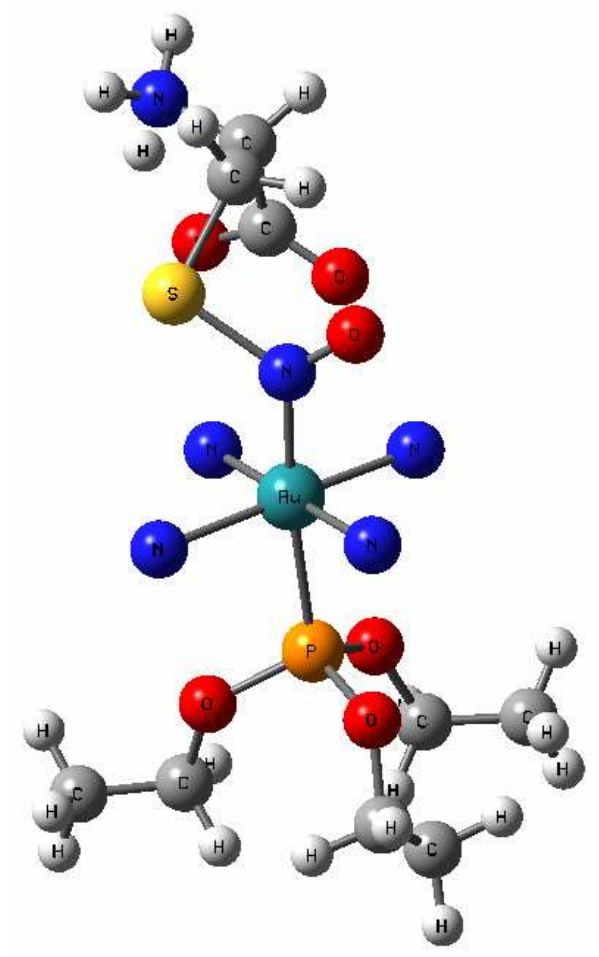

Figura 3A: Estrutura da espécie trans-[Ru(NH$\left.)_{3}{ }_{4} \mathrm{P}(\mathrm{OEt})_{3} \mathrm{~N}(\mathrm{O}) \mathrm{SR}\right]^{\mathrm{n}-1}$ 
Tabela 1A - atividade antipromastigota de doadores de NO em diferentes concentrações

\begin{tabular}{|c|c|c|c|c|c|}
\hline \multicolumn{6}{|c|}{ Atividade antipromastigota $(\% \mathrm{IC})^{\mathrm{a}}$} \\
\hline \multirow{2}{*}{ Compostos } & \multicolumn{5}{|c|}{ Concentração $\left(\mu \mathrm{mol} . \mathrm{L}^{-1}\right)$} \\
\hline & 11 & 33 & 100 & 300 & 900 \\
\hline NO & $39 \pm 7$ & $66 \pm 18$ & $71 \pm 4$ & 100 & 100 \\
\hline trans- $\left[\mathrm{Ru}(\mathrm{NO})\left(\mathrm{NH}_{3}\right)_{4} \mathrm{imN}\right]\left(\mathrm{BF}_{4}\right)_{3}$ & $16 \pm 9$ & $50 \pm 10$ & $68 \pm 6$ & $89 \pm 7$ & 100 \\
\hline trans- $\left[\mathrm{Ru}(\mathrm{NO})\left(\mathrm{NH}_{3}\right)_{4} 4-\mathrm{pic}\right]\left(\mathrm{BF}_{4}\right)_{3}$ & $7 \pm 5$ & $44 \pm 9$ & $75 \pm 6$ & $78 \pm 5$ & 100 \\
\hline trans-[Ru(NO) $\left.\left(\mathrm{NH}_{3}\right)_{4} \mathrm{pz}\right]\left(\mathrm{BF}_{4}\right)_{3}$ & $11 \pm 6$ & $49 \pm 10$ & $69 \pm 6$ & $90 \pm 6$ & 100 \\
\hline trans- $\left[\mathrm{Ru}(\mathrm{NO})\left(\mathrm{NH}_{3}\right)_{4} \mathrm{py}\right]\left(\mathrm{BF}_{4}\right)_{3}$ & $20 \pm 9$ & $32 \pm 7$ & 79 & $86 \pm 4$ & 100 \\
\hline trans $-\left[\mathrm{Ru}(\mathrm{NO})\left(\mathrm{NH}_{3}\right)_{4} \mathrm{P}(\mathrm{OEt})_{3}\right]\left(\mathrm{PF}_{6}\right)_{3}$ & 0 & 0 & $62 \pm 9$ & $83 \pm 4$ & $91 \pm 4$ \\
\hline trans $-\left[\mathrm{Ru}(\mathrm{NO})\left(\mathrm{NH}_{3}\right)_{4} \mathrm{~L}-\mathrm{hist}\right]\left(\mathrm{BF}_{4}\right)_{3}$ & 0 & 0 & $50 \pm 8$ & $76 \pm 6$ & $85 \pm 5$ \\
\hline $\mathrm{Na}_{2} \mathrm{~N}_{2} \mathrm{O}_{3}$ & 0 & $41 \pm 8$ & $48 \pm 8$ & $55 \pm 4$ & $80 \pm 4$ \\
\hline $\mathbf{N P}$ & 0 & 18 & 33 & 74 & 100 \\
\hline trans $-\left[\mathrm{Ru}(\mathrm{NO})\left(\mathrm{NH}_{3}\right)_{4} \mathrm{isn}\right]\left(\mathrm{BF}_{4}\right)_{3}$ & 0 & 0 & 19 & $51 \pm 5$ & 100 \\
\hline trans- $\left[\mathrm{Ru}(\mathrm{NO})\left(\mathrm{NH}_{3}\right)_{4} \mathrm{SO}_{3}{ }^{-2}\right] \mathrm{Cl}$ & 0 & $1 \pm 0$ & $8 \pm 4$ & $53 \pm 4$ & $59 \pm 9$ \\
\hline trans- $\left[\mathrm{Ru}(\mathrm{NO})\left(\mathrm{NH}_{3}\right)_{4} \mathrm{nic}\right]\left(\mathrm{BF}_{4}\right)_{3}$ & 0 & $5 \pm 5$ & $7 \pm 4$ & $35 \pm 11$ & $49 \pm 2$ \\
\hline$[\operatorname{Ru}(\mathrm{NO})$ Hedta $)]$ & 0 & 0 & 17 & $33 \pm 4$ & $48 \pm 6$ \\
\hline trans $-\left[\mathrm{Ru}(\mathrm{NO})\left(\mathrm{NH}_{3}\right)_{4} \mathrm{imC}\right]\left(\mathrm{PF}_{6}\right)_{3}$ & 0 & 0 & 0 & 0 & $29 \pm 4$ \\
\hline
\end{tabular}

Resultados expressos como média \pm e.p.m., $\mathrm{n}=3-5, \mathrm{P}<0,05 .{ }^{\mathrm{a}} \% \mathrm{IC}=$ porcentagem de inibição de crescimento nas concentrações de 11, 33,100,300 e $900 \mu \mathrm{mol} \mathrm{L}^{-1}$. 